FEDERAL DISASTER MENTAL HEALTH RESPONSE

AND COMPLIANCE WITH BEST PRACTICES

by

JODY MAY MCINTYRE

A. A., Methodist University, 1998

B. S., Methodist University, 1998

M. S., Indiana State University, 2000

\begin{abstract}
AN ABSTRACT OF A DISSERTATION
submitted in partial fulfillment of the requirements for the degree

DOCTOR OF PHILOSOPHY

School of Family Studies and Human Services

College of Human Ecology
\end{abstract}

KANSAS STATE UNIVERSITY

Manhattan, Kansas

2009 


\begin{abstract}
The purpose of this study was to review state disaster mental health response plans and actual disaster mental health responses to examine not only adherence to identified disaster mental health best practices, but also to highlight procedures being performed during deployment of disaster mental health response teams. This research study was developed to gain a thorough understanding of disaster mental health response in both the planning and implementation phases. Interviews with three state disaster mental health officials were completed and a review of each state's disaster mental health state plan was completed. The study investigated the conclusiveness of state plans and their adherence to published best practices in three post 9/11 disasters: 2005 Hurricane Katrina response in Mississippi; 2007 Greensburg, Kansas tornado; and 2008 Indiana flooding.

A phenomenological approach was used to identify themes in disaster mental health response that should be considered for future disaster mental health planning. Each state's disaster mental health plan varied in compliance to identified best practices; however, it was noted that all states were more compliant to best practices in their response than in the written state disaster mental health state plan.

Several themes for disaster mental health responses were identified that were not previously fully addressed in the published best practices. Such themes addressed issues in disaster mental health teams and training, local disaster mental health response, communication, research and data collection, relationships with external organizations, and long-term recovery. This research may serve as a guide for those developing disaster mental health plans and encourage further considerations in disaster mental health response.
\end{abstract}




\title{
FEDERAL DISASTER MENTAL HEALTH RESPONSE AND COMPLIANCE WITH BEST PRACTICES
}

by

\section{JODY MAY MCINTYRE}

\author{
A. A., Methodist University, 1998 \\ B. S., Methodist University, 1998 \\ M. S., Indiana State University, 2000
}

\author{
A DISSERTATION \\ submitted in partial fulfillment of the requirements for the degree \\ DOCTOR OF PHILOSOPHY \\ School of Family Studies and Human Services \\ College of Human Ecology \\ KANSAS STATE UNIVERSITY \\ Manhattan, Kansas
}

2009

Approved by: Major Professor Briana Nelson Goff, PhD 


\section{Copyright}

JODY MAY MCINTYRE

2009 


\begin{abstract}
The purpose of this study was to review state disaster mental health response plans and actual disaster mental health responses to examine not only adherence to identified disaster mental health best practices, but also to highlight procedures being performed during deployment of disaster mental health response teams. This research study was developed to gain a thorough understanding of disaster mental health response in both the planning and implementation phases. Interviews with three state disaster mental health officials were completed and a review of each state's disaster mental health state plan was completed. The study investigated the conclusiveness of state plans and their adherence to published best practices in three post 9/11 disasters: 2005 Hurricane Katrina response in Mississippi; 2007 Greensburg, Kansas tornado; and 2008 Indiana flooding.

A phenomenological approach was used to identify themes in disaster mental health response that should be considered for future disaster mental health planning. Each state's disaster mental health plan varied in compliance to identified best practices; however, it was noted that all states were more compliant to best practices in their response than in the written state disaster mental health state plan.

Several themes for disaster mental health responses were identified that were not previously fully addressed in the published best practices. Such themes addressed issues in disaster mental health teams and training, local disaster mental health response, communication, research and data collection, relationships with external organizations, and long-term recovery. This research may serve as a guide for those developing disaster mental health plans and encourage further considerations in disaster mental health response.
\end{abstract}




\section{Table of Contents}

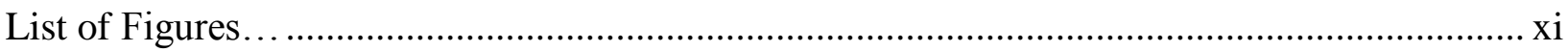

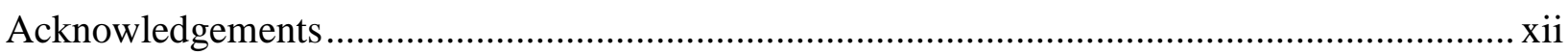

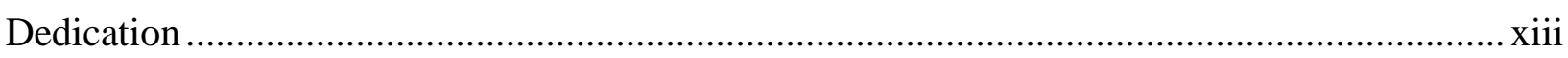

CHAPTER 1 - Disaster Response: A look at the Past ………............................................... 1

Johnstown Flood, Johnstown, Pennsylvania, May 31, 1889 ....................................................... 1

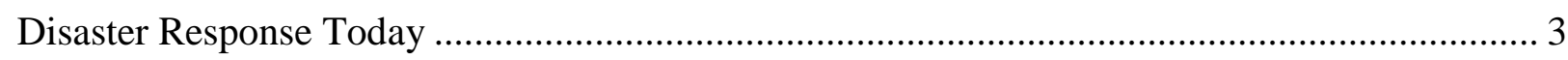

Purpose of Current Study ……………………………................................................. 4

CHAPTER 2 - A Review of Disaster Mental Health Response …………………………........... 5

The History of Mental Health in Disaster Response ................................................................ 5

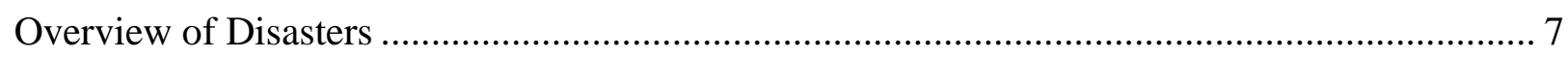

The Stages of Disaster Response....................................................................................... 10

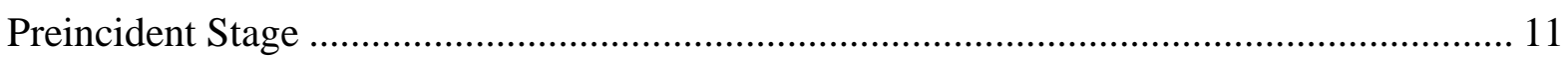

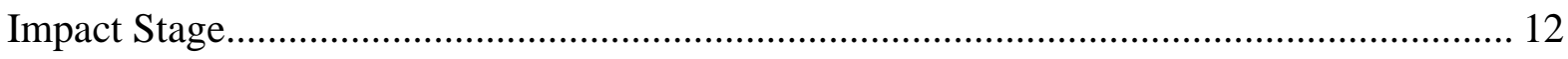

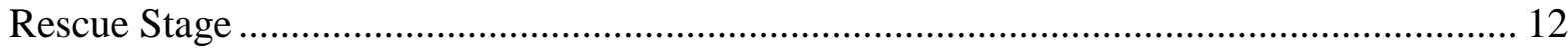

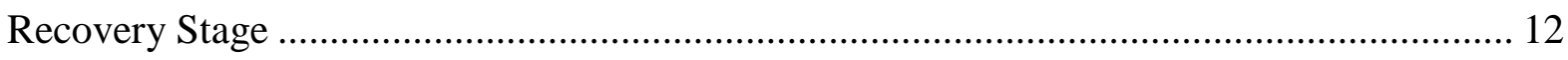

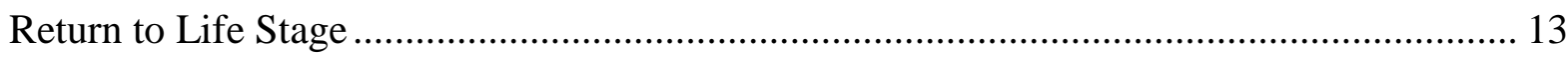

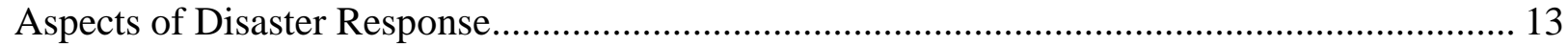

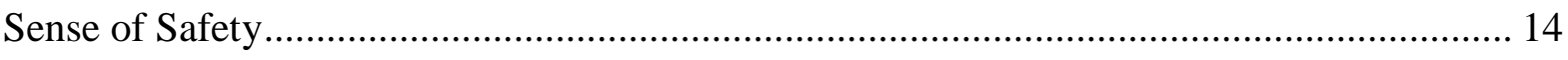

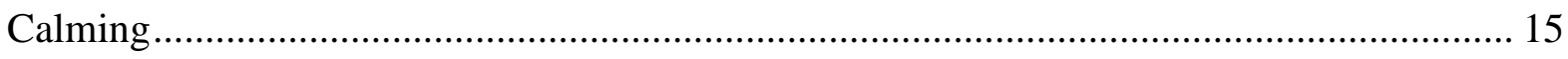

Sense of Self and Community Efficacy …………………................................................. 16

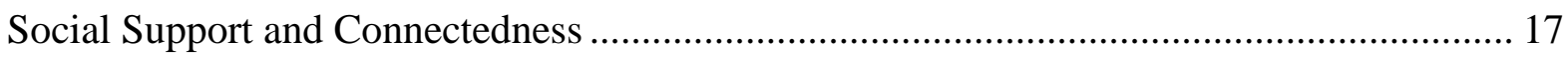

Hope

Role of the Mental Health Workers Across the Disaster Phases …………………….............. 21

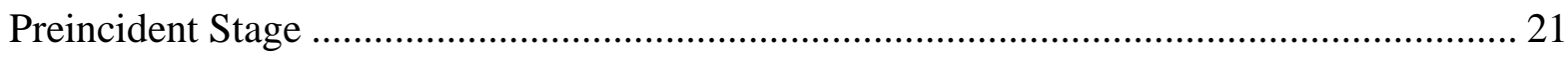

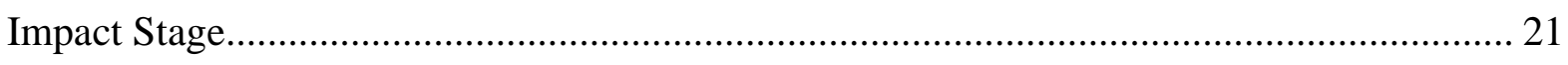

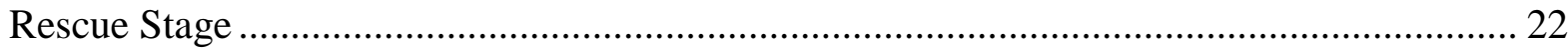

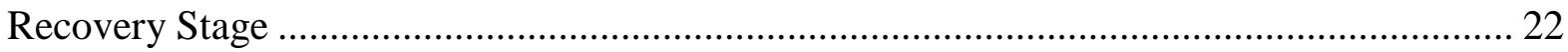

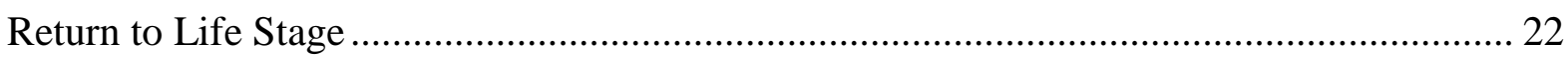




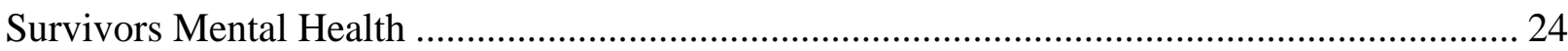

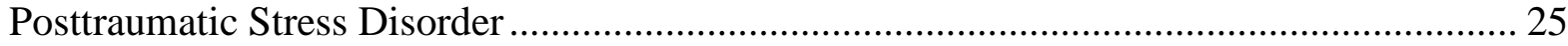

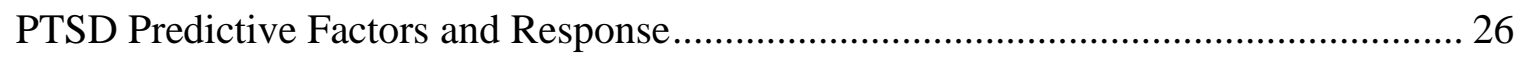

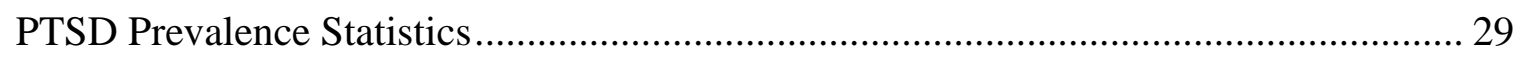

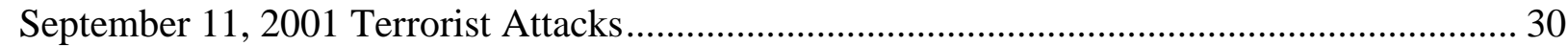

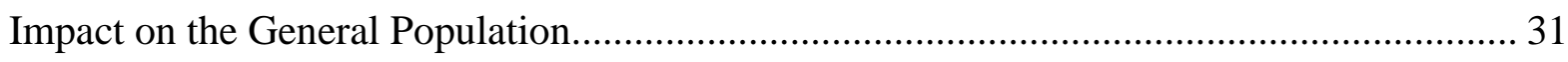

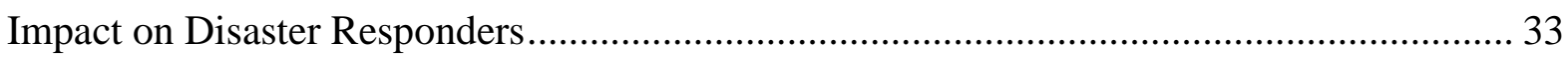

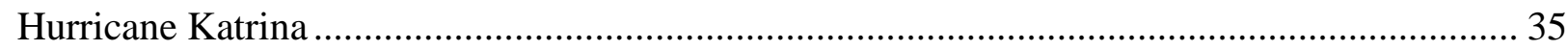

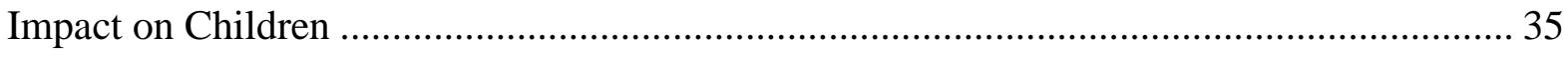

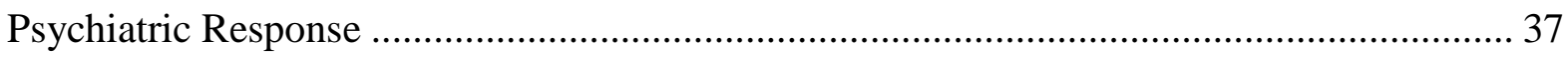

Disaster Mental Health Programs......................................................................................... 38

Critical Incident Stress Management ……………............................................................ 39

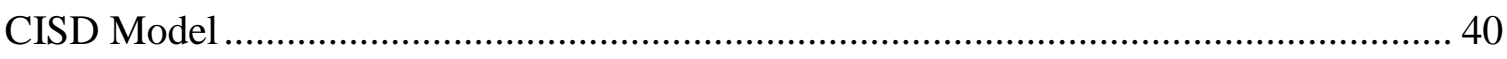

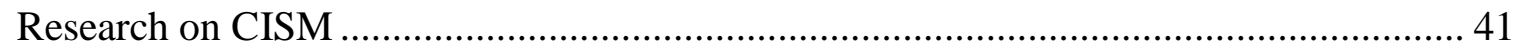

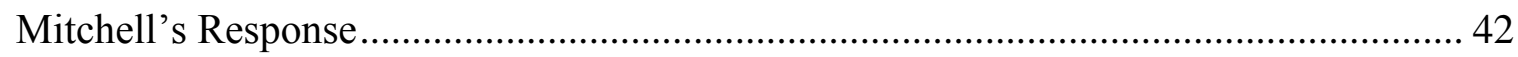

Psychological First Aid ............................................................................................ 44

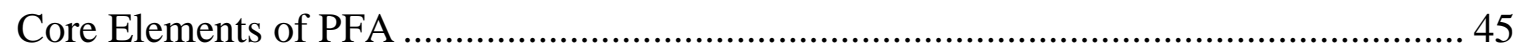

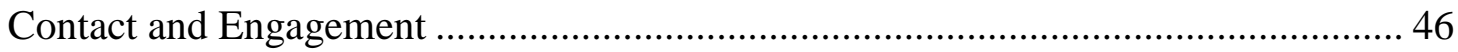

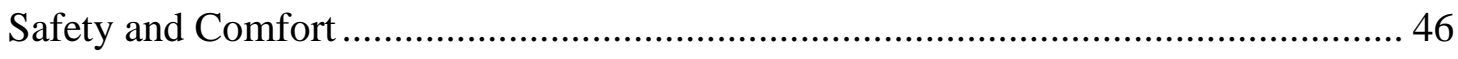

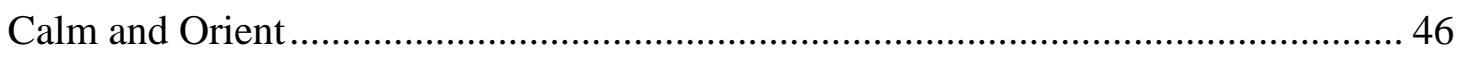

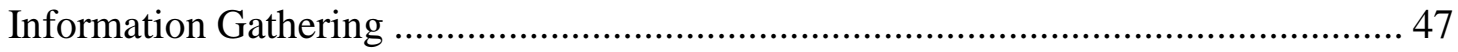

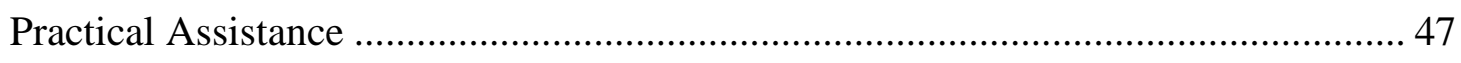

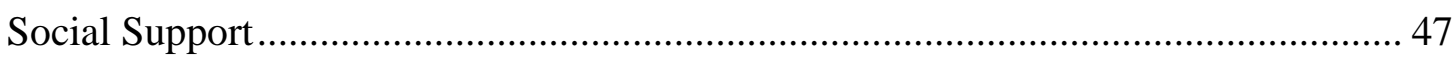

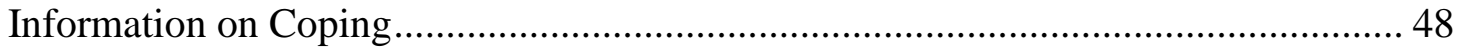

Linkage to Collaborative Services ....................................................................... 48

FEMA/SAMHSA Crisis Counseling Program Model .......................................................... 49

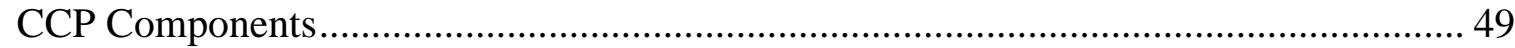

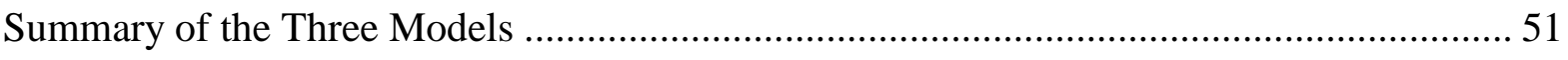

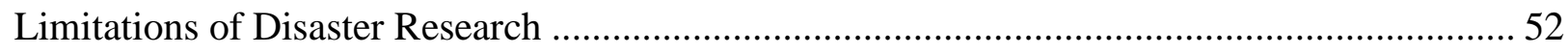

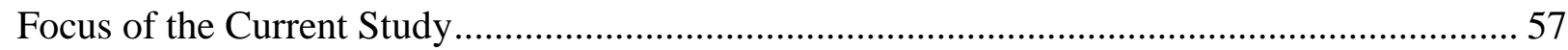

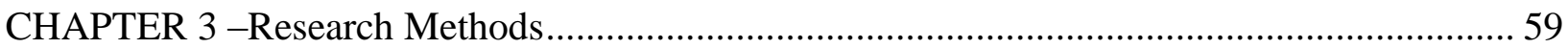




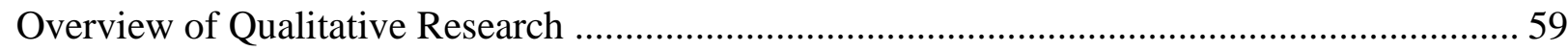

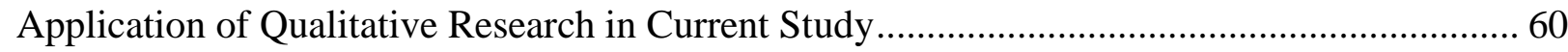

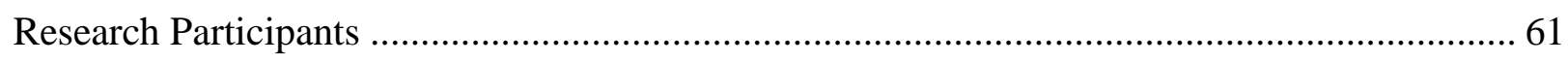

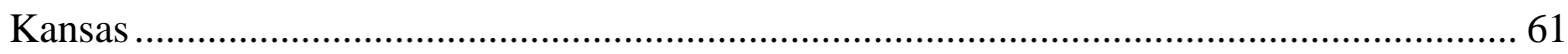

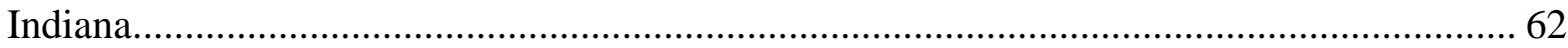

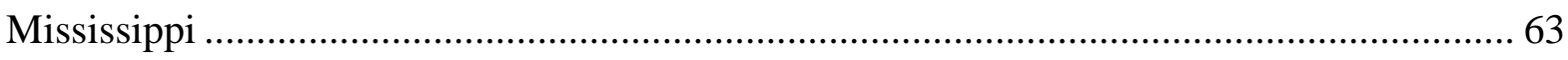

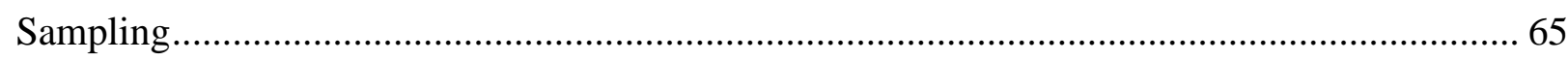

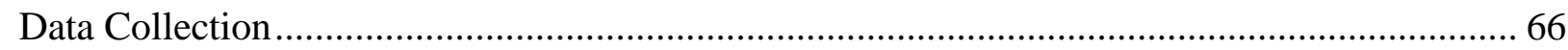

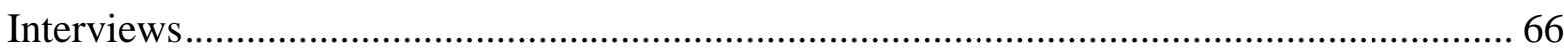

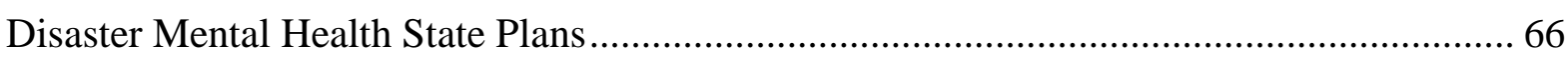

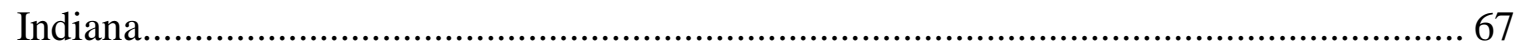

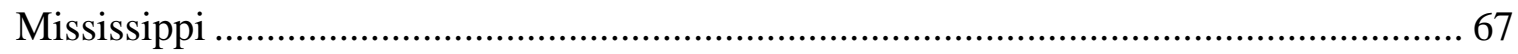

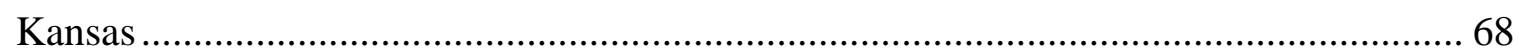

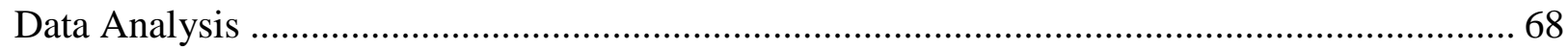

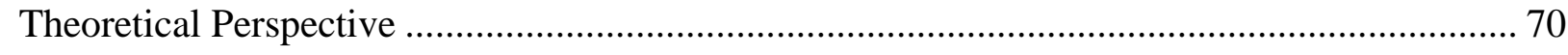

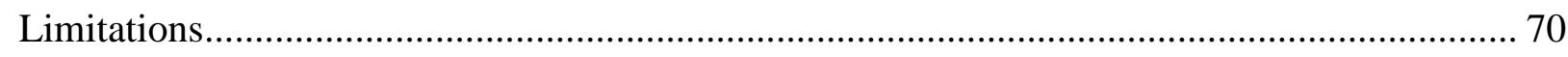

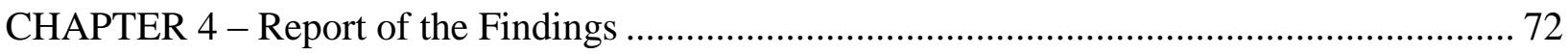

State Disaster Mental Health Overview .............................................................................. 73

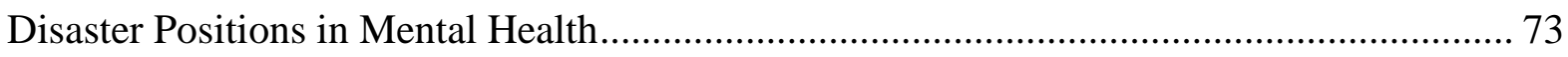

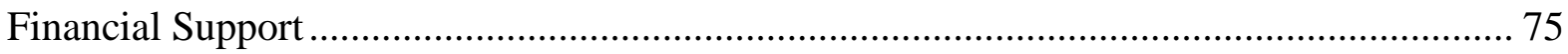

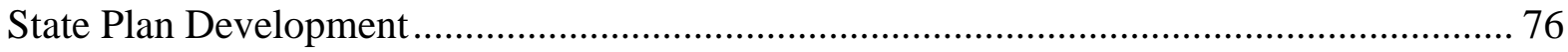

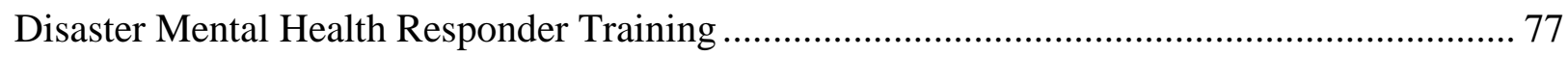

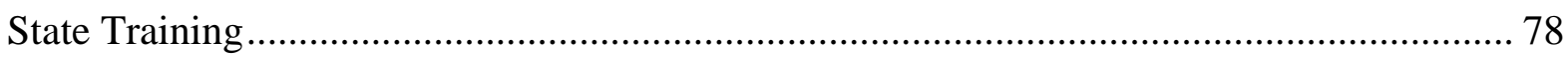

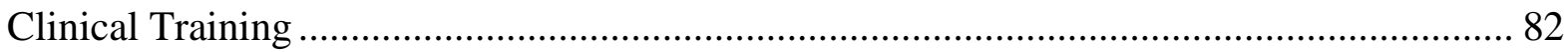

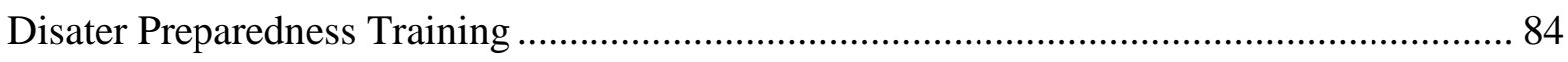

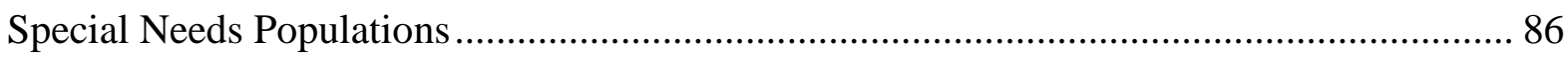

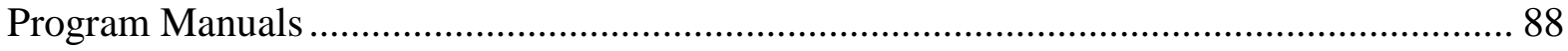

Local Disaster Mental Health Response ………………................................................. 88

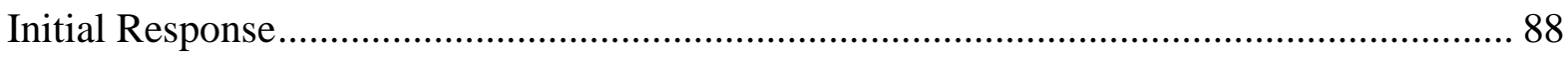

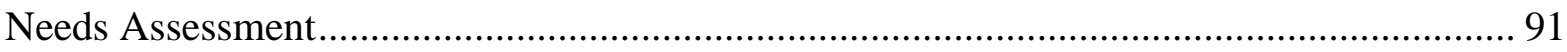

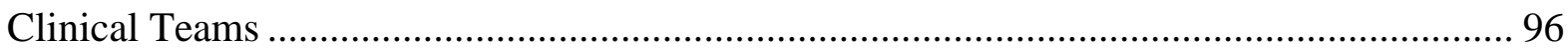




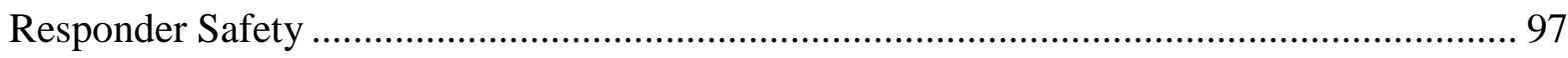

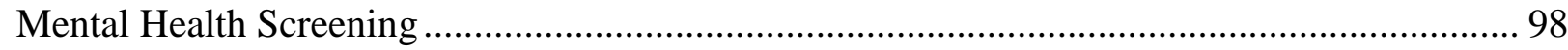

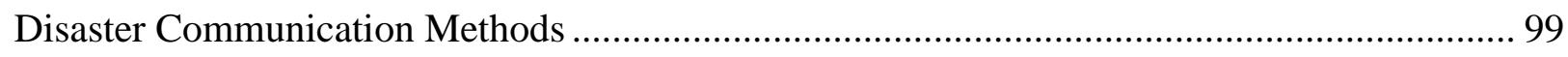

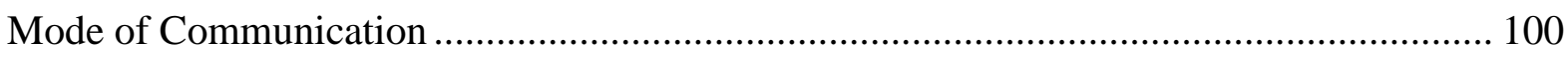

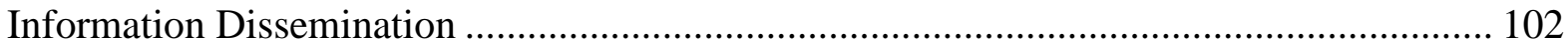

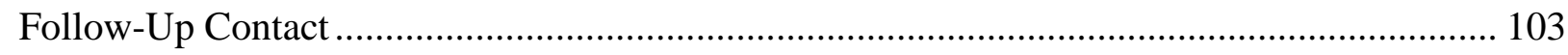

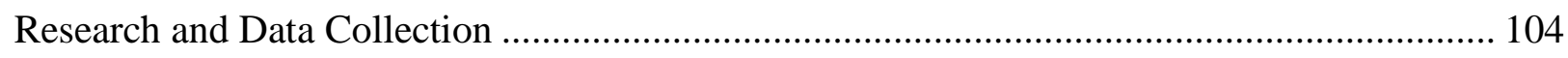

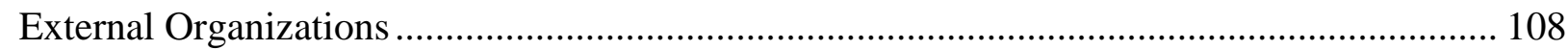

Disaster Mental Health Response Timeline ......................................................................... 112

Preparation and Deployment Phases.......................................................................... 112

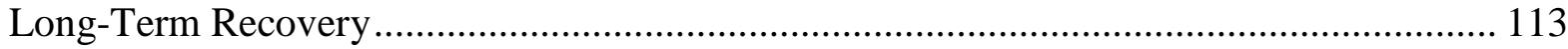

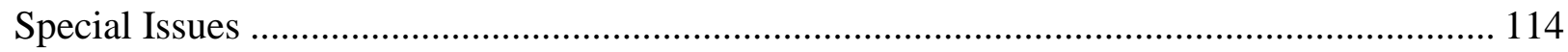

Naming Your State Disaster Mental Health Team ............................................................ 115

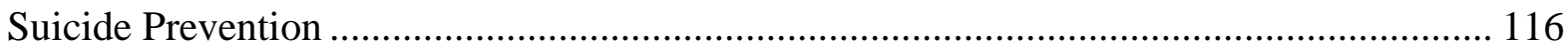

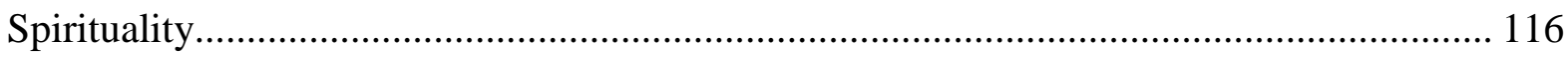

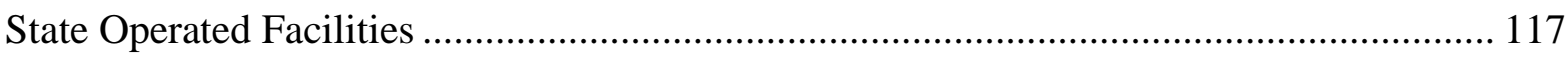

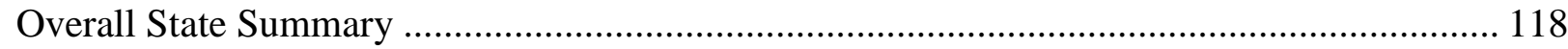

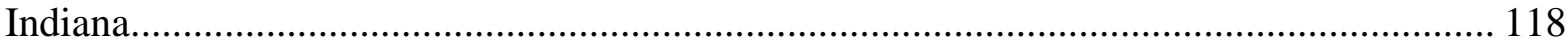

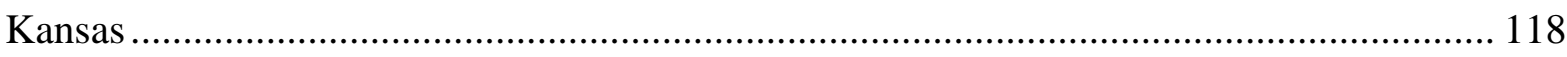

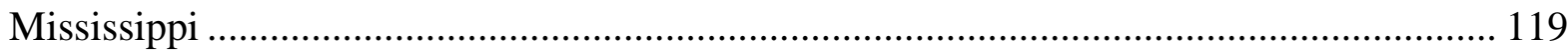

CHAPTER 5 - Discussion............................................................................................. 120

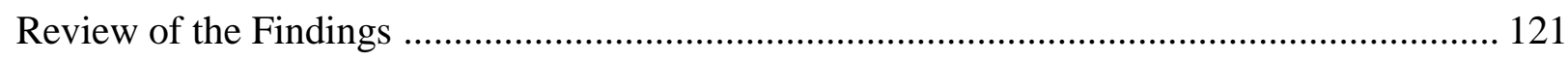

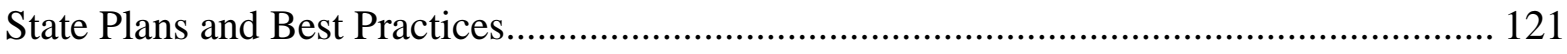

Disaster Mental Health State Training............................................................................. 124

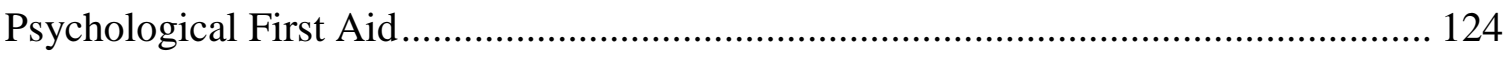

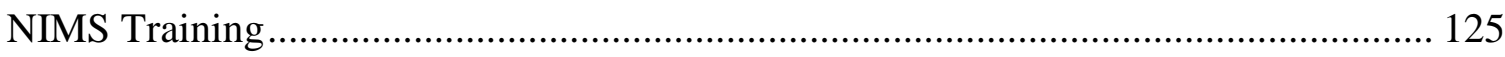

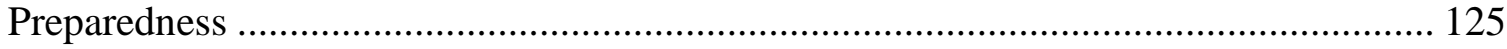

Naming Your State Disaster Mental Health Program..................................................... 126

Additional Training Options .................................................................................... 127

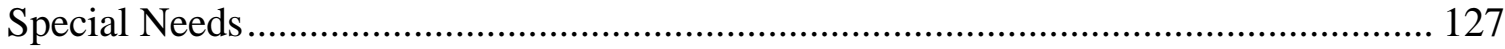

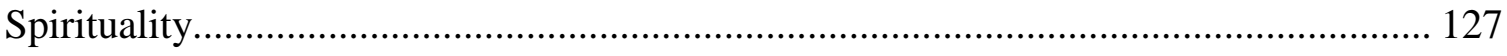




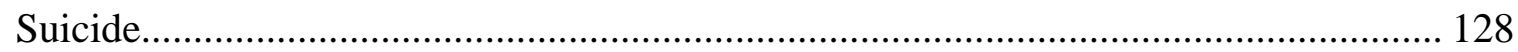

Local Disaster Mental Health Response ……………..................................................... 128

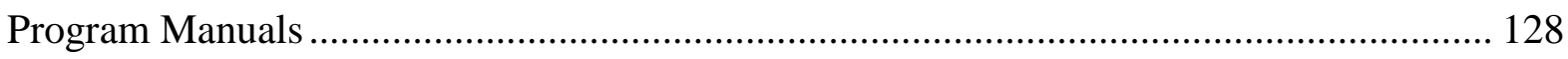

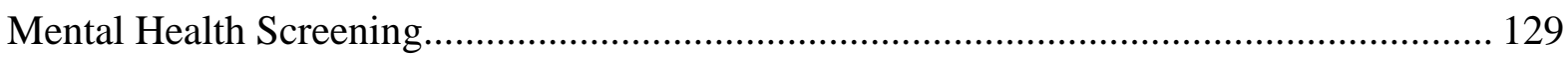

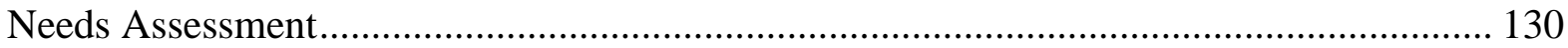

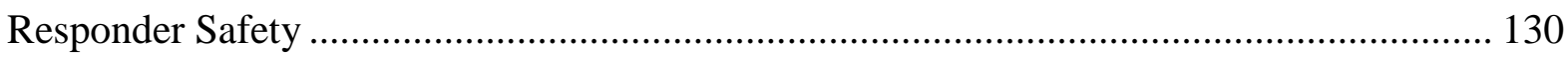

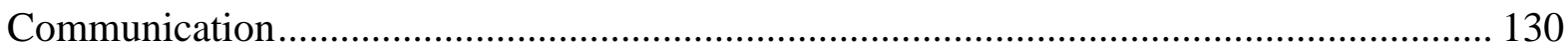

Information Dissemination ................................................................................... 130

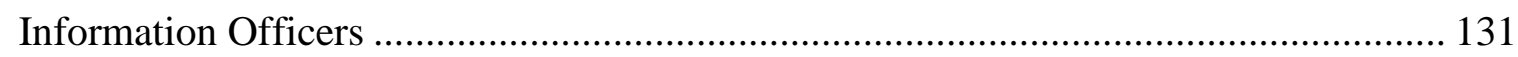

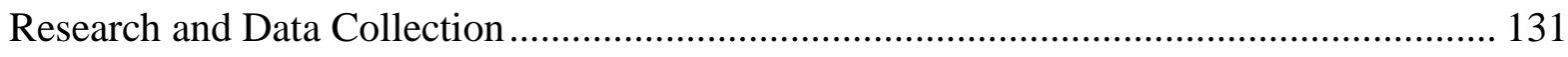

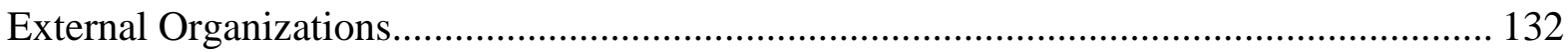

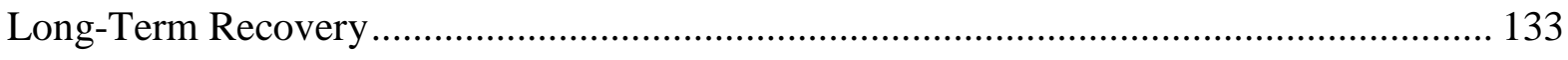

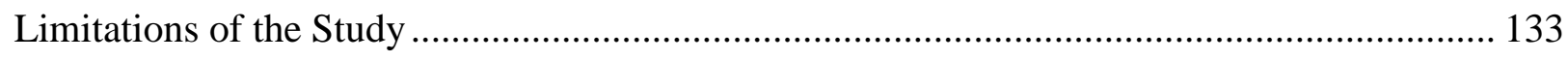

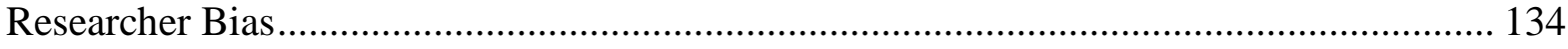

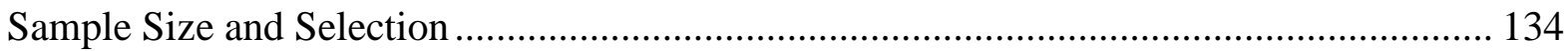

Researcher's Limited Experience ................................................................................. 135

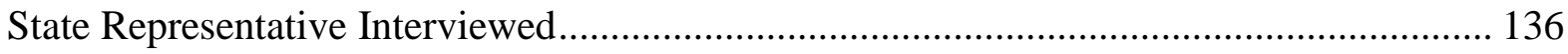

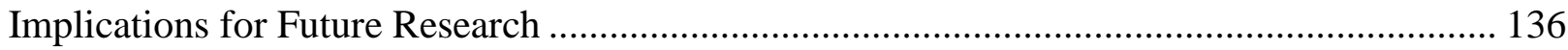

Implications for the Field of Marriage and Family Therapy ………...................................... 139

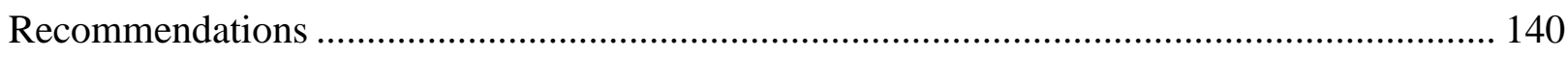

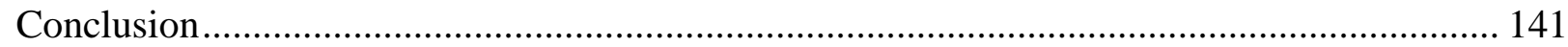

Appendix A -Glossary of Acronyms............................................................................. 142

Appendix B - Semi-Structured Interview for State Representatives........................................ 146

Appendix C - Best Practices Evaluation Sheet .......................................................................... 148

Appendix D - Best Practices Evaluation Sheet - Indiana …………........................................ 152

Appendix E - Best Practices Evaluation Sheet - Kansas ....................................................... 157

Appendix F - Best Practices Evaluation Sheet - Mississippi ..................................................... 162

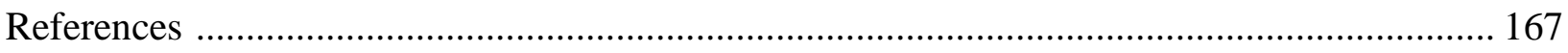




\section{List of Figures}

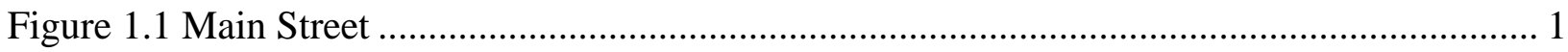

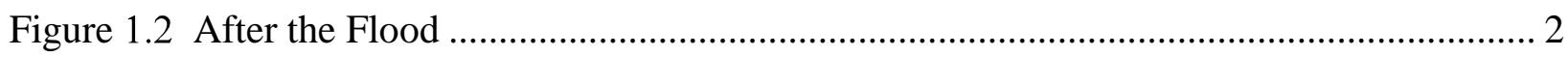

Figure 2.1 Phases of Disaster (Zunin \& Myers, 2000) ....................................................... 11

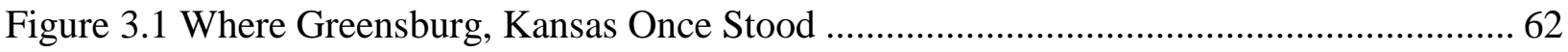

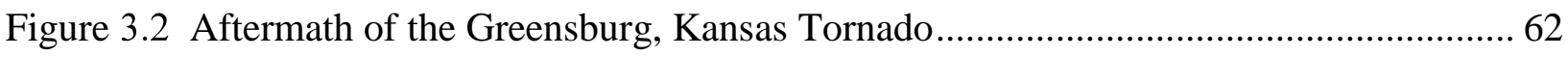

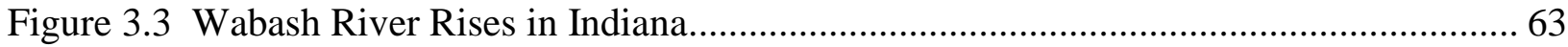

Figure 3.4 Families Caught Unprepared in Indiana Flooding …......................................... 63

Figure 3.5 Gulfport, Mississippi Houses Moved Out to Sea ............................................... 64

Figure 3.6 Remnants of Beach Housing in Biloxi, Mississippi ........................................... 65 


\section{Acknowledgements}

I would like to thank, Dr. Briana Nelson Goff, Chair of my Dissertation Committee, who never gave up on me over the years. Her understanding and support have been an essential component in enabling me to complete this paper. I could not have asked for a more motivating and exceptionally talented mentor.

I am also very blessed to have an exceptional dissertation committee who have been understanding and patient with me and have added great depth to my dissertation. I would like to thank Dr. Michael Lynch, Dr. William Meredith, Dr. Joyce Baptist, and Dr. Chwen Sheu for their encouragement and insight.

This dissertation would not have been possible without the involvement of three state disaster mental health representatives. Thank you for your participation. Also, thank you for all the hard work you have done in each of your states in the area of disaster mental health planning and response. 


\section{Dedication}

This paper is dedicated to all of those who have supported me through the years.

To my parents, who never stopped believing in me and always supported me even when my path was visiting the scenic route. What a trip it has been! Thank you for your endless love and support.

To my husband, who painfully endured lonely nights at home while I was working on this paper. For sacrificing homemade dinners for pizza, and for listening to endless questions inquiring "Where's Momma at?" To you, I thank you and I love you.

But mostly to Luke, who has spent way too much time away from me this last year and who has been patiently waiting for a long deserved trip to the New Orleans Zoo. Thank you for your inspiration and smiling face every night. I love you. 


\section{CHAPTER 1- Disaster Response: A Look at the Past}

Disasters have always been a part of human familiarity. Historically, it was the responsibility of the community to predict, respond to, assess, and support their fellow neighbors in this time of need. Below is one of these stories that will exemplify why disaster policy and response is essential. This following excerpt is from the Substance Abuse and Mental Health Services Administration (SAMHSA) website (www.samhsa.gov) (See Appendix A for a glossary of disaster acronyms used throughout the current paper).

\section{Johnstown Flood, Johnstown, Pennsylvania, May 31, 1889}

On the chilly, wet afternoon of May 31, 1889, residents of Johnstown heard a low rumble that grew to a "roar like thunder." Some knew immediately what had happened as floods were a regular fact of life to the citizens of this town, which was built between two rivers. After a night of heavy rains, the South Fork Dam had finally broken. This dam had been neglected and had collapsed due to a treacherous storm. Twenty million tons of water crashed into the narrow valley.

Most saw no sign of danger until the 36-foot wall of water, already packed with huge chunks of debris, rolled over them at 40 miles per hour, consuming everything in its path. Those who did see it said it "snapped off trees like pipe stems" and "crushed houses like eggshells." A violent wind preceded it, blowing down small buildings. The blanket of black smoke and steam that covered the area Johnstown, PA was remembered by survivors as the

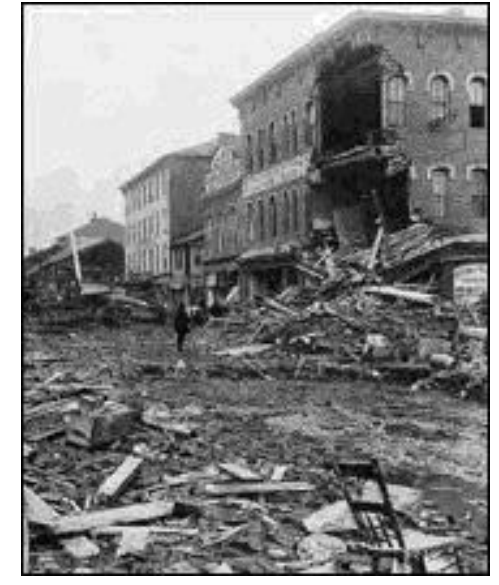

Fig 1.1 Main Street "death mist." 
Thousands of people desperately tried to escape the wave, but they were slowed by the 2 to 7 feet of water already covering parts of town. One observer said the streets "grew black with people running for their lives." Some remembered reaching the hills and pulling themselves out of the flood path seconds before it overtook them.

Those caught by the wave found themselves swept up in a torrent of oily, yellow-brown water; they were surrounded by tons of debris which crushed some people and provided rafts for others. Many became helplessly entangled in miles of barbed wire from a destroyed factory. People indoors raced upstairs seconds ahead of the rising water, which reached the third story in many buildings. Some never had a chance, as homes were immediately crushed or ripped from foundations and added to the churning rubble, ending up hundreds of yards away. Everywhere, people were hanging from rafters or clinging to rooftops or railcars being swept downstream,

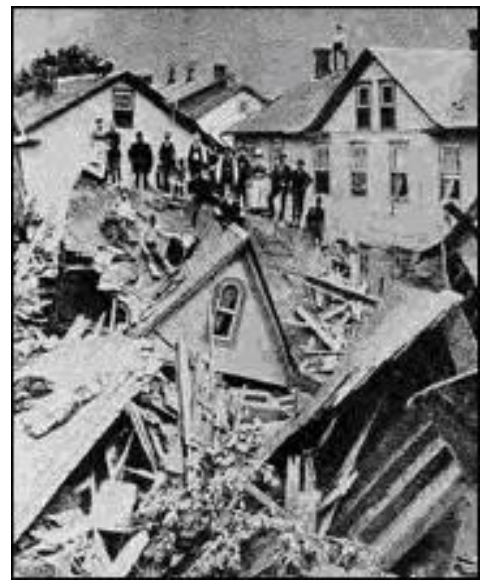
frantically trying to keep their balance as their rafts pitched in the flood.

The day after, committees met at a local schoolhouse and set up a distribution of supplies, messengers, information, and transportation. Citizens were asked to report on those who survived and those who were lost. Residents volunteered to assist with removal of debris and dangerous buildings, and committees were Fig 1.2 After the Flood established to handle issues related to sanitation and employment. A clearinghouse was set up to assist those seeking loved ones, and patients were treated in a temporary hospital. Within two days, 2,209 bodies were buried, including 99 entire families and 396 children. More than 750 victims were never identified. 
Less than two weeks later, the town was divided into districts, each with its own engineer and contractor. This event marked a new chapter in hazard mitigation, the process for states and communities to identify policies, activities, and tools needed to act in response to disaster. Response activities that followed this disaster helped reduce or eliminate long-term risk to life and property. After the flood, people came together to organize resources, assess risks, and develop a mitigation plan, and then implement and monitor the plan. By October 12th, the State Board of Health determined that Johnstown was no longer a threat to the public health.

After this disastrous event, increased recognition was paid to river ecosystems, and increased focus and resources were paid to important ecologic functions. Restoration goals began to include the development of sustainable management plans that minimized flood hazards while improving and maintaining the ecologic values of rivers and other bodies of water. The Johnstown Flood helped establish the recognition of rivers as evolving systems that respond to major human interventions which can alter landscapes. Soon after, management plans evolved which included the integration of maintenance plans into any structural modifications. Eventually, this led to an effort, consistent with those identified by resource and regulatory agencies, of developing alternative approaches to restoring and managing river corridors while reducing flood hazards.

\section{Disaster Response Today}

The need for disaster mental health response is not a new concept but has evolved over time to become a conclusive reaction that involves first responders, mental health workers, community advocates, constructions companies, and government entities. The Robert T. Stafford Disaster Relief and Emergency Assistance Act of 1988 outlined the inclusion of mental health services in disaster response to alleviate mental health concerns (DeWolfe, 2000). In 2003, 35 
states received funding to help establish all hazards disaster preparation and planning (SAMHSA's National Mental Health Information Center, 2003). These disaster mental health response plans were to outline minimal state response and allowed states to independently identify the infrastructure of their response (Bulling, 2006).

In 2001, shortly after the 9/11 terrorist attacks in the United States, a renowned group of disaster mental health workers gathered to develop best practices in disaster mental health response (NIMH, 2002). These published practices are a guide for mental health responders to follow and utilize when they are responding to a catastrophic event. Although these best practices have been published and are available for programs to use as a guide, the extent to which these best practices are followed, both in the written state disaster mental health plans and in actual disaster mental health response, is currently unknown.

\section{Purpose of the Current Study}

The purpose of the current study was to review state disaster mental health response plans and reported disaster mental health responses to examine not only adherence to identified disaster mental health best practices, but also to highlight procedures being performed during deployment of disaster mental health response teams. The present study investigated the conclusiveness of state plans and their adherence to published best practices in three post 9/11 disasters: 2005 Hurricane Katrina response in Mississippi; 2007 Greensburg, Kansas tornado; and 2008 Indiana flooding. This research study was developed to gain a thorough understanding of disaster mental health response in both the planning and implementation phases. With the frequency of disasters striking the United States today, there is a need to ensure that best practices are being followed by disaster mental health responders. 


\section{CHAPTER 2- A Review of Disaster Mental Health Response}

There are over 500 incidents of disasters that occur on a yearly basis, affecting 80 million people, displacing five million people from their homes, seriously injuring 74,000 people and killing nearly 50,000 (Freedy \& Simpson, 2007). With an increase of the population living in high risk disaster areas and the increase of technologic complexity, Freedy and Simpson (2007) reported that the impact of disasters will continue to increase in the future. Thus, the need for a mental health response component to disasters will continue to grow.

\section{The History of Mental Health in Disaster Response}

Over the centuries, communities have responded to provide comfort and assistance to friends and neighbors during times of disaster. Mental health response has been an important benefit in many large disasters. The first documented organized response that involved the goal to provide "comfort and relief" in the United States was a coordinated response to the Chicago fire of 1871 (Oliver, 2000). The mayor of Chicago at the time, R. B. Mason, developed the Chicago Relief and Aid Society to help in dealing with the stresses of victims of fire in the town (Oliver, 2000). The Chicago Relief and Aid Society operated as a scientific charity, which managed any need-based aid and distributed materials and funds to victims of fire (Finnegan, 2003). Many of today's nonprofit and religious organizations that respond to disasters still operate on a similar concept. The National Voluntary Organizations Active in Disaster (NVOAD) and the America Red Cross (ARC) are examples of two such organizations.

The American Red Cross is a well known responder to all types of disasters assisting with medical and shelter needs. The American Red Cross (ARC) was formed in 1881 as a model of the International Red Cross, which was formed in 1863 to aid in the care of wounded soldiers 
during battle (Walter Reed Medical Center, nd). The ARC 1905 Charter confirmed its role in disaster relief and military assistance for those in combat and for their families at home. This charter forced the United States to comply with the 1882 Geneva Convention Treaty (Walter Reed Medical Center, nd).

In 1989, in the midst of the devastation left by Hurricane Hugo and closely followed by the Loma Prieta earthquake, ARC made the decision to extend their services to include mental health for both responders and victims (Saleh, 1996; Weaver, Dingman, Morgan, Hong, \& North, 2000). Mental health workers had been involved in responses on an individual and voluntary basis, thus the ARC decided to formalize the mental health position and training (Weaver et al., 2000) The primary goal of the American Red Cross Disaster Mental Health Services (ARC DMHS) is to recognize the psychological effects of a disaster on those involved in both the incident and its recovery (Weaver et al., 2000). In addition, they promote an understanding of disaster-related stress to optimize the intervention and recovery phases of the disaster (Saleh, 1996). In 1992, the American Red Cross listed 91 trained mental health workers available for assignment. In less than four years the number of available responders increased to over 600 (Saleh, 1996). In 2000, the American Red Cross Disaster Services Human Resource System listed over 9,000 mental health workers that had been trained, with over 2,000 mental health workers who are members of the ARC national disaster team (Weaver et al., 2000).

The Disaster Act of 1950 (Jacobs, 1995) authorized the federal government to assist state governments that were affected by the devastation of disaster; however, this Act left individual assistance up to charities like the America Red Cross and other volunteer and religiously affiliated organizations. In 1974, after a series of tornadoes hit the Midwest, an amendment to the Act was written, which created the Disaster Relief Act of 1974 (Jacobs, 1995). This Act laid the 
foundation of the Crisis Counseling Programs and set guidelines that stated that the National Institute of Mental Health would be responsible for providing relief to survivors after a disaster (Farberow, 1978).

Legislative authority is given to the President of the United States under Section 416 of The Robert T. Stafford Disaster Relief and Emergency Assistance Act, which was signed into law on November 23, 1988 (Public Law 100-707) to provide training and services to alleviate mental health problems caused or exacerbated by major disasters (FEMA, 2007b). The Act states:

Crisis Counseling Assistance and Training. The President is authorized to provide professional counseling services, including financial assistance to State or local agencies or private mental health organizations to provide such services or training of disaster workers, to survivors/victims of major disaster in order to relieve mental health problems caused or aggravated by such major disaster or its aftermath (FEMA, 2007b).

The Crisis Counseling Assistance and Training Program, commonly referred to as the Crisis Counseling Program (CCP), is now managed by the Federal Emergency Management Agency (FEMA) in cooperation with the SAMHSA's Center for Mental Health Services (CMHS) (FEMA, 2008).

\section{Overview of Disasters}

Disaster comes from the Latin dis astro meaning "bad star” (Norris, Galea, Friedman, \& Watson, 2006a). Norris et al. (2006a) defined disaster as "a potentially traumatic event that is collectively experienced, has acute onset, and is time-delimited; disasters may be attributed to natural, technological, or human causes" (p. 4). Other definitions of disaster include "a humancaused or natural event that results in significant destruction and often the loss of life, and has a 
lasting impact on the environment and the community" (Goodman \& West-Olatunji, 2008, p. 122) and "a sudden and unexpected situation which threatens both physical safety and the unity of the family" (Lustad, 1985, p. 13). The American Red Cross defines a disaster as involving 100 or more persons, 10 or more deaths, or an appeal for assistance (International Federation of Red Cross and Red Crescent Societies and the Centre for Research on the Epidemiology of Disasters, 1993).

Disasters can be traumatic, humbling, and inspiring to those who experience them. When discussing disasters, it is essential to identify the differing types of disasters. When considering the typology of disasters, disaster classification is divided into two main types: natural disasters versus human-caused disasters (Norris, Galea, Friedman, \& Watson, 2006a). Natural-caused disasters include flooding, hurricanes and tornadoes. Human-caused disasters can be divided into two main categories: technological accidents or mass violence incidents. A human-caused technological disaster is a disaster caused by human error or a failure of technology, such as nuclear melt-downs and bridge collapses. A human-caused mass violence incident would be caused by malicious intent with the purpose of injuring others, such as a school shooting or terrorist bombing.

Norris (2002) found that natural disasters and human-caused technological disasters produced statistically similar mental health responses. However, it was noted that these results differ slightly when dealing with developed countries, as technological disasters had a greater effect on individual mental health than that of a natural disaster (Norris, 2002). Norris and Elrod (2006) found that human-caused mass violence disasters have a greater negative impact on mental health than natural disasters and human-caused technological disasters. 
Disasters can be further divided into centripetal or centrifugal disasters. A centripetal disaster is a disaster that strikes a group of people who live or work in a specific area. In this area, the responders and the victims are often the same. Centrifugal disasters are disasters that affect a specific group of people that are together by chance, such as a nightclub fire or mass transportation accident (Norris et al., 2006a).

When assessing a disaster, it is important to evaluate the onset and duration of the disaster. In many natural disasters, there is a period of time that is a precursor to the disaster when one is aware of the impending disaster or aware that conditions are prime for the disaster (Norris et al., 2006a). In such cases of flooding and hurricanes, there is often a period of preparation and a longer period of mitigation in a hurricane-prone area or a flood zone (DeWolfe, 2000). In natural disasters, the period preceding the disaster may range from moments to days. In human disaster, there may or may not be any warning for those involved. During chemical spills, there is often an evacuation with often unknown long-term effects on the environment or the people (Norris et al., 2006a). The Chernobyl nuclear disaster caused people to be exposed to the effects of the traumatic event for several years with long-term physical and psychological consequences (Loganovsky, Havenaar, Tintle, \& Guey, 2008). Duration may be as brief as several minutes, as in the case of a tornado, or as long as years, when studying the effects of the Chernobyl nuclear disaster.

Another consideration when addressing a disaster is the severity of exposure at both a population and an individual level. Within the disaster, there will be experiences that the whole population is exposed to, as well as individual experiences that differ among the group members (Phifer \& Norris, 1989). At the population level, researchers will refer to the impact ratio of the disaster, which statistically represents the proportion of the population that was affected by the 
disaster. As the impact ratio increases, the effect on the population's mental health becomes more prevalent (Phifer \& Norris, 1989).

The amount of warning preceding a disaster that communities receive varies depending on the disaster event. Earthquakes typically hit with minimal warning, depending on the awareness of the National Weather Center and the warning systems that may be utilized. Hurricanes and floods typically arrive within hours to days of warning, which is beneficial for preparation but they can also evoke many psychological symptoms prior to the disaster occurring. When there is no warning, survivors may feel more vulnerable, unsafe, and fearful of future unpredicted tragedies (DeWolfe, 2000). Survivors are often left with a feeling of helplessness, as if they had little control over protecting themselves or their family.

When people choose not to follow mitigation procedures or evacuation warnings and suffer losses as a result, feelings of guilt, blame and anger are exacerbated (DeWolfe, 2000). Once people experience a disaster of great magnitude, they will often show sensitivity to future recommendations and immediate implementation of mitigation enforcement to safeguard themselves and their property from future damage.

\section{The Stages of Disaster Response}

Identifying the stages of a disaster response helps researchers and professionals to understand the disaster process and how responses change as the length of time since the onset of the disaster passes. Myers and Wee (2005) outlined the following five phases of disaster response: pre-incident, impact (0-48 hours), rescue (0-1 week), recovery (1-4 weeks), and return to life ( 2 weeks to 2 years). These stages coincide with the Zunin and Myers (2000) disaster education manual for social service workers (See Figure 2.1). While each of these phases has common trends, they are not mutually exclusive. In addition, these phases and time periods are 
guidelines that help professionals understand human response to disaster and should not be seen as absolute. The phases of disaster will be described next.

\section{Typical Phases of Disaster}

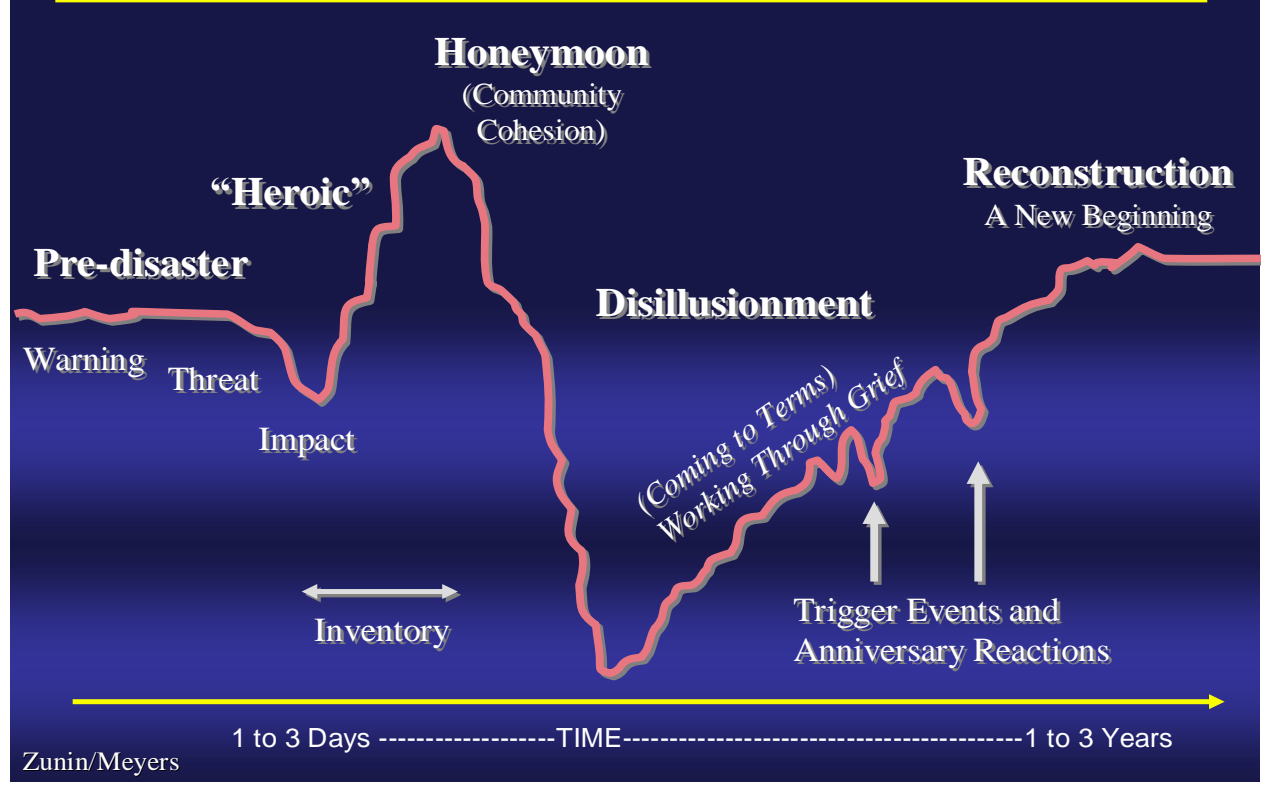

Figure 2.1 Phases of Disaster (Zunin \& Myers, 2000)

\section{Pre-incident Stage}

The pre-incident stage of disaster response is the time between the end of one response and the time preceding the next disaster. The goal in the pre-incident stage of response is in preparation for future disasters and improvement of coping and resiliency skills in the community (Gaffney, Barry, Chiocchi, \& Theis, 2005). Behaviorally, there is a fluctuation between preparation for and denial of future disaster responses. The pre-incident phase also involves comprehending and adjusting to the news of the disaster, collecting and making sense of any facts and information available, and gearing up to respond (Smoyak, 2006). In a warning period in which workers and potential victims are waiting to see whether an event will materialize, experiences of vague feelings of anxiety, restlessness, and irritability may occur 
(Kiser, Heston, Hickerson, Millsap, Nunn, \& Pruitt, 1993). An orientation or briefing for workers before they first enter the disaster area can help to prepare them for the conditions they may find and can help to reduce some emotional shock.

\section{Impact Stage}

The impact stage of the disaster response is the time from when the disaster occurs through the first 48 hours. The impact period of a disaster can fluctuate from the slow and controlled, with low-threat buildup associated with some types of floods to the violent, dangerous, and destructive outcomes associated with tornadoes and explosions. The goals of the impact stage of disaster response are to aid in survival and increase communication in the affected region, where there is a focus on safety, food and shelter (Rubel, 2008). Behaviorally, those affected will experience a fight or flight response and their experience begins to affect cognitive functioning. This innate physiological response in all people helps maintain one's selfpreservation. When faced with a life threatening situation, the body responds with heightened awareness and response to keep one's self safe.

\section{Rescue Stage}

The rescue stage of disaster response is from the time the disaster occurs until the end of the first week post-disaster. During this time, the main goal is to help survivors adjust to the disastrous situation. People will struggle between exhaustion and motivation, and they will look out for each other and risk their own safety to help strangers (Rubel, 2008). Responders will work in the community communicating what is needed to stabilize the community and link the demands with available resources.

\section{Recovery Stage}

The recovery stage of disaster response begins about seven days after the disaster occurs and lasts for approximately four weeks. During this time, many people will appraise the situation 
and plan for future projects. Behaviorally, people will be grieving and many may be having intrusive memories or other symptoms. It is during this phase that victims will begin to verbalize their experiences and need for assistance. This time is also a time for strengthening community cohesion (DeWolfe, 2000). Responders may see up to $13 \%$ of those involved in the disaster showing symptoms of posttraumatic stress (Whalley \& Brewin, 2007).

\section{Return to Life Stage}

The return to life stage of disaster response can range from two weeks to two years post disaster. The goal of this stage is reintegration through recovery and rebuilding (Rubel, 2008). Integration is the process of incorporating survivors back into their communities. Behavioral response can be as normal as personal adjustment and as complicated as posttraumatic stress disorder (PTSD; American Psychiatric Association [APA], 2000), depression, or other psychological symptoms or disorders. Many victims may feel abandoned as workers and funding leaves their area (DeWolfe, 2000).

\section{Aspects of Disaster Response}

Hobfoll et al. (2007) published an article outlining the absence of evidence-based consensus supporting immediate and mid-term post-disaster mental health response. In attempts to gain research-informed psychological interventions, a worldwide panel of experts in the area of disaster mental health response and mass violence came together to establish a set of best practices for mental health responders (Hobfoll, Watson, Bell, Bryant, Brymer, Friedman, et al., 2007). They recommended that the following five elements of psychological response be promoted when responding to victims involved in a disaster: 1) a sense of safety, 2) calming, 3) a sense of self and community efficacy, 4) connectedness, and 5) hope. These elements of disaster 
response, which will be described next, are not empirically identified, but through observation, these prominent themes have been reported in the literature.

\section{Sense of Safety}

The promotion of a sense of safety derives from investigations involving both objective reality and perceived reality (Hobfoll et al., 2007). During a disaster, people are forced to respond to events that threaten the lives of themselves, family, and friends, with further loss including material items they hold dear. Hobfoll et al. (2007) extended the definition of safety beyond one's self to include the safety of family and friends, which ultimately may be more important to some people, ranking above their own personal safety.

When establishing safety in the midst of a disaster, it is essential to have an intervention that includes locating and identifying loved ones and determining how they are doing (Hobfoll et al., 2007; Norris, Baker, Murphy, \& Kaniasty, 2008). If the response does not include the 'location of victims' component or the component did not work quickly or efficiently enough, survivors may develop their own ways to seek their family, as was shown in the aftermath of the 9/11 terrorist attacks. Family members and friends of Twin Tower employees covered walls and buildings with pictures and contact information in attempts to make contact with someone who may have known where their loved one was, or any information at all about their family and friends.

The media can both increase or decrease one's sense of safety. Specific messages disseminating information and giving reassurance can be helpful to the general population. However, the world of media is a business, and increased fear increases the profit to a company. Market research suggests that "uncertainty and fear promote increased viewing of the news" (Hobfoll et al., 2007, p 288). After the 9/11 terrorist attacks in New York City in 2001, the media 
repeatedly displayed the two terrorist planes crashing into the twin towers. Research suggests that this type of constant display of a traumatic event can increase the psychological distress of the individuals watching (Nader \& Pynoos, 1993).

The term "safety" also includes maintaining the safety of the victims from rumors, misinformation and other factors that may increase the sense of threat (Hobfoll et al., 2007). These other factors include such things as listing possible additional terrorist attacks that may occur. It may be disseminating information that is based on a hunch regarding the biological warfare that is being planned in local water systems. Consequently, the intent to fully inform the public of all possibilities can cause great insecurity and decease the feeling of safety; thus, public information must be factual, timely, and balanced to ensure safety.

Solomon, Shklar, and Mikulincer (2005) found that soldiers in Israel who were experiencing acute traumatic stress had decreased symptoms when moved from the threatening situation on the front line to a safe location out of the line of fire. A safe environment has a great impact on the perceived safety of an individual, and thus affects their psychological sense of safety. Those victims who are able to retreat to a safer environment prior to, or during the disaster will fare better over time (Rodriguez, Wachtendorf, Kendra, \& Trainor, 2006). If safety is not established, the sense of threat will be exaggerated and it will prevent a psychological return to safety (Hobfoll et al., 2007). Those who are able to re-establish a sense of safety have a lower risk of developing PTSD than those who do not (Bleich, Gelkopf, \& Solomon, 2003; Greiger, Fullerton, \& Ursano, 2003; Hobfoll et al., 2007).

\section{Calming}

Large scale disaster mental health responses should include an element of education aimed at normalizing and validating all stages of victim response (Hobfoll et al., 2007). One way 
to decrease anxiety and invoke calm in people is to educate them. By educating people about the normal and expected reactions to stress, they will often not define themselves as being 'crazy' and have a better ability to cope (Geonjian et al., 1997). Education about reactions to a traumatic event can be effective in reducing posttraumatic stress (Geonjian et al., 1997).

Hobfoll et al. (2007) found that people in a disaster often feel overwhelmed by the magnitude of the disaster. By teaching basic problem-solving skills that break down the problem into smaller more manageable pieces, people feel less overwhelmed and more in control of a situation. This can be done by identifying specific stressors and making a plan of how to deal with each aspect of that stressor in a short or immediate time frame.

\section{Sense of Self and Community Efficacy}

The importance of having a sense of control over positive outcomes is one of the wellinvestigated constructs in psychology (Skinner, 1996). Self-efficacy is the sense that a person believes that his or her actions will have positive outcomes (Hobfoll et al., 2007). When people face the devastation of a disaster, they often feel unable to cope and lose their sense of competency (Foa \& Meadows, 1997). The lack of understanding surrounding the specific disaster can migrate to other areas, leaving victims feeling incompetent in all areas of their lives. A sense of control is essential for coping in both victims and responders.

Hobfoll et al. (2007) reported that there are two aspects of self-efficacy to consider. The first is the skills and behaviors needed to overcome threats and solve problems. The second is the resources to utilize skill building to obtain resources. Those who are able to sustain their resources have a higher chance of recovery (Benight, 2004).

Hodges, Keeley, and Troyan (2008) found that nurses were able to become successful in their careers and excel during crisis situations by developing positive work interactions that built 
confidence and resiliency. A combination of these interactions, defined purpose, energy, and resources merge to create resiliency to stressful situations. Resiliency is defined as the ability to “recover quickly and adjust to adversity" (Hodges et al., 2008). As people learn to work in stressful situations, they develop an awareness of their own evolving competence and personal resources (Hodges et al., 2008).

Community bonding occurs as a result of sharing the catastrophic experience and the giving and receiving of community support. Survivors may experience a short-lived sense of optimism that the help they receive will make them whole again. When disaster mental health workers are visible and perceived as helpful during the response, they are more readily accepted and have a foundation from which to provide assistance in the difficult phases ahead.

Norris et al., (2008) outlined the need to address the reaction to a disaster on both an individual and community basis. With this multi-level approach, the importance of personal and community confidence is clearly apparent.

\section{Social Support and Connectedness}

Feeling socially connected after a disaster is a major component of psychological health (Solomon, Mikulincer, \& Hobfoll, 1986). Being connected to family, community, and state is an important concept that is usually forgotten during response planning. Social support is a critical buffer in stressful situations and a predictor of emotional and physical health (Groh, 2007).

Multiple studies support the concept that social support increases directly after a disaster, but the actual and perceived support deteriorates over time, resulting in a post-disaster decline in support (Arata, Picou, Johnson, \& McNally, 2000; Kaniasty \& Norris, 1993). Social support deteriorates on multiple levels from interpersonal relationships to family units to entire communities (Cohan \& Cole, 2002). 
Norris et al. (2008) further explored this realm of social support. They emphasized that social support needs to be addressed from the individual and community levels and the need to acknowledge both kin and non-kin supports. Solomon et al. (1986) found that a lack of social connectedness caused war combatants to feel lonely and distant. This lack of contact with family and infrequent meaningful conversations with those around them enhanced their perception of depression and inability to connect with a meaningful population (Solomon et al., 1986).

Apanovitch, Hobfoll, and Salovey (2002) studied how negative social influence could negatively change the views of others. They found that those who had been negatively influenced by a confederate were more likely to view the situation as negative when compared to an individual who was influenced by a confederate with neutral opinions. This supports the idea that negative thoughts and opinions can change one's perception of an event and must be minimized during immediate disaster mental health response to allow optimal mental health recovery.

Biglan and Craker (1982) reported that positive emotions enhanced the ability to connect with others and cope with a stressful situation. By providing an immediate environment where people feel comfortable, loved, joy at times, and experience laughter, their ability to cope may be enhanced. Unfortunately, this concept also works in reverse. Reading, hearing, or viewing items that create a negative emotion like fear, hate, and anger may decrease one's ability to cope (Hobfoll et al., 2007).

Hobfoll et al. (2007) also addressed the need for a healthy social system in the early stage of disaster mental health response, as this can contribute to feelings of security. Social systems are seen as family and immediate friends that are a daily fixture, who are cared for or are receiving care from that individual. After the Indian Ocean Tsunami, fishermen were unable to 
work and provide for their families. This change in responsibility of care contributed greatly to the inability of those individuals to feel safe and secure, disrupting the establishment of emotional regulation (Rodriguez et al., 2006). This is why the establishment of a preexisting infrastructure is essential when developing a disaster mental health response plan.

Lustad (1985) described that, when dealing with children involved in disaster, the first line of defense should be the family. Bassuk, Mickelson, and Perloff (2002) found that a positive relationship with siblings had a more positive effect on mental health than the relationship with the mother. The equilateral relationship of siblings can induce calm, control, and understanding amongst the group. Consequently, a hierarchal maternal relationship between sibling and mother was a predictor of depression as no such understanding was conveyed between the two and the relationship often contributed to the escalation of the child's stress (Groh, 2007).

When there are physical hazards or family separations during the evacuation process, survivors often experience post-trauma reactions. When the family unit is not together due to shelter requirements or other factors, an anxious focus on the welfare of those not present may distract from the attention necessary for immediate problem-solving. Post-disaster mental health responses may include anxiety, grief, depression, somatic symptoms; behavioral changes such as increase substance use or domestic violence, and problems in occupational and everyday functioning (Cwikel, Havenaar, \& Bromet, 2002).

During huge disasters, like 9/11 and Hurricane Katrina, the separation of families caused large distress and much chaos in the communities. When families are in different geographic locations during the impact of a disaster, survivors may experience considerable anxiety until they are reunited (Hobfoll et al., 2007). 


\section{Hope}

Foa (1997) suggested that the natural recovery after a traumatic experience is related to having a rational and reasonable view of the dangerousness of the world. Such thought patterns that continue to see the world as a dangerous and potentially deadly place contribute to the development of posttraumatic stress disorder (PTSD; APA, 2000; Hobfoll et al., 2007).

After a mass trauma, the loss of hope is one of the first causalities (Hobfoll et al., 2007). People who remain optimistic throughout a traumatic event are more likely to have better outcomes because they see a positive future in spite of their present condition (Carver \& Scheier, 1998). Research conducted with Holocaust survivors who managed to maintain hope throughout this horrible event showed that they had maintained a sense that things would work out the way they were supposed to (Antonovsky, 1979). Many people, in spite of horrendous conditions, often find hope in their spiritual beliefs (Hobfoll et al., 2007).

Groh (2007) found that women who felt incompetent and lacking in knowledge prior to the disaster were likely not to maintain the hope needed to move forward in recovery. Thus, they did not respond to traditional mental health approaches after the disaster, as they felt nothing could help them, nor did they have the power to help themselves.

Internal reactions to disaster greatly influence the behaviors and perceptions of all involved in disasters (Hobfoll et al., 2007). Regardless of how people are involved in a disaster, they will be affected by it. Unique experiences, as seen in disaster workers throughout the disaster response, will be described next. 


\section{Role of Mental Health Workers across the Disaster Phases \\ Pre-incident Stage}

The role of the mental health responder in the pre-incident stage is to train and educate future responders, collaborate with other community based agencies, evaluate policy, and ensure an expedient response when the need arises (NIMH, 2002). Mental health training has been successfully utilized to prepare community responders without formal mental health experience (North \& Hong, 2000). During this pre-incident time, many states utilize tabletop and reenactment training to help sharpen their skills to prepare for responding to a disaster.

\section{Impact Stage}

In the immediate aftermath of a disaster, survival, rescuing others, and promoting safety are priorities. Evacuation to shelters, motels, or other homes may be necessary. For some, postimpact disorientation gives way to adrenaline-induced rescue behavior, which leads to saving lives and protecting property. While activity level may be high, actual productivity is often low,

as many of the responders are also victims of the disaster (Gard \& Ruzek, 2006). An example of this is the multiple medical shelters that were set up immediately after the terrorist attacks of $9 / 11$, and which sat empty as few survivors were located. The capacity to assess risk may be impaired and injuries can result. Altruism is prominent among both survivors and emergency responders (Kaniasty \& Norris, 1997).

In the first 48 hours, first responders are rescuing and protecting the community in attempts to establish a sense of safety among victims and responders. Mental health professionals tend to the basic needs of individuals by uniting resources and providing psychological first aid (Gard \& Ruzek, 2006). Mental health responders continue to monitor the environment for 
concerns and provide consultation with other organizational entities to maintain the safety of those effected (NIMH, 2002).

\section{Rescue Stage}

Workers quickly recover from their initial shock and start developing and coordinating plans. The transition from the disaster operation back into the normal routine of work and family life can be a difficult one for workers if feelings have been suppressed or denied during the action phase, and the feelings now begin to surface. In addition, workers may experience feelings of loss and "burnout" as they move out of the challenging disaster assignment and return to their usual activities (DeWolfe, 2000).

\section{Recovery Stage}

Recovery-phase disaster work has a slower pace and can be less immediately rewarding than early-phase response (Gard \& Ruzek, 2006). Because disaster survivors do not usually seek out counseling services in large numbers, outreach and community education activities make up a large part of recovery activities (Gard \& Ruzek, 2006). Because of the lack of large numbers of "clients," combined with the difficulty of evaluating the effectiveness of outreach and education efforts, disaster mental health workers can lose heart and eventually question the value of their work.

\section{Return to Life Stage}

As the community returns to pre-disaster functioning, community outreach becomes an essential component of the response. Key findings by North and Hong (2000) support that victims prefer to seek support from members of their own communities rather than mental health professionals. Many out of town people respond to the disaster. In the field they are known as Spontaneous Uninvited Visitors or SUVs. By providing support within the community affected, 
North and Hong (2000) were able to show an increase in mental health services provided to survivors. As time passes, the role of the community helper extends into long term service and support and the continuation of assistance is sustained as needed. Mental health professionals may transition into the treatment mode of service as they address specific symptomatology seen in the community and as referrals for services are sent from the field (NIMH, 2002).

The emotional impact of disaster is especially strong for workers if contact with survivors is prolonged (Harvey \& Bryant, 1998; Moynihan, Levine, \& Rodriguez, 2005). Staff members identify with the survivors and sometimes take on the frustrations in their rebuilding efforts. Continuous exposure to survivors' stories of loss and grief can be painful for workers, and, if unrecognized, can play into an unconscious desire to avoid listening to painful material (Gard \& Ruzek, 2006). During disaster mental health response it is imperative to prevent burnout and responder fatigue (Gard \& Ruzek, 2006).

Disaster workers may go through a series of emotional phases related to the nature of their jobs. At times, workers may feel "out of sync" with the reactions of survivors. This is especially common in the early hours and days of the disaster while workers are still making heroic efforts to organize and deliver services (Rubel, 2008). At other times, mental health workers may closely identify with survivors and experience their emotions vicariously. While it is impossible to specify exactly what a given mental health worker may experience, it is important to be aware of workers whose coping resource have diminished and stress reactions are setting in (DeWolfe, 2000). All responders must be aware of the consequences of secondary traumatic stress that may manifest as a result of being exposed to other's traumatic experiences (Pulido, 2007). 
While responders diligently work to give help and support to those affected by disaster, survivors of the disaster have a higher risk of mental health distress (DeWolfe, 2000). Although individuals will respond differently to the stress thrust upon them, many common mental health themes are seen post-disaster.

\section{Survivors' Mental Health}

Exposure to disasters immediately challenge survivors and evoke an instant response (Ruzek, Brymer, Jacobs, Layne, Vernberg, \& Watson, 2007). Those who have endured longterm exposure and those who have witnessed death are at the most risk for developing long-term illnesses (DeWolfe, 2000). Given the magnitude of traumatic events to produce great distress, disaster mental health response covers efforts to tend to survivors in the immediate aftermath of disaster and to respond to their psychological needs (Ruzek et al., 2007).

Freedy and Simpson (2007) described the psychological impact of disaster on survivor's mental health, which includes emotional liability, negative emotions, cognitive dysfunction and distortions, physical symptoms, irritability, distrust, withdrawal, and a needed sense of control. Many of these psychological symptoms will resolve in the first few weeks, but in some cases, it may take months or even more than a year to return to baseline functioning (Freedy \& Simpson, 2007). During the first 48 hours after being exposed to a traumatic event, an increased sense of arousal is expected and appropriate (Hobfoll et al., 2007). This increased arousal or numbing response may provide the needed psychological cushioning during the initial impact of the crisis (Bryant, Harvey, Guthrie, \& Moulds, 2003). However, this increased arousal becomes a problem if it ceases to decrease as time passes (Hobfoll et al., 2007). This symptom will be frequently observed during the impact and rescue stage post-disaster, but it should lessen as they move throughout the recovery stage and return to life stages. For some, the symptoms will not decrease 
in intensity and may develop into the more severe condition of posttraumatic stress disorder (PTSD; APA, 2000).

\section{Posttraumatic Stress Disorder}

In the 1980 version of the Diagnostic and Statistical Manual of Mental Disorders (American Psychiatric Association [APA], 2000), the field of psychology recognized a better understanding of trauma related to individual and community crisis with an inclusion of symptoms observed in those returning from combat and civilians post-disaster. This cluster of symptoms was named Posttraumatic Stress Disorder (PTSD; APA, 2000; Goodman \& WestOlatunji, 2008). During World War I, PTSD was called “shell shock," and in World War II, it was referred to as "combat fatigue" (Schiraldi, 1999, p. 363). After the Vietnam War, the symptoms known as PTSD were called Post Vietnam Syndrome. The symptoms of PTSD long preceded the formal identification of the term (Schiraldi, 1999).

Posttraumatic stress disorder develops after a petrifying event that involves physical harm or the threat of physical harm (McCarthy \& Butler, 2003). PTSD is defined by the presence of symptoms that include avoidance of reminders of the traumatic stress, intrusive trauma-related thoughts and images, hyper arousal of the nervous system and disruption of cognitive, affective, and somatic processes. In the most rigorous state, these symptoms can be diagnosed as either acute stress disorder (ASD) or PTSD (APA, 2000). Goodman and West-Olatunji (2008) criticized the present definition of PTSD (APA, 2000) stating that this limited definition only includes direct experience of the incident and overlooks those who are traumatized by transgenerational experiences and secondary trauma as seen in professionals and family members of trauma survivors. 
A person who develops PTSD may be the one directly affected by the event, a witness to a loved one being involved in the traumatic event, or the event may have just been witnessed. Some events that may elicit a PTSD-response include personal assaults, natural or manmade disasters, accidents, or war (McCarthy \& Butler, 2003). Symptoms of PTSD usually begin within three months after the event, but may emerge up to years afterwards, with any initial symptoms seen after six months being referred to as "late onset." Late onset PTSD often has a poorer prognosis than earlier onset (WebMD, nd.). Symptoms must be present for a minimum of one month and cause significant distress that impairs one's ability to function (Schiraldi, 1999)

After a formal posttraumatic stress disorder diagnosis was developed, the way researchers looked at disaster mental health response also changed. Research focus was now on decreasing these PTSD symptoms, a measurable guide that did not exist previously. Those who suffer from PTSD show increased rates of suicide, hospitalizations, and alcohol and drug abuse (Chou et al., 2003; Gard \& Ruzek, 2006; Vlahov et al., 2004). With such severe consequences to PTSD, it is imperative to recognize and defuse any situation or symptom that may contribute to PTSD symptoms.

\section{PTSD Predictive Factors and Responses}

Bryant et al. (2003) reported that extremely high levels of emotion may lead to panic attacks, disassociation, and possibly PTSD. Extended periods of heightened arousal may lead to increased agitation, depression, appetite changes, and sleep disturbances (Harvey \& Bryant, 1998). Most individuals will return to pre-event levels of arousal within days or weeks after the trauma (McNally, Bryant, \& Ehlers, 2003). Survivors who do not return to pre-event levels are at an increased rate of experiencing posttraumatic stress symptoms (McNally et al., 2003). Hensley and Varela (2008) found support for hurricane exposure to be a significant predictor of PTSD in 
all ages, with anxiety sensitivity interacting with trait anxiety to be a predictor of PTSD and somatic symptoms.

Predictive factors of disaster mental health response in survivors are their pre-disaster mental health and social support before, during, and after the event and the age of the person affected (Freedy \& Simpson, 2007). Individuals who exhibited pre-disaster mental health problems are 50\% more likely to develop a post-disaster psychiatric disorder (Johnson, North \& Smith, 2002). The best way to reduce long-term pathology due to a disaster is to prepare or mitigate for the incident before it happens.

One of the strongest predictors of posttraumatic stress in Hurricane Andrew survivors was the inability to obtain finances to rebuild their homes (Ironside et al., 1997). These hurricane survivors lost all hope in the system in which they once believed. Ginexi, Weihs, Simmens, and Hoyt (2000) described how the loss of possessions, money, work, and personal resources was a good prediction of post-disaster mental health. Financial stability is an essential piece in instilling hope in victims of disasters who lost their homes and livelihoods (Hobfoll et al., 2007). Mental health professionals need to be more aware of the red tape survivors are facing and develop assistance programs to assist with these situations (Hobfoll et al., 2007).

Ginexi et al. (2000) reported a negative correlation between income and depressive symptoms post-disaster. When completing research after the Midwestern floods of 1993, they found that a $\$ 5,000$ decrease in household income was accompanied by increased flood impact scores. In addition, they found that communities that were already dealing with stress due to financial concerns also had an increase in flood impact scores.

The greater the scope, community destruction, and personal losses associated with the disaster, the greater the psychosocial effects (Norris, Galea, Friedman, \& Watson, 2006a). 
Researchers have consistently shown that the more personal exposure a survivor has to the disaster's impact, the greater his or her post-disaster reactions (Solomon \& Green, 1992). Emotions run extremely high during this time and $66 \%$ more people will report having symptoms of PTSD within the first 48 hours post-disaster than two weeks after the event (Whalley \& Brewin, 2007).

Depending on the uniqueness of the incident, "people's reactions range from numb, limited, stunned, or shock-like responses to the less common overt expressions of panic or hysteria" (DeWolfe, 2000, p. 10). Typically, people respond initially with confusion and skepticism and focus on their survival and their loved ones (DeWolfe, 2000). As disaster assistance agencies and crisis worker groups begin to leave, survivors may feel deserted and angry. The "reality of their losses and the limits and terms of the available assistance becomes apparent” (DeWolfe, 2000, p. 11). Survivors assess assistance they have received compared to what they will need to return to pre-disaster functioning. The greater the degree of difference between what they have and what they need will increase the stress of the individual and family (DeWolfe, 2000).

A larger community less impacted by the disaster may return to business as usual, which is typically discouraging and alienating for survivors in directly affected areas. Ill will and resentment may surface in neighborhoods as survivors receive unequal monetary amounts for what they perceive to be equal or similar damage (Hobfoll et al., 2007). Defensiveness and hostility among neighbors undermine community cohesion and support. This breakdown of cohesion and support increases the chances of developing acute stress symptomatology and PTSD (Hobfoll et al., 2007). 


\section{PTSD Prevalence Statistics}

The National Comorbidity Survey reported that $19 \%$ of men and $15 \%$ of women in the United States have been exposed to a traumatic experience, with the probability of experiencing PTSD in their lifetime being 3.7\% in men and 5.4\% in women (Castellano \& Pilonis, 2006; Creamer, Burgess, \& McFarlane, 2001; Kessler, Sonnega, Bromet, Hughes, \& Nelson, 1995). The law enforcement field has about a 10\% prevalence of developing PTSD, with firefighters' prevalence between 10-30\% (Castellano \& Pilonis, 2006). North et al., (1999) reported that those directly exposed to a mass disaster have a prevalence rate of $34 \%$ for a potential PTSD diagnosis. Six months after the Alfred Murrah Federal Building bombing in Oklahoma City, $45 \%$ of the survivors reported mental health needs, with 34\% displaying PTSD (North et al., 1999). In spite of variations in the statistical data, all studies indicated that direct exposure to a traumatic event greatly increased the chances of developing PTSD.

PTSD is said to affect about 8-12\% of American adults in their lifetime (Schiraldi, 1999). Studies report that PTSD symptoms are more prevalent in females and further studies suggest that the disorder may have a genetic link (McDermott, Lee, Judd, \& Gibbon, 2005). The National Comorbidity Study indicated that symptoms of PTSD are more prevalent immediately after the traumatic experience, but rapidly decline over the first 12 months with a continued decline over the next 36 months (Kessler et al., 1995). One year after the Alfred P. Murrah Building was bombed, $5 \%$ of elementary aged children reported clinically significant post traumatic stress symptoms (Whalley \& Brewin, 2007). Two years after the Pentagon attack on 9/11, 20\% of those who were present in the building at the time of the attack were diagnosed with PTSD (Whalley \& Brewin, 2007). 
Johnson et al. (2002) studied the effects of a 2002 court room shooting on the 80 people who witnessed the event either by direct sight or by hearing the incident. The study observed the participants and evaluated them for symptoms of PTSD at six to eight weeks, one year and then three years after the shooting. Johnson et al. (2002) reported that $25 \%$ of the subjects involved in the research had a post-disaster psychiatric disorder. However, upon further review, only 4 of the 25 subjects reported no psychiatric disorder prior to the courthouse shooting. While this study showed a 9\% increase in post-disaster psychiatric disorders, it did not address changes in individual symptoms of existing disorders.

When people begin to see meaning, personal growth, and opportunity from their disaster experience despite their losses and pain, they are well on the road to recovery. Over time, survivors begin to recognize the limits of available disaster assistance (DeWolfe, 2000). They become physically exhausted due to many enormous demands, financial pressures, and the stress of relocation or living in a damaged home (DeWolfe, 2000). The unrealistic optimism initially experienced can give way to discouragement and disaster fatigue. For most survivors, psychopathology effects appear to decrease as time passes from the onset of the event (Ginexi et al., 2000). In our most recent history, two major disasters have had an impact on the whole country: the September 11, 2001, terrorist attacks and Hurricane Katrina. The impact of these disasters has indicated the need for mental health services post-disaster. These two events will be described next.

\section{September 11, 2001 Terrorist Attacks}

On September 11, 2001, a terrorist attack on the United States led to the hijacking of four commercial airplanes and the collapse of the World Trade Center (WTC). Two hijacked planes were directed into the WTC in New York City, another hit the Pentagon in Arlington, Virginia, 
and another plane crashed in Pennsylvania (Miller, 2002). The official fatality figure in the WTC disaster was 4,167 people (Miller, 2002).

After the September $11^{\text {th }}$ attacks, a plethora of articles were published that examined the mental health response and need in areas affected by the terrorist attacks. Many of the articles that were published were personal accounts of mental health workers' experiences working at the disaster sites. Although these articles are great accounts of personal experiences, they were not included in this literature review, because they are not empirical research. The following are several pertinent studies of the 9/11 experience.

\section{Impact on the General Population}

Following this terrorist attack, increased fear swept across the nation as Americans struggled to make sense of the tragedy. Research completed by Schlenger et al. (2002) reported that $4-11 \%$ of the U.S. adult population knew someone who was killed on 9/11. Neria et al. (2008) found that $27 \%$ of Manhattan residents reported knowing someone who was killed in the 9/11 attacks. Those who experienced loss on 9/11 were twice as likely to develop a mental disorder (Neria et al., 2008). For those who experienced loss, 29\% reported major depressive disorder, 19\% reported anxiety-related disorders, and 17\% reported PTSD symptoms directly related to the $9 / 11$ attacks (Neria et al., 2008).

Although the most severe cases of PTSD symptoms will be identified and diagnosed, other equally debilitating symptoms may arises that affect the functioning of those in a community affected by tragedy. The Archives of General Psychiatry (2005) reported finding that $28.6 \%$ of children in New York City suffered from anxiety/depressive-related disorders after 9/11. This study also described the positive relationship between the level of exposure to $9 / 11$ and the likelihood of anxiety/depressive disorders in children in the community. These 
symptoms appear to have a significant impact in the community six months after the disaster hit, as a rise in mental health services was observed (Archives of General Psychiatry, 2005).

Burnham (2007) reported findings from a pre-9/11 and post-9/11 evaluation, which indicated that children between the ages of 2-12 scored significantly higher on nine different terror fear items. These items included being more fearful of "our country being invaded by enemies," "terrorist attacks," and "flying in a plane" (Burnham, 2007). Burnham (2007) inferred that television exposure of the planes flying into the World Trade Center had a negative effect on the children in this study, particularly with the younger children studied.

Other research has considered physical location and proximity to the $9 / 11$ disaster sites. Burnham (2007) reported that regardless of physical location, children reported similarly on the nine terror fear items. Johnson and Richter (2003) reported that, although people away from the disaster site experienced increased stress symptoms, those closer to the World Trade Center site reported more severe symptoms.

A study by Levine, Whalen, Henker, and Jamner (2005) looked at the impact of the 9/11 terrorist attack on adolescents in California. They found that adolescents had less negative feelings about the terrorist attack than their parents (Levine et al., 2005). This study showed a positive relationship between parental stress and adolescent anxiety. Levine et al. (2005) concluded that, since adolescents see themselves as less vulnerable than others, they often isolate themselves from family and in return this may serve a protective function for adolescents confronted by distant traumatic events.

In the wake of the 9/11 attacks, Project Liberty was the counseling crisis program developed to assist those affected by the disaster. Shear, Jackson, Essock, Donahue, and Felton (2006) found that $44 \%$ of Project Liberty service recipients screened positive for complicated 
grief issues. These individuals did not meet the clinical criteria for major depression or PTSD but reported significant sadness and loss of functioning. These authors emphasize the importance of early recognition of grief/bereavement symptoms and ensuring a plan is in place to attend to the psychological consequences of disasters.

In response to stressful situations, many people will rely on coping techniques that aid in the acceptance and masking of their emotions. Vlahov et al. (2004) conducted phone surveys and found that New York City residents reported increased drug and alcohol use after 9/11. Consistent with Johnson and Richter (2003), Vlahov et al. (2004) found that those with an increased use in cigarettes were more likely to report symptoms consistent with PTSD. In addition, Vlahov et al. (2004) found that although symptoms of depression and PTSD declined significantly six months after 9/11, similar trends were not found for those who increased their

use of alcohol and drugs. This suggests that the impact of the increased drug and alcohol use may not be seen until it is assessed from a long-term perspective (Vlahov et al., 2004).

With the magnitude of 9/11, the whole world watched as our firemen, police officers, clergy, medical workers, and other emergency and disaster services personnel responded to the need for recovery. With few living people removed after the $9 / 11$ attacks, the mental health toll of this disaster was magnified. Those who responded first will forever be reminded of this great tragedy.

\section{Impact on Disaster Responders}

Not only do researchers need to consider those primarily affected by the events of $9 / 11$, but they also need to consider the thousands of individuals who respond to this catastrophe. Hundreds of fire fighters, police officers, medical professionals, construction workers, and various mental health workers were on the frontlines post-9/11. The Centers for Disease Control 
(CDC) (2004) conducted studies on the rescue and recovery workers involved in 9/11. The CDC reported that $51 \%$ of the workers met the threshold criteria for a clinical mental health diagnosis. It was found that $20 \%$ of these responders met the criteria for PTSD. When considering mental health response to a disaster, there is a great need to ensure those who have responded to help also receive the benefits of the mental health support being provided.

After 9/11, the peer cop-to-cop program in New Jersey experienced a 300\% increase in calls and became overwhelmed with their intensity (Castellano \& Pilonis, 2006). A new inclusion to disaster mental health response was added when the terrorist attacks of 9/11 hit New York City. Officers were dealing with the loss of co-workers and fear for their lives and their families (Castellano \& Pilonis, 2006). After 9/11, Castellano and Pilonis (2006) identified two new concepts to disaster mental health response: the "high-risk rescuer" and the "rescuer victim."

Suite, Rollin, Bowman, and La Bril (2007) found that in a study of Southern Baptist Church-affiliated responders, participants felt unprepared and under-trained for dealing with the 9/11 terrorist attacks. These responders felt unprepared in areas of short and long-term effects of mass trauma, trauma evaluation, identification of key problems, and how to triage survivors. As a result, the New York Southern Baptist Church developed training to address these issues and to increase the competence and safety of their staff and those with whom they are interacting.

The country acknowledges the lack of preparedness for the 9/11 attacks, never imagining that the United States could be so unpredictably attacked on its own soil. But even with the devastation of $9 / 11$, no one could have envisioned the hurricane that would devastate a whole coast for years to come. 


\section{Hurricane Katrina}

On August 29, 2005, a category five hurricane barreled down the Gulf Coast region evoking havoc on all in its path. Seven states were hit, 15 million residents were affected, 275,000 homes were completely destroyed, 400,000 people lost their jobs, 1,836 people lost their lives, and 705 people still remain missing as result of this powerful hurricane (Hurricane Katrina Relief, nd). Hurricane Katrina was the largest and most costly natural disaster to ever hit the United States with approximately $\$ 110$ billion in damages (Hurricane Katrina Relief, nd).

The impact that Hurricane Katrina had on the mental health field would be felt in the Gulf Coast region for years to come. Seven weeks after Hurricane Katrina, it was estimated by the Centers for Disease Control and Prevention (CDC) that of 166 individuals interviewed, 45\% showed scores high enough on an assessment tool to be diagnosed with PTSD (Voelker, 2006). With this statistic in mind, it was estimated that between 142,000 and 214,000 adults returning to New Orleans would qualify for a mental health referral (Voelker, 2006). The Substance Abuse and Mental Health Services Administration (SAMHSA) estimated that 25-30\% of those living in areas hit the hardest by the hurricane would have a clinically significant mental health need and an additional $10-20 \%$ of the population would have subclinical mental health needs (Voelker, 2006).

\section{Impact on Children}

This traumatic event affected people of all ages, particularly those who remained in the affected areas reported increased symptoms. Scheeringa and Zeanah (2008) examined the onset of symptoms in 70 preschool children ages 3-6 and their caregivers after Hurricane Katrina. They found overwhelming results indicating that $50 \%$ of the preschoolers displayed child- 
adapted PTSD criteria symptoms, with $62.5 \%$ of those who stayed in New Orleans displaying these modified PTSD symptoms, and $43.5 \%$ who evacuated meeting the criteria of modified PTSD. In addition, Scheeringa and Zeanah (2008) reported 88.6\% of those with PTSD also met the criteria for a co-morbid diagnosis, with oppositional defiant disorder (ODD) and separation anxiety being the most common. Caregivers' rates of PTSD were reported to be $35.6 \%$, with $47.6 \%$ of the symptoms commencing after Hurricane Katrina. No children and only two caregivers reported new psychiatric symptoms without meeting the criteria for PTSD (Scheeringa \& Zeanah, 2008).

Support for co-morbid symptoms was also found when assessing adolescent reaction to Hurricane Katrina. Marsee (2008) completed research on 166 adolescents post-Hurricane Katrina and found an association between exposure to Hurricane Katrina and reactive aggression via PTSD systems and poorly regulated emotions. In addition, Marsee (2008) further found a relationship indicating that minority youth were more likely to experience reactive aggression within PTSD than Caucasian youth. More research to date has examined internal symptoms of PTSD, as opposed to the externalizing problems, such as aggression (Marsee, 2008).

After Hurricane Katrina, Pina et al. (2008) established support for a negative relationship between extra-familial social support and levels of child-rated symptoms of PTSD. These researchers found that, as children had more support from their families, they reported less childrated PTSD symptoms. In addition, Pina et al. (2008) reported that a positive predictive relationship was seen between helpfulness from a professional and PTSD, which they interpreted as a parent seeking help for their child when they exhibited increased levels of PTSD. Furthermore, youth who displayed avoidant coping behaviors were seen to have more PTSD and anxiety symptoms (Pina et al., 2008). 
One year after Hurricane Katrina, more than half of the city of New Orleans had still not returned (Burton, 2008). Fifty percent of parents on the Gulf Coast reported that at least one of their children had emotional or behavioral problems that did not exist prior to Hurricane Katrina (Burton, 2008). Thirty-four percent of the children surveyed reported one diagnosed medical condition since Hurricane Katrina (Burton, 2008). This decreased emotional stability may be related to family instability, as the average affected family moved 3.5 times, with some moving as many as 9 times, in the first year (Burton, 2008).

\section{Psychiatric Response}

Not only did Hurricane Katrina inflict mental stress on those in its wake, the wave of mental health care that was debilitated imposed greater strain on an already low resource area. Three months after Hurricane Katrina hit land, many psychiatric patients were still living and receiving services on a Carnival cruise ship, which was provided for emergency, temporary housing (Voelker, 2006). Lamberg (2006) reported a 57\% decrease in available psychiatric beds in Louisiana four months following Katrina; therefore, the city of New Orleans transported patients more than 150 miles to the nearest inpatient psychiatric beds (Lamberg, 2006).

Two years after Hurricane Katrina hit the Gulf Coast, one half of mental health providers surveyed reported a "lack of infrastructure" as a major challenge to mental health services (Healthcare Financial Management Association [HFMA], 2007). A marked increase had been seen in major depression, anxiety disorders, PTSD, and addictions as reported by an online survey completed by mental health providers in New Orleans and Baton Rouge, Louisiana (HFMA, 2007). An inability to create stability in their own lives due to their personal response to the hurricane had seriously impacted provider burnout. Lack of resources and decreased financial 
stability are major issues faced by mental health professionals in the post-Hurricane Katrina Gulf Coast area (HFMA, 2007).

Over the past decade, with disasters affecting the mental health of all populations, many agencies and organizations have identified mental health as an area that needed formalized intervention. Utilizing existing mental health involvement within individual and community crisis, the field of disaster mental health began to grow and evolve. The major disaster mental health programs that have most significantly impacted the disaster mental health field will be described next.

\section{Disaster Mental Health Programs}

Disaster mental health is an evolving field of practice that involves interventions and practices that are designed to address specific stress reactions in contrast to developmental mental health needs (Jackson \& Cook, 1999). Disaster mental health differs in several ways from the traditional psychotherapy models. Traditional mental health services are aimed at treating pathology via group and individual interventions, whereas disaster mental health is a proactive attempt to deny acute stress pathology and normalize reactions to abnormal events (DeWolfe, 2000). The traditional mental health model is based on the medical model with the clinician assessing and treating the patient in an office setting. In contrast, the disaster mental health model requires practitioners to work with individuals and communities in the field rather than in an office-type setting (DeWolfe, 2000). Disaster mental health practitioners are more likely to observe the emotional distress through a sociological lens, which focuses on normal experiences, rather than pathological responses following a disaster (Warheit, 1988). The timing of traditional mental health services is usually within weeks, months, or even years after the development of a 
problem, whereas, in disaster mental health, services begin during or immediately after the incident (Mitchell, 2003).

With the differences in disaster mental health services and traditional mental health services being well recognized, Edwards (1998) used an ecological model to gain knowledge of the complex relationships among individuals, families, and communities. As in any system, there is a need to maintain a specific balance to allow growth and change to occur. Edwards' (1998) understanding of the multi-faceted relationship between disasters and mental health contributed to the recommendation of mental health services being inter-disciplinary and holistic in their approach. This approach supports the involvement of both mental health professionals and community citizens to carry out disaster mental health interventions.

In the past two decades, three disaster mental health models have become popular postdisaster interventions. Critical incident stress management (CISM), psychological first aid (PFA), and crisis counseling programs (CCP) have offered responders a way to intervene with survivors to alleviate some mental health stress. Each method has its distinct structure and deployment in the field as described in the next section.

\section{Critical Incident Stress Management}

Critical incident stress management (CISM) was introduced to the world in 1983 when Dr. Jeffrey Mitchell created a process called critical incident stress debriefing (CISD), published it in a trade journal and presented the process as an approach to the management of stress responses in emergency services (Bledsoe, 2003). Mitchell developed CISM after applying what he had learned as a paramedic/firefighter to the area of critical stress (Mitchell, nd). Mitchell (2003) outlined CISM as a field of study, where as CISD is a process within CISM. "CISM is the strategy, CISD is merely the tactic" (Mitchell, 2003, p 3). 


\section{CISD Model}

The traditional CISD model contains the following seven steps: the introduction, the fact phase, the thought phase, the reaction phase, the symptom phase, the education phase and the re-entry phase (Mitchell, 2003). The introduction step is a chance for the facilitator to review group rules and guidelines. During this time, logistics, such as where the restrooms are located, if smoking is allowed, and if everybody is required to participate, would be discussed. It is also important to note things that may affect those who leave the room. Many facilitators will ask that the assistant follow the participant out of the room to ensure they are okay. It is essential to set up boundaries of confidentiality during this time.

The fact phase of CISD is the phase of the intervention that researchers have identified as being possibly traumatic for those involved. During this stage, the facilitator asks each member of the group what they experienced (Devilly, Gist \& Cotton, 2006). It is beneficial to develop an in-depth picture from start to finish, establishing what was seen, heard, felt, smelled, and tasted, if applicable. This stage is based solely on fact and not on interpretation.

The thought phase identifies what was going through the minds of those involved (Devilly et al., 2006). Often the facilitator may get people telling him or her that they became frozen with fear, their mind was racing, and they had problems thinking of what they should do (Malcolm, Seaton, Perera, Sheehan, \& Van Hasselt, 2005). During this phase, it is important to keep people focused on thoughts and not on physical reactions.

The reaction phase is where people discuss what they did during the incident. What was their first reaction, personally (Malcolm et al., 2005)? Did they help the person, did they run, did they call 911 (Devilly et al., 2006)? 
During the symptom phase, members should share some of the physical symptoms they were experiencing at the time of the incident, and these experiences should be normalized (Malcolm et al., 2005). Some people may have difficulty sleeping. Others may have the urge to drink more, while some people may feel physically ill, irritable, or have an urge not to return to the scene.

The educational phase is used to normalize the responses people are having and predict and prepare for things that may arise in the future (Devilly et al., 2006). Education focused on symptoms, supports both at home and at work, and predictions of feelings and reactions that may arise when they go back to the scene or experience something similar are all important components of this phase (Malcolm et al., 2005).

The re-entry phase is the last phase in CISD, and it is when the facilitator explores where the group will go from here and referral options (Devilly et al., 2006). At a minimum, each member of the group should have a follow-up contact by the facilitator after the group ends to check on their status. This stage focuses on returning to the workplace and future adjustment (Malcolm et al., 2005).

\section{Research on CISM}

Recent studies have indicated that psychological debriefings do not prevent posttraumatic stress disorder, nor do they thwart long-standing distress or dysfunction (McNally et al., 2003). In fact, some studies have even indicated that psychological debriefings may be harmful to those who were directly affected by the disaster (Litz \& Gray, 2002). These debriefing type models have been criticized in recent years as they tend to increase the arousal of those involved in the immediate trauma (McNally et al., 2003).

Concurrently, Van Emmerick, Kamphuis, Hulsborch, and Emmelkamp (2002) concluded, after completing a meta-analysis on seven studies, that critical incident stress debriefing had no 
significant effect on reducing symptoms of posttraumatic stress. Some concerns about this format of intervention are that many interventions are done within the first week and only constitute one face-to-face encounter (Norris \& Elrod, 2006; Van Emmerick et al., 2002). Furthermore, "some survivors (e.g., those with high arousal) may be put at heightened risk for adverse outcomes as a result of such early interventions" (NIMH, 2002).

Although there is a time for ventilation after a traumatic event, forced telling or hearing about the traumatic event may be harmful to one's psychological well-being. Regehr (2002) reported that the "fact phase" of the Critical Incident Stress Debriefing (CISD) model is the most criticized component of the model due to the possibility of "increasing intrusion symptoms by vicarious traumatization (p. 87)." However, Regehr (2002) also found positive empirical support for other phases of the Mitchell and Bray (1990) CISD model. She was clear to identify that the enhancement of social support and the psycho-educational components are a beneficial component to those affected by a traumatic experience (Regehr, 2002). Implications from this study support the inclusion of a social support component and psycho-educational component in future post-trauma interventions (Regehr, 2002).

Bledsoe (2003) explained that the reason CISM does not work is because it interferes with the normal recovery process within individuals. Furthermore, Bledsoe (2003) explained that CISM may lead a victim to bypass personal support from friends, family, co-workers, and clergy for a false sense of security in CISM. Additionally, each person affected appears to have his or her own timetable to heal, and in spite of intervention, no external program may be capable of shortening this interval (Bledsoe, 2003).

\section{Mitchell's Response}


Mitchell (2003) refuted allegations of the CISD process being seen as an ineffective way to address traumatic stress. Although research has supported the idea that CISD shows no effect on combating PTSD symptoms, Mitchell (2003) argues that this research is flawed. In addition, Mitchell noted that the components being tested are not consistent with the CISD protocol. Mitchell (2003) has encouraged more studies to evaluate the effectiveness of the CISD process.

Mitchell (2003) emphasized that there are six core competencies that are necessary for an effective CISM program. First is the assessment ability of the personnel to evaluate the severity of an event and whether reactions are normal or significant enough for an outside referral. Second is strategic planning, which is knowledge of who needs intervention and what tactics should be used, when, and by whom. Third is that those intervening should have the skills to aid individuals if they need assistance. Fourth, interveners must have large group intervention skills; the intervener must understand group dynamic sand be able to manage a group throughout the process, while not overlooking some of the participants involved. Fifth, the intervener must have small group intervention skills; the intervener must be able to keep a group on task and be aware of those who may mislead the group. Lastly, those involved must also have the follow-up and referral skills to ensure the safety of those affected. In addition, Mitchell (2003) clearly stated that one should always use the model as intended and this should be group, not individually, administered with groups like first responders who have much group cohesion and a similar understanding and experiences related to the disaster situation.

A plethora of research in the past decade that placed the CISM process in a negative light has been responsible for various organizations refraining from using CISM. The World Health Organization (WHO) and National Institute of Mental Health (NIMH) withdrew their support for 
CISM, stating the potential for re-traumatizing victims. These organizations placed their support in Psychological First Aid (Bledsoe, 2003).

\section{Psychological First Aid}

With the National Institute of Mental Health withdrawing its support for the CISM model, those in the field of disaster mental health responded to an increased need for an immediate intervention after a disaster hit (Gard \& Ruzek, 2006). Out of these efforts, Psychological First Aid (PFA) was proposed as a primary initial response during a disaster (Gard \& Ruzek, 2006). Psychological First Aid aims to soothe the painful range of emotions and physical responses experienced by people exposed to disaster. These reactions include combinations of confusion, fear, hopelessness, helplessness, sleeplessness, physical pain, anxiety, anger, grief, shock, aggressiveness, mistrustfulness, guilt, shame, shaken religious faith, and loss of confidence in self or others. There is consensus among international disaster experts and researchers that PFA can help alleviate these painful emotions and reduce further harm that could result from initial reactions to disasters (Norris et al., 2006b). PFA is not intended to treat extensive psychological needs (Gard \& Ruzek, 2006); however, PFA is not an intervention as much as it is a practical support approach to disaster recovery (Bledsoe, 2003).

PFA is an evidence-informed approach and intervention, built on the concept of human resilience, to help survivors cope in the immediate aftermath of a traumatic event, crisis, or natural disaster (National Child Traumatic Stress Network and National Center for PTSD, 2005). Evidenced-based practice, as defined by the Institute of Medicine, is "the integration of best researched evidence and clinical expertise with patient values" (Institute of Medicine, 2007, p. 147). Evidence-informed practices are the clinical best practices that are observed in the field where they are applied (National Child Traumatic Stress Network and National Center for PTSD, 
2005). PFA evidence-informed support is gained by being consistent with research on resilience and risk management following trauma, clinically applicable in the field, developmentally appropriate, and culturally informed (Vernberg et al., 2008). It is essential to report that there is no outcome research on the efficacy of PFA in spite of millions of federal dollars being used to train responders. In 2008, the National Child Traumatic Stress Network (NCTSN) put together a subcommittee to further aid in building this area of research (Vernberg et al., 2008).

PFA can help individuals of all ages and it is designed to reduce the initial distress caused by disaster. PFA acknowledges the seriousness of the experience of danger and the increased feelings of vulnerability that often follow. PFA fosters long- and short-term adaptability, basic functioning, and coping skills. Basic objectives of PFA include the following (National Child Traumatic Stress Network and National Center for PTSD, 2005):

- To enhance immediate and ongoing safety and provide physical and emotional comfort for survivors.

- To establish a non-intrusive, human connection, and compassionate manner. Help survivors tell, specifically, what their immediate needs and concerns are and gather additional information as appropriate.

- To offer practical help such as food, water, and blankets to help survivors cope effectively with the situation at hand.

\section{Core Elements of PFA}

PFA is organized with eight core elements that may appear to go in a logical order, but individuals may fluctuate among different stages. The following descriptions of the PFA stages are adapted from the Psychological First Aid Field Operations Guide (National Child Traumatic Stress Network and National Center for PTSD, 2005). The eight PFA core elements include: 
contact and engagement, safety and comfort, calm and orient, information gathering, practical assistance, social support, information on coping and linkage to collaborative services.

Contact and engagement. The goal of contact and engagement is to initiate contacts with those involved in the disaster in a non-intrusive and helpful style while considering cultural implications (Vernberg et al., 2008). This contact establishes a respectful relationship between the responder and the victim that fosters the receptiveness for further helpful interactions. The initial contact should reengage victims in social interaction in a respectful, predictable, and calming manner (Borja, Callahan, \& Long, 2006). If a collaborative interaction is not established, it will impede the ability for the responder to further aid the victim.

Safety and comfort. The second stage of PFA is the establishment of safety and comfort. The goal during this stage is to enhance immediate and ongoing safety and provide physical and emotional comfort (Vernberg et al., 2008). This is established by performing active, practical, and familiar interactions to increase the survivor's sense of control. When people are faced with disaster situations, this in itself will invoke a fight/flight/freeze response. PFA is designed to help address these physiological responses (Lawyer et al., 2006; Vernberg et al., 2008).

Calm and orient. The third goal of PFA is to calm and orient emotionallyoverwhelmed/distraught survivors. This does not mean to calm the loudly expressive victims, but to look for signs of someone who is overwhelmed. Disaster-fatigued responders react with glassy eyes, disorientation, unresponsiveness, and, at times, a need to continue their work in spite of directions and deployment length. Victims may display uncontrollable crying, shaking, trembling, inability to eat, rocking, engaging in high-risk activities, anxiety, or depression (Vernberg et al., 2008). Rational thought is often not present during this time, so trying to convince someone to calm down is not seen as beneficial (Schiraldi, 1999). 
During the 9/11 terrorist attack response, American Red Cross responders reported that the best thing they could do to help someone was to get them water or food (J. Dennis, personal communication, June 7,2002 ). This contact would often bring about a smile, a tear, or, at times simple conversation. Many responders will coordinate their teams with similar-colored shirts. Responders were aware of the job description depending on the color, so just their presence brought forth comfort and calmness to victims and responders who may have been experiencing increased stress at the time.

Information gathering. The goal of the information gathering stage is to identify immediate needs and concerns, gather additional information, and tailor PFA interventions to the individual victim. Information gathering is a constant job throughout all stages of PFA, but it is essential in aiding in the healing of those affected. It is important to gain as much information as possible about the survivors' experiences to help assess their needs. This is a time to let victims tell their story, not pushing for information, but simply asking open-ended questions and being aware of body language, as intrusive questioning can cause additional unnecessary distress (Devilly et al., 2006).

Practical assistance. The fifth stage of PFA is practical assistance. Disaster survivors who have lost the most intimate resources, such as their home, financial stability, and social support are those most devastated by the trauma. Those who are able to sustain these essential resources have a better prognosis of recovery (Norris \& Kaniasty, 1996). Often, simple and practical ways to connect people to resources are not in the minds of those affected by trauma, as decision-making skills may be impaired during these times of crisis (Schiraldi, 1999). Practical assistance is seen as helping individuals and families stabilize their lives by using simple problem-solving skills to eliminate challenges these people are facing. 
Social support. The sixth stage in PFA is the connection of survivors to social support systems. This is used to help establish brief or ongoing contacts with primary support persons or other sources of support, including family members, friends, and community helping resources. Social support is directly related to improved mental state and recovery after a traumatic event (Vernberg et al., 2008).

Information on coping. The seventh stage in PFA is the dispersion of information on coping. The goal is to provide information about stress reactions and coping with the intention to reduce distress and promote adaptive functioning (Vernberg et al., 2008). Providing information on coping increases a sense of self-efficacy and hope and enables victims to feel they have the capability to survive (Benight $\&$ Harper, 2002).

Linkage to collaborative services. The eighth stage of PFA is linkage with collaborative services. During this stage, the PFA responder will connect survivors with needed services and inform them about available services that may be needed in the future. It is important that the PFA responder take direct steps to connect victims with mental health workers who can help them, as many victims will not seek mental health services on their own (Wang et al., 2008). This may be done by introducing those victims to helpers who will replace the PFA responder and providing contact information about mental health centers in the area that are opened or contact information to state agencies that can connect them with services.

In summary, PFA is a disaster mental health model that is utilized by mental health professionals to address community crisis. In attempts to better serve areas affected by disaster, the crisis counseling (CCP) model was introduced to allow all people of a community to aid in their communities' assistance and recovery. The CCP model is intended for community response to overwhelming mental health needs. 


\section{The FEMA/SAMHSA Crisis Counseling Program Model}

The FEMA/SAMHSA Crisis Counseling Program (CCP) model has been regularly used in response to natural disasters (Castellano \& Pilonis, 2006). The purpose of the CCP is to help those affected, both directly and indirectly, by a disaster to understand that their reaction to the trauma is normal and to aid in the development of coping strategies (FEMA, 2008). The intent of crisis counseling is to maximize one's ability to return to pre-disaster mental health conditions as soon as possible. The CCP is not intended to take the place of mental health treatment; however, it may be utilized to identify those who may benefit from a referral for formal mental health treatment (FEMA, 2008). The CCP model has five components: to assess strengths, seek to restore pre-disaster functioning, accept content at face value, validate common reactions, and provide a psycho-educational focus (Castellano \& Pilonis, 2006).

\section{CCP Components}

The first component of the CCP model is to assess the strengths of the situation. This is done by looking at the whole picture. In spite of the traumatic event occurring, there are many strengths emerging in the community, the population and the responding agencies. By identifying the strengths, the crisis counselor can use these strengths to help victims see things in a more productive light. This instills hope in those devastated by the disaster.

The second component of the $\mathrm{CCP}$ is to seek to restore pre-disaster functioning. When training counselors in the CCP model, it is always important to emphasize that the job is not to go in and take over the duties of the town, but to support their infrastructure until it can support itself. To do this effectively, an assessment of the pre-disaster and post-disaster functions must be completed with the intention to identify where the breakdown in the infrastructure has occurred (Castellano \& Pilonis, 2006). If systems did not work prior to the disaster, they will not 
work after the disaster. During this assessment of functioning, it is essential to identify whether or not the breakdown was due to personnel, equipment, or leadership/government restrictions.

The third component of the CCP model relies on the proper development of a CCP team and educating them on accepting content given to them at face value. A CCP should be delivered by those in the community who know the culture and town the best. Key findings by North and Hong (2000) indicate that victims prefer to seek support from members of their own communities rather than mental health professionals or people from outside the community. These are everyday citizens who may or may not have a mental health background. With this in mind, it is important to keep content at face value, and the CCP model does not train responders to analyze and assess at a deeper level. It is essential to be able to identify when someone needs more in-depth services and refer them appropriately.

The fourth component of the CCP model is validating the reactions of the people in the disaster. Listening, caring, and helping people understand that what they are experiencing is a normal reaction to an abnormal situation. After a disaster, survivors struggle to redevelop their norm and the response of the crisis counselor can help survivors identify their emotional reactions.

The fifth component of the CCP model is educating those affected by the disaster. This information dissemination can be done by house-to-house visits, town meetings, or at general gathering areas. It is the job of the crisis counselor to educate everyone on normal reactions to a disaster, safety concerns, how to contact FEMA and other disaster services, mitigation, what they can expect in the following weeks, and where to find more support for shelter, food and water. This dissemination can be done verbally or through written materials. 
CCPs are funded by FEMA in two scenarios. First, CCPs may be funded as an Immediate Services Program (ISP), which allows an immediate intervention to aid disaster mental health response by providing mental health and outreach services for up to 90 days post-disaster (FEMA, 2008). A second funding source is by the Regular Services Program (RSP), which is designed to provide crisis counseling and community outreach and education to those affected by a Presidentially-declared disaster for up to a year (FEMA, 2008).

\section{Summary of the Three Models}

While CISM, PFA, and CCPs are regularly seen in post-disaster mental health responses, each response model appears to have strengths to offer a community. CISM was developed for use with first responders and this model is widely accepted among firefighters, police, and paramedics. Due to its popularity, many responders in the field continue to use this model and many continue to request and require 'debriefings' for all responders to a disaster.

PFA offers a framework for mental health professionals and takes typical disaster response and structure into account when carrying out its phases. Many of the phases in PFA coincide with evidence seen in the literature on resiliency and trauma. PFA is a newer concept and still lacks empirical data to support its effectiveness.

CCPs strongly encourage those in the community to participate in post-disaster mental health responses. With the goals of educating the community on normal responses to disaster and offering guidance, CCPs strive to serve all affected by the disaster. Even with these nationally acknowledged responses, there is still a need for more conclusive support for the benefits of delivering such disaster mental health programs. 


\section{Limitations of Disaster Research}

Researchers in the field of disaster mental health have done much of their observation post-disaster. There is a need for more surveillance of mental health prior to disaster, so that the true impact of the disaster on the mental health of those involved can be evaluated. Due to ethical concerns, it is difficult to find empirically sound, controlled disaster research data to support evidence-based practices in the field of mental health. There are a few studies that have investigated mental health interventions in an experimental or quasi-experimental setting (Hobfoll et al., 2007). These were carefully designed and cautiously executed randomized, controlled trials, which have a critical role in establishing parameters for best practices. There is little evidence to confirm or contest the effectiveness of any early psychological intervention following mass violence and disasters, specifically using PFA and CCP models.

In 2001, an international group of trauma and disaster mental health researchers developed best practices for early intervention of disaster mental health. First, there is some evidence for the effectiveness of early, brief, and focused psychotherapeutic intervention for reducing distress in bereaved spouses, parents, and children. Second, that is some evidence that selected cognitive behavioral approaches may help reduce incidence, duration, and severity of ASD, PTSD, and depression in trauma survivors. Third, there is some evidence suggesting that early intervention in the form of a single one-on-one recital of events and expression of emotions evoked by a traumatic event do not consistently reduce risks of later developing PTSD or related adjustment difficulties. Some survivors may be put at heightened risk for adverse outcomes as a result of such early interventions. Fourth, there is no evidence that eye movement desensitization and reprocessing (EMDR) (Shapiro, 1989) as an early mental health intervention following mass violence and disasters is a treatment of choice over other approaches. 
Unfortunately, there are few well-designed psychosocial research studies that show the positive impact of early intervention on posttraumatic stress symptomatology (Norris et al., 2006a). This does not mean that the crisis mental health responses are ineffective; it simply means that researchers need to find better ways to evaluate the programs. One of the greatest concerns in disaster mental health is the ethical restraints that affect research potential and its application to field-based professionals. Mixed interpretations about the possibility of disaster research upsetting participants are seen throughout the literature (Newman, Walker, \& Gefland, 1999). Federal regulations guide studies to guarantee that protection is given to participants and to take steps to ensure that no further harm is done to the participants as a result of the research. As a part of ensuring participant safety, informed consent is a mandatory part of any research project. Federal regulations emphasize that additional care is given to "vulnerable participants such as children, prisoners, fetuses, people with decision impairments, and the economically and educationally disadvantaged" (Fleischman, Collogan, \& Tuma, 2006, p. 79; Protection of Human Subjects, 2005).

Disaster-affected populations should not necessarily be considered "vulnerable" in the regulatory sense (Fleischman et al., 2006). However, research proposals should address the individual psychological state of potential participants and have explicit mechanisms available for the timely referral of participants in need of mental health consultation, including training investigators and research staff to recognize emotional problems in research participants (Fleischman et al., 2006; Levine, 2004). Frontline clinicians should be aware of people with high exposure to a traumatic event, as these individuals should be thoroughly assessed for research appropriateness (Rosenstein, 2004). 
In addition to assessing the vulnerability and the informed consent of individuals involved in disaster research, it is also essential that researchers consider the format of the research design. Although more controlled random sample designs can have much stronger research power, these controlled studies may provide an unfair advantage to those receiving the intervention and cause harm to those who do not receive the intervention. Additionally, disaster-affected individuals appear to respond better to interview-based questions, as opposed to questionnaire-type research studies (Newman et al., 1999).

When evaluating the need for a given research proposal, one must evaluate the risks and benefits of the research (Collogan, Tuma, Dolan-Sewell, Borja, \& Fleishman, 2004). Newman and Kaloupek (2004) focused on the benefits and risks of completing trauma-focused research. They reported several positive results for participants who were involved in research studies. The positive consequences that were reported were that participants were connected with mental health providers for referral purposes, and participants also often gained insight about their experience through catharsis in a safe, controlled environment (Newman \& Kaloupek, 2004). In addition, it was reported that many participants felt satisfaction from contributing to the welfare of others and the field of future knowledge (Newman \& Kaloupek, 2004).

Some of the risks to participants in disaster research may be "physical harm, inconvenience, legal action, economic hardship, psychological discomfort, loss of dignity, breach of confidentiality, and unwanted media attention" (Collogan et al., 2004, p. 367). Collogan and colleagues (2004) identified characteristics that may exacerbate the risks to some participants. These characteristics include a history of mental illness, age, history of multiple trauma exposure and social vulnerability. Collogan et al. (2004) reported that the most recently discussed area of concern within the realm of risk is emotional distress. Although the authors noted that 
participants may become upset during the study, overall the participants found the research study beneficial and without re-traumatization. However, some studies have not supported these findings.

One study reported that $12.9 \%$ of those involved in a telephone survey immediately post9/11 reported negative effects from the survey (Newman \& Kaloupek, 2004). The reported negative affects rose to $15 \%$ when responders were questioned six to eight weeks post-9/11. It is unclear which personal characteristic increase the resiliency in trauma-based studies (Newman \& Kaloupek, 2004). It is important to consider how one may be negatively affected by a research study, compared to the benefit from the gained information.

Fleishman et al. (2006) collaborated with professionals in the area of disaster mental health research and families involved in the Oklahoma City and World Trade Center disasters to develop a list of recommendations for future researchers. Their recommendations included the following: 1) It should be assumed, that as a group, those affected by a disaster have the capacity to provide meaningful and voluntary informed consent to participation in research; 2) when questions arise, individual assessments should be conducted; and 3) the decision to participate in research should be entirely up to the judgment of a competent participant (Fleischman et al., 2006).

Specific research proposals should be scrutinized based on the level of risk, the novel nature of the research, and the uncertainty of the risk-benefit ratio. Such scrutiny may result in the need for additional procedural safeguards for that specific proposal (Fleischman et al., 2006). Ideally, representatives of the community who will be participants of the research should have some level of involvement in the planning and implementation of the research (Fleischman et al., 2006). 
Informed consent procedures should reduce the likelihood of participants mistaking research for clinical services, therefore avoiding the therapeutic misconception (Fleischman et al., 2006).

Elrod, Hamblen, and Norris (2006) conducted research with 36 state agency directors who managed the SAMHSA emergency response grant funds to evaluate the challenges in executing crisis counseling programs in their areas. These researchers found that many states that did not regularly experience disasters did not have a disaster mental health plan in place and many of the plans that did exist were vague and immature in content. In addition, many disaster plans only minimally addressed the mental health concerns of the community they were to serve (Elrod et al., 2006). Common themes that were found during the preparedness stage of the disaster mental health response were that there are three major preparedness components that were perceived as necessary: logistics and supplies, prior relationships with other organizations, and a plan for having all key stakeholders at the disaster response staging area (Elrod et al., 2006). The investigators further concluded the need for training for state directors in a disaster mental health response, with guidance on how to complete the grant request and manage the community demands against administrative necessity.

Elrod et al. (2006) emphasized that the communication among all levels of organization may become frustrating when disconnected and inhibit those involved in the disaster mental health response. The authors provided several suggestions for overcoming future state agency responses. The following is a list of recommendations for states from that study (Elrod et al., 2006, pp. 168-169):

- Have a disaster plan with mental health as an integral part of this plan;

- Implement more training for disaster mental health coordinators; 
- Have all state directors review the grant application prior to a disaster occurring;

- Develop manuals to outline the roles of the outreach workers, the counselors and the referral procedure;

- Develop a fiscal management plan before implementing the program;

- Develop a standardized approach to Crisis Counseling Programs;

- Build relationships with other organizations prior to working together with them in a disaster setting;

- Implement evaluation procedures and exit interviews with responders.

With the publication of guidelines that mold the shape of disaster mental health response and plans, there is a need to evaluate adherence to such practices.

\section{Focus of the Current Study}

In 2002, the National Institute of Mental Health (NIMH) convened a workshop and published the proceedings on best practices for disaster mental health response. This article was influenced by the most well-known researchers and clinicians in the field of disaster mental health, trauma, and resiliency. The result was an outline that guides mental health responders and state officials in the most efficient way to respond to a disaster (NIMH, 2002). The proceedings also included specific tasks and infrastructure that needed to be in place for optimal efficiency.

In attempts to aid in the development of more in depth disaster mental health plans and training of responders, in 2003, the Substance Abuse and Mental Health Services Administration (SAMHSA) provided grant opportunities for state directors to develop their disaster mental health response plan and an all-hazards team (SAMHSA, 2003). The goal of these grants was for states to develop an infrastructure to guide mental health response specific to their state. 
Since the implementation of state disaster mental health plans, little has been done to evaluate the quality and content of these plans and the disaster mental health response in the field. The current study sought to address this limitation in the field, by evaluating three disaster mental health state plans to assess their adherence to best practices noted by research (NIMH, 2002) and based on the experiences of those well versed in the disaster mental health field, specifically the disaster mental health state directors in these states. The research methodology of the current study will be described next. 


\section{CHAPTER 3- Research Methods}

\section{Overview of Qualitative Research}

Qualitative research is the global term used to describe several research methods that use language data (Polkinghorne, 2005). Within the realm of qualitative research, Polkinghorne (2005) and McCaslin and Scott (2003) have organized approaches under five basic traditions: biography, grounded theory, ethnography, case study, and phenomenology. The phenomenological approach to qualitative research will be utilized in this study.

Phenomenology is described as the study of the shared meaning of experience of a phenomenon for several individuals (McCaslin \& Scott, 2003). Phenomenology is an inductive process that allows themes, patterns, and categories to emerge from the data, rather than only assessing a phenomenon based on prior criteria (Moustakes, 1994). In its most basic form, phenomenology attempts to create conditions for the objective study of topics usually regarded as subjective (Wikipedia, 2009a). Phenomenology is the reflective study of the essence of consciousness as experienced from the first-person point of view (Smith, 2007). The goal of phenomenology is to "determine what an experience means of the persons who have had the experience and are able to provide a comprehensive description of it" (Moustakes, 1994, p.15).

Phenomenology uses systematic reflection to determine the essential properties of consciousness and conscious experience. This is an approach to philosophy that begins with an exploration of phenomena as a means to finally grasp the absolute, or the metaphysical spirit that is behind phenomena (Wikipedia, 2009a). It is imperative for the researcher to develop a thick 
description of the phenomenon to fully understand the emerging themes in the written experience.

\section{Application of Qualitative Research in Current Study}

One primary purpose of a qualitative study was to describe and clarify an experience as it “constituted awareness" (Polkinghorne, 2005, p. 138). This study utilized the phenomenological approach to qualitative research to gather significant and relevant themes in disaster mental health response as displayed in the written disaster mental health state plans. This research enriched the understanding of disaster mental health response by identifying themes and comparing these themes to identified best practices as set forth by the National Institute of Mental Health (NIMH, 2002).

There were two purposes of the current study. The initial primary purpose of this study was to examine existing state disaster mental health plans to gather shared content among plans and gather an understanding of disaster mental health response as a phenomenon. The secondary purpose was to appraise state disaster mental health plans and their adherence to existing best practices in the field of disaster mental health response.

These results allowed the researcher to highlight common response preparation and deployment practices that were seen in the field of disaster mental health. This study guided future disaster mental health responders and trainers on what was needed to competently deploy their team into the field. In addition, this research contributed to the greater understanding of disaster mental health response and safety, allowing well prepared individuals to be deployed. This researcher was able to develop an understanding of how state responses have grown in philosophy and procedures over the years, particularly since September 11, 2001. This research also showed how time and experience had influenced state plans in each of the states involved. 


\section{Research Participants}

Polkinghorne (2005) wrote that "participants and documents for a qualitative study are not selected because they fulfill the representative requirements of statistical inference but because they can provide substantial contributions to filling out the structure and character of the experience under investigation" (p. 139). The primary data in the current study consist of three existing state disaster mental health plans and three related key state leaders in disaster mental health in the states of Kansas, Indiana, and Mississippi. These states were selected for their involvement in diverse disaster mental health responses that have influenced their state plans. All the states involved in this study have responded to nationally declared disasters in the past five years and have been granted funding to implement a SAMHSA Crisis Counseling Program in their affected areas. By selecting these states, the study gathered experience from state disaster mental health plans that involved hurricanes, flooding, and tornados. This diverse experience allowed the researcher to evaluate various disaster experiences.

\section{Kansas}

On May 4, 2007, an F5 category tornado ripped through Greensburg, Kansas eliminating a town with a population of 1,574 (Wikipedia, 2009) that once stood strong and leaving 8 dead in its wake (National Geographic, 2007). With winds recorded up to 205 miles per hour, this tornado was the first F5 documented storm since 1999 (National Geographic, 2007). On May 8, 2007, the President of the United States declared 41 Kansas counties national disaster areas (FEMA, 2007a). This declaration not only included areas devastated by the tornado, but surrounding counties affected by wind damage and flooding (see Figures 3.1 and 3.2 for pictures of the Greensburg tornado). 


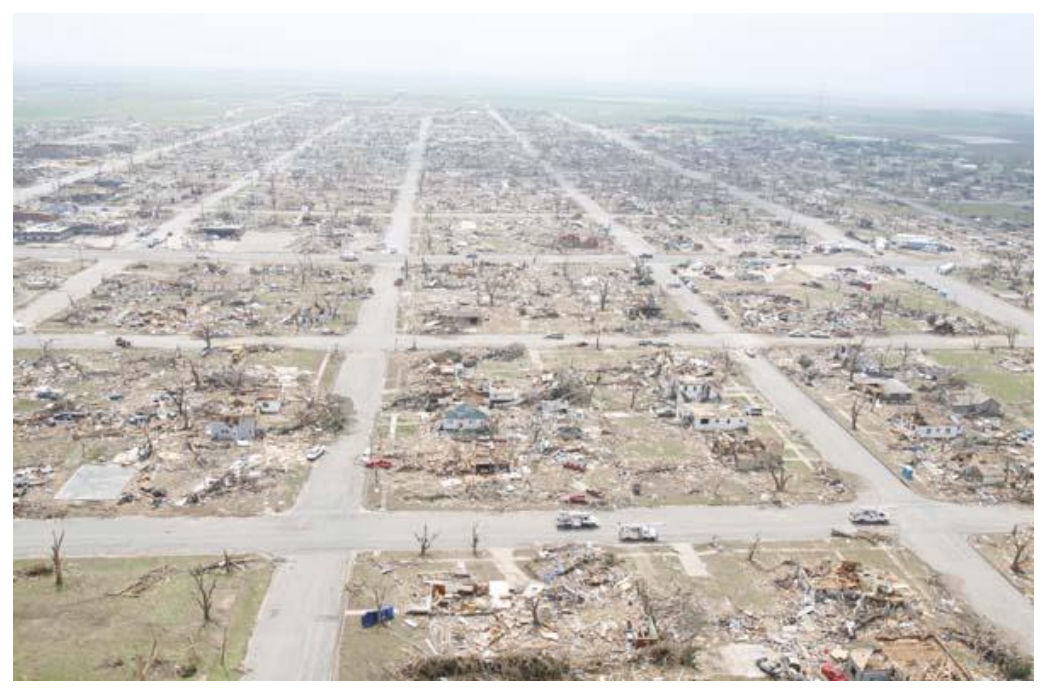

Figure 3.1 Where Greensburg, Kansas Once Stood.

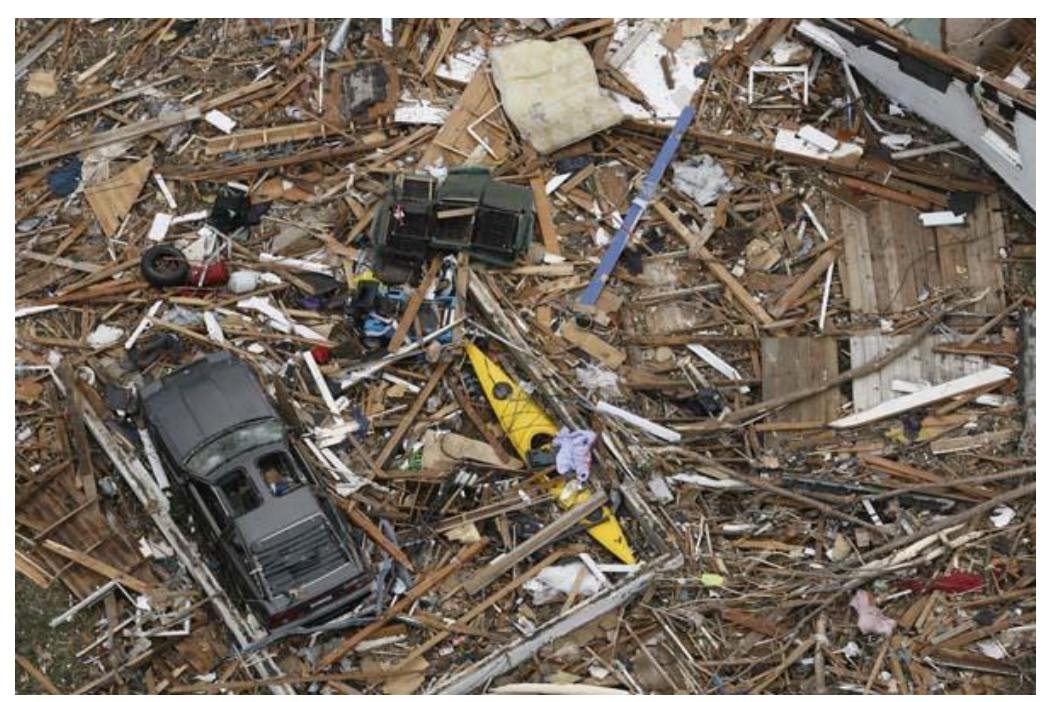

Figure 3.2 Aftermath of the Greensburg, Kansas Tornado

\section{Indiana}

On June 4, 2008, the rain began to pour into south-central Indiana dropping more that 10 inches onto an already saturated state (Wikipedia, 2008). With an excess of 10 inches of precipitation falling in only a few hours in many parts of the state, many were caught unprepared for such devastation (Wikipedia, 2008). Some parts of the state had flood levels exceeding records set in 1913 (see Figures 3.3 and 3.4 for pictures of the 2008 Indiana flooding). On June 
$9^{\text {th }}, 29$ counties were declared major disaster areas and Indiana quickly applied for state and federal monies to support the needed physical and mental health demands of the state (J. Hortsman, personal communication, June 9, 2008).

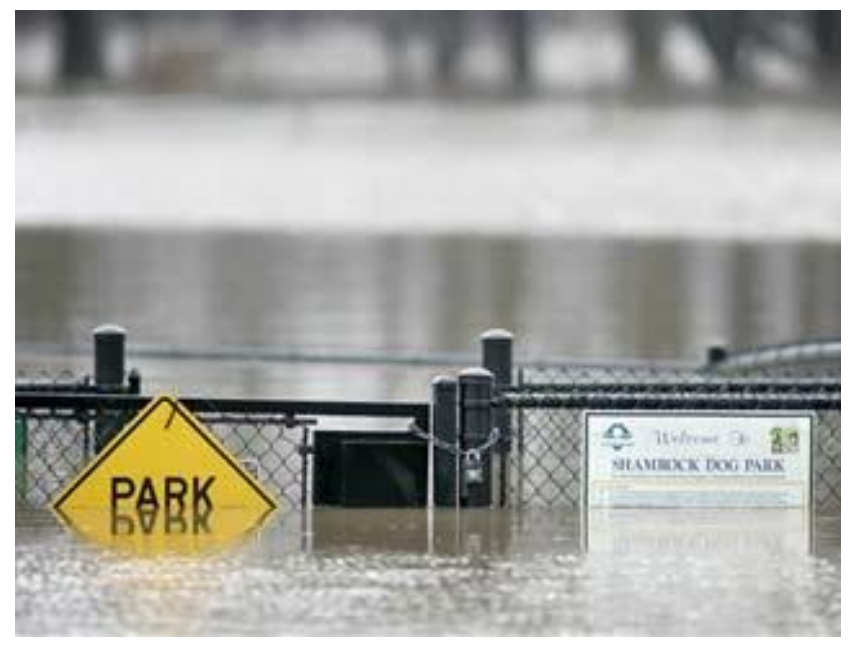

Figure 3.3 Wabash River Rises in Indiana

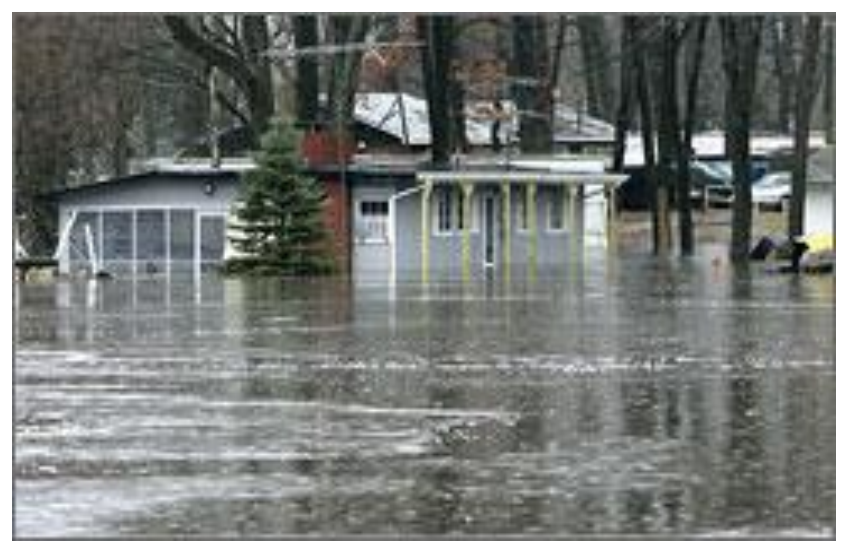

Figure 3.4 Families Caught Unprepared in Indiana Flooding

\section{Mississippi}

On August 29, 2005, Hurricane Katrina, a category five hurricane, made impact in Gulf Port, Mississippi, destroying all in its path. Over 90,000 square miles were declared national disaster zones (Madrid \& Grant, 2008). Homes were swept away by the storm surge leaving 
barren land where once communities thrived (See Figure 3.5 for picture of Gulfport, MS).

Flooding and wind damage was reported all across Mississippi, leaving much of the southern half of the state without electricity (See Figure 3.6 for picture of Biloxi, MS). All 82 counties in Mississippi were declared a national disaster zone (Madrid \& Grant, 2008).

With the assault of Hurricane Katrina on the Mississippi gulf coast, it was evident that the response would be difficult covering a huge land area. With assistance from surrounding states and internal resources, the state was able to provide the needed mental health response (K. Jones, personal communication, December 1, 2008). Mississippi applied for a federal FEMA/SAMHSA Crisis Counseling Program (CCP) grant in the aftermath of Hurricane Katrina and utilized SAMHSA funds to provide the mental health response in affected areas (K. Jones, personal communication, December 1, 2008).

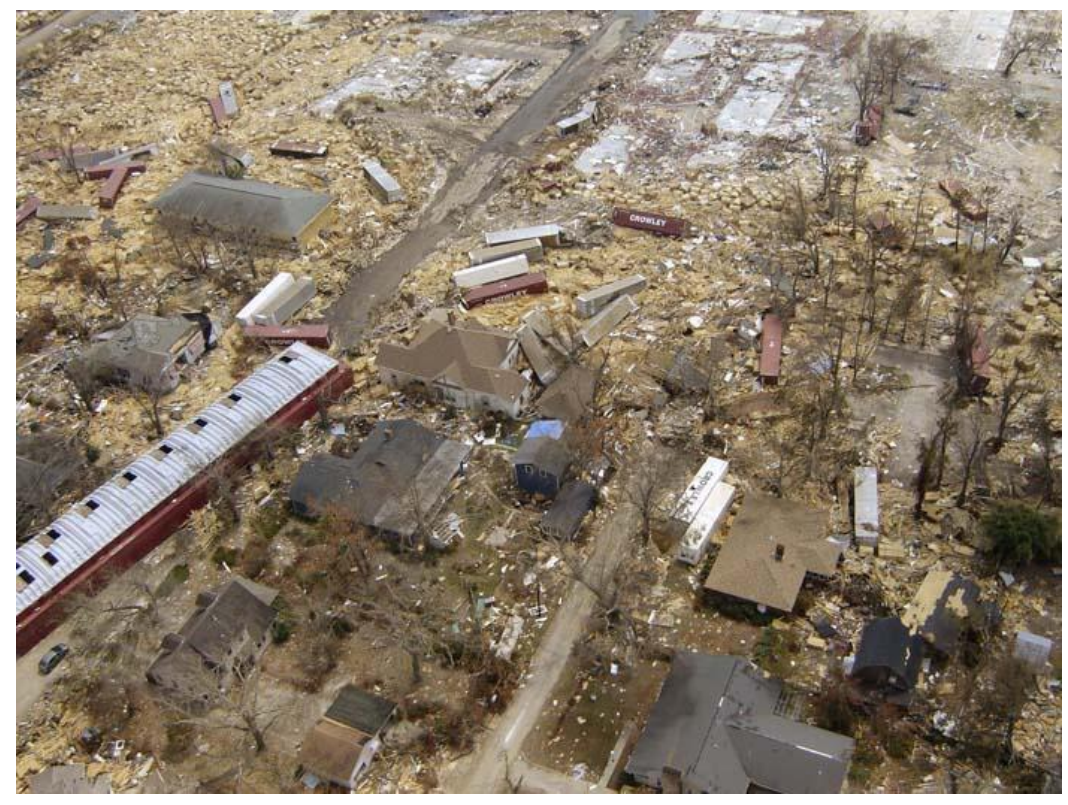

Figure 3.5 Gulfport, Mississippi Houses Moved Out to Sea 


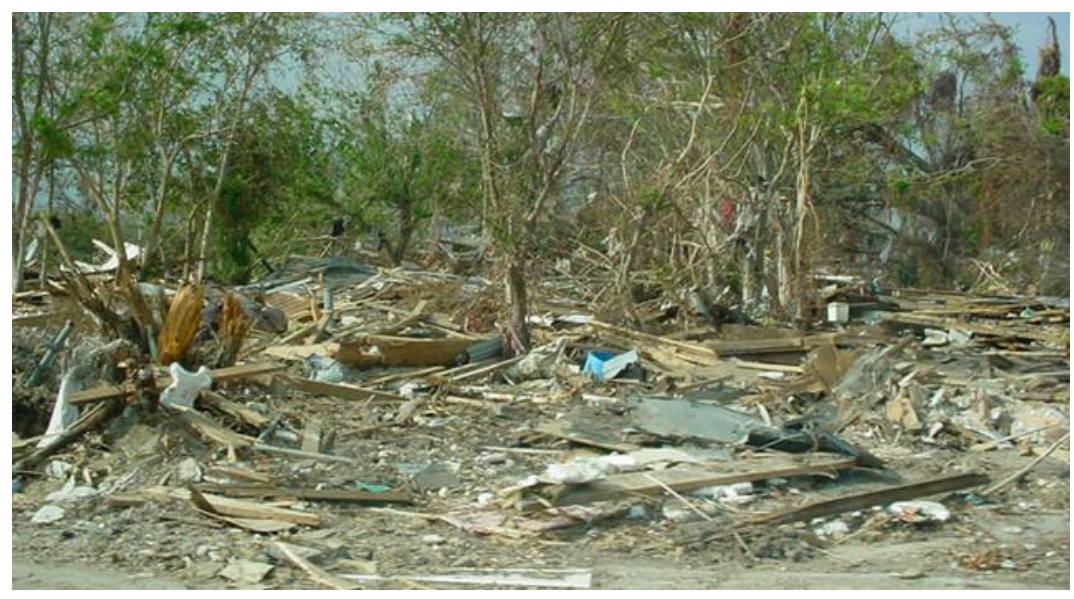

Figure 3.6 Remnants of Beach Housing in Biloxi, Mississippi

\section{Sampling}

The sampling involved in this study was static sampling, which infers that the documents existed prior to the research study (Polkinghorne, 2005). This type of sampling was more practical for this study because it involved evaluating state disaster mental health plans that were developed prior to the specific state disaster. However, one limitation of this type of sampling was that it inhibited the researcher's ability to reach out to more individuals who might have added greater knowledge to the phenomenon. It was the hope of the researcher that by intentional selection of representative states, possible sampling limitations could be minimized.

Polkinghorne (2005) encouraged qualitative researchers to examine the quality of documents or experiences rather than quantity, insisting that a purposeful sample will be the sample from which most can be learned. This process is called "purposive" or "purposeful sampling" (Polkinghorne, 2005). This study purposefully selected to explore three states with diverse disaster experiences. 


\section{Data Collection}

\section{Interviews}

A semi-structured interview with each state disaster mental health coordinator was initially completed. This interview was used to gather information about the implementation of the state plans and to develop a "thick" description of these procedures (Ponterotto \& Grieger, 2007). This interview clarified questions about the disaster mental health state plan and contents of the plan. Each interview was recorded and transcribed for more in-depth analysis, following the actual interview. All interview transcripts were reviewed to ensure accurate entry. The interview questions are listed in Appendix B.

\section{Disaster Mental Health State Plans}

Each state plan was reviewed for emerging themes and categories utilizing the phenomenological approach to data collection (McCaslin \& Scott, 2003). This saturation of information allowed themes and anomalies to rise from the data. The phenomenological method in this research design allowed the researcher to understand the disaster mental health response holistically. The themes and categories that developed were evaluated based on their adherence to best practices in the disaster mental health field.

Best practices for this study were gathered from the information printed in the Mental Health and Mass Violence: Evidence-Based Early Psychological Intervention for Victims/Survivors of Mass Violence: A Workshop to Reach Consensus on Best Practices (NIMH, 2002). The consensus of these recommendations was reached by those most highly trained clinical and research-focused individuals in the field of disaster mental health response (NIMH, 2002). Additional best practices used for evaluation of the state plans were also included from two disaster mental health response publications (Elrod et al., 2006; Hobfoll et al., 2007). 
Recommendations of best practices were placed in table format (See Appendix C) to easily identify the best practices and to be able to evaluate their presence in the three identified state plans.

Each item listed as a best practice was identified and evaluated as either compliant (included) or non-compliant (excluded) from the disaster state plans. A section for notes was available to list additional information that was gained from the interview process. The interview process took place before any state plans had been reviewed and evaluated based on the identified best practice criteria. The following is a brief description of the key state leaders from Kansas, Indiana, and Mississippi who were interviewed for the study.

\section{Indiana}

The Indiana State Representative interviewed was the Indiana state Program Director for the Office of Emergency Preparedness, within the Indiana Division of Mental Health and Addiction (DMHA). He has worked in the field of mental health and developmental disabilities for 25 years, the past 15 years with the State of Indiana. He is a nationally known speaker and has presented on the topics of psychological aspects of terrorism, disaster preparedness, and mental health planning. He has been the director of Project Aftermath, the title of the crisis counseling program in Indiana. Project Aftermath has responded to five major federally declared disasters in Indiana since 1997.

\section{Mississippi}

The Mississippi representative interviewed was the Division Director for the Mississippi Division of Disaster Preparedness and Response. She is responsible for the Mississippi Department of Mental Health (DMH) responsibilities, as outlined in the Mississippi Comprehensive Emergency Management Plan, the DMH statewide disaster mental health 
response system, and DMH disaster mental health response plan. In addition, this division assists the DMH-operated facilities and local community mental health centers (CMHC) with disaster preparedness and response efforts. This division operated Project Recovery post Hurricane Katrina and has responded to several major hurricanes since 2005 (DMH, nd).

\section{Kansas}

It was planned that the Kansas representative to be interviewed would be the Kansas Director of State Planning and Coordination and the Project Director of the Kansas All-Hazards Behavioral Health Preparedness \& Response Program for the Kansas Department of Social and Rehabilitation Services (SRS). She had served as the team leader for the KARE (Kansas Assisting Recovery Efforts) response for the tornado in Greensburg, KS. In the midst of data collection, this representative resigned from the Kansas Department of Social and Rehabilitation Services and was no long able to participate in the study. Prior to vacating her position, this individual arranged for another SRS manager to be the contact person at the state level. Upon contacting this individual, she referred me to another disaster mental health worker, stating that this individual would be better informed of disaster mental health issues and better able to contribute to the study. The person interviewed was the special projects coordinator for Kansas Health Solutions. Kansas Health Solutions is a managed care company that provides Medicaid benefits for mental health recipients in Kansas. She is leader for the state disaster mental health response in Kansas and has held that position since January 2009. Since being in this position, she has added an addendum to the Kansas All-Hazards Behavioral Health Plan. At the time of this study, this individual had not been directly involved in a disaster mental health response in Kansas.

\section{Data Analysis}


Data analysis was informed by phenomenological inquiry that aimed to elicit the meaning units within the data. A combination of thematic analysis and ethnography was applied where data collection and data analysis were completed concurrently (Marshall \& Rossman, 2006). Data was reviewed repeatedly in order to identify and describe themes in the data (Creswell, 2009). In accordance with ethnography, transcribed interviews, field notes and other existing documents were reviewed regularly to elicit major themes and ideas that were chronicled (Creswell, 2009).

All interviews with the state representatives were conducted before document evaluation. Data analysis was done concurrently with the interviews. After the first interview, the field notes completed during the interview were reviewed and additional questions that were prompted from the field notes were integrated into subsequent interviews. After all interviews were completed, they were transcribed verbatim by the researcher and checked for accuracy. The transcripts were analyzed in turn individually and themes that emerged were identified. After analyzing the first transcript, the same analytical procedure was used for the second transcript, except common themes in both transcripts were collapsed together. When a new theme emerged from the second transcript, the researcher returned to the first transcript to see if it existed within that transcript. This process of triangulating the data was applied to the third transcript as well, which added credibility and trustworthiness to the findings (Creswell, 2009).

After all transcripts were analyzed and themes identified, the researcher began to review the state plans against the best-practices evaluation sheet (Appendix D-F). During this process, themes that described the best-practices emerged through the process of triangulating the bestpractices for all three states. The themes from the examination of state plans and best-practices were then compared to the themes that emerged from the interviews and through the process of 
triangulation, were collapsed to broader themes that captured the interconnectedness of the two types of data. When appropriate, sub-themes that described specific components of each theme were subsequently created.

To increase the validity of the study, a peer debriefing process was utilized to review the findings and inquire about the study. Questioning about the study and the themes identified in the study allowed the researcher to gain knowledge about what perspective another professional had in regards to the data. The findings were reviewed several times over the course of the data analysis.

\section{Theoretical Perspective}

This study was viewed from the perspective of "chaos theory" (Bussolari \& Goodell, 2009; Pryor, Amundson, \& Bright, 2008). The systemic component of chaos theory emphasizes the interconnectedness of elements. When functioning as a system, the elements begin to display characteristics of patterns (Kaufmann, 1995). Although systems at times may be seen as having a randomness quality, there is simply unpredictability resulting from complexity (Pryor et al., 1995). Thus, very small changes in a complex system can greatly change the systems output (Bussolari \& Goodell, 2009). Disaster mental health response often appears chaotic and random when first observed. However, this field is complex with multiple factors, and upon a more indepth look, patterns arise from the chaos. The goal of this study was to identify these patterns in disaster mental health preparation and response.

\section{Limitations}

The present study did not intend to analyze disaster mental health response on all levels of the response (e.g., program administrators, disaster responders, local disaster survivors). 
Although this approach would allow a broad and more in-depth analysis of disaster mental health response, this was not the intended goal and is beyond the scope of the current research study.

Unlike quantitative research, the researcher in a qualitative study becomes part of the process. Being a part of this process may have changed the interpretation of constructs and biased the results. Acknowledging this process prior to engaging in the study helped the researcher to better understand the necessity of being a neutral observer.

This researcher had experience from the field of disaster mental health in responding to six federally-declared disasters since 2002. This researcher was familiar with policy development of disaster mental health plans as well as clinical application of the plans. She was trained in Critical Incident Stress Debriefing, Psychological First Aid, and in the National Organization of Victims Assistance (NOVA) community disaster mental health response. She served as clinical director for two major state disasters, including Hurricane Katrina, where she was placed in Biloxi, MS for 17 days with her team. She has responded with the Emergency Management Assistance Compact (EMAC), to Florida and Mississippi to respond to federally-declared disasters. This experience helped the researcher understand state disaster mental health plans and responses and initiated her interest in furthering the empirical work in the field of disaster mental health by developing the current study. 


\section{CHAPTER 4- Report of Findings}

This study investigated the disaster mental health plans and disaster mental health response of three states: Indiana, Kansas, and Mississippi. This study utilized two sources of data collection: reviews of state disaster mental health plans and interviews with state disaster mental health representatives.

The disaster mental health plans were reviewed to assess their adherence to the 59 best practices identified for this study (Elrod et al., 2006; Hobfoll et al., 2007; NIMH, 2002). Each state plan was examined and each best practice procedure was identified as either being compliant (included) or non-compliant (excluded) with each best practice. Best practices were placed into categories by the researcher while reviewing the data. These categories are identified in the tables of the best practices in Appendices D, E, and F.

The state representatives were interviewed regarding their state disaster mental health plans and their disaster mental health preparation and deployment procedures. The interviewer used a semi-structured interview style to guide the interviews. Each interview was conducted between July and September of 2009; each interview was transcribed and reviewed by the researcher to gain full knowledge of the information reported. During the analysis, categories within the plans and interviews were identified and are reported here as subtopics. The 10 categories outlined are: state disaster mental health overview, disaster mental health responder training, local disaster mental health response, mental health screening, disaster communication methods, follow-up contact, research and data collection, external organizations, disaster mental health response timeline, and special issues. In each category, the data are reported based on whether they were identified in the state plans or in the interviews with state representatives. 


\section{State Disaster Mental Health Overview}

This section describes how each state disaster mental health response has progressed to its current form. There are three major areas that reveal the history and growth of each state. The current state representatives' positions are reviewed, which allows an understanding of where the position fits in each state system. This section also presents an analysis of financial support for the program to develop an idea of the type and amount of resources each state has available.

Lastly, this section examines the progress of each state disaster mental health plan to the version that was reviewed for this study.

\section{Disaster Positions in Mental Health}

This section describes where each state representative works and explores the percentage of their current job description that is allocated to disaster mental health in each state. This will help readers understand the states' disaster mental health background and how the positions are supported by the state government.

State Plans

No information was provided in the state plans that addressed this theme.

\section{Interviews with State Representatives}

Indiana has the longest history of disaster mental health response of the three states in this study. Prior to 2003, the state of Indiana allocated 5\% of an existing position to disaster mental health response. In 2003, Indiana applied for and received a targeted expansion grant from SAMHSA, which helped to establish the Office of Emergency Preparedness and Response and provided funding for part of a full time position. In addition, Centers for Disease Control funding from the Indiana Department of Health further supported the expansion and stability of this office. In 2003, Indiana developed their first disaster mental health response plan. The 
Indiana State representative described this as primarily an "internal document." In 2006, at the end of the expansion grant, the first state level disaster mental health plan was completed for distribution.

The State of Kansas Department of Social and Rehabilitation Services (SRS) is the state agency tasked with disaster mental health response. SRS contracts the state disaster mental health response out to other organizations. The present contract is held by Kansas Health Solutions (KHS). Kansas Health Solutions is a managed care company that provides Medicaid benefits for mental health recipients in the state of Kansas. Prior to 2008, during the Greensburg tornado, Kansas State University held the contract. The contract came up for bid in 2008 and Kansas State University did not place a bid to renew this contract. In 2008, Kansas Health Solutions secured the bid and began work on their disaster mental health response program in January 2009. Prior to 2009, Kansas Health Solutions had no experience in disaster mental health response. The Kansas state representative interviewed is the Special Projects Coordinator who oversees the contract at Kansas Health Solutions. The Kansas state representative described her part in the Kansas disaster mental health response in an addendum to the Kansas All-Hazards Behavioral Health Program (KAHBHP) and the original state disaster mental health plan, with Kansas Health Solutions providing future state response. This contract has a full-time position allocation that is split among four individuals at Kansas Health Solutions. This position will become their main focus in the event there is a need for a state level disaster mental health response.

The Mississippi representative described her job as a full time position within that state's Department of Mental Health. This position is titled Director of Disaster Preparedness and Response. In 2005, prior to Hurricane Katrina, the position of Director of Disaster Preparedness 
and Response had been a part-time position. Presently, the Mississippi Director of Disaster Preparedness and Response position is a full time position, but includes other responsibilities within the agency.

\section{Financial Support}

This section addresses the funding resources to provide disaster mental health programs in each state. This section also presents the relationships that reduce some of the financial burdens from the disaster mental health sector.

\section{State Plans}

No information was provided in the state plans that addressed this theme.

\section{Interviews with State Representatives}

In Indiana, financial support for disaster mental health preparedness and response comes from several different areas. Salaries for the Indiana state representative and his support worker are provided from the Indiana Department of Mental Health and Addictions (INDMHA) general funds and by state block grants. Training funds for district teams are granted by collaborating with the Department of Homeland Security and a memorandum of understanding with the Indiana Health Department. This funding allowed Indiana to be on the forefront of disaster response.

In Kansas, Kansas Health Solutions is provided a subcontract from the Kansas Department of Social and Rehabilitation Services (SRS) to provide state disaster mental health response. This money is allotted for salaries, state disaster mental health response, and tabletop exercises, if money permits. No money is allocated for training responders. When planning Psychological First Aid training, the trainer is a volunteer and the room and any support services are donated to the program. The contract specifically places any training exercises, like tabletop 
exercises, at the end of the budget year so that any remaining funds can be put towards the training and reimbursement of lost revenue at Community Mental Health Centers. With no funds being allotted for responder training, the push to establish internet-based training is a priority due to its financial feasibility.

The state of Mississippi does not have a budget for disaster mental health training and relies on joint efforts with the Mississippi Department of Health to accomplish this goal. The salary for the Director of Disaster Preparedness and Response is allocated in the general budget.

\section{State Plan Development}

This section outlines how the plan used in this study was first developed. This section also outlines what, if any, events stimulated the plan to be completed.

\section{State Plans}

No information was provided in the state plans that addressed this theme.

\section{Interviews with State Representatives}

The initial disaster mental health plan in Indiana was funded by SAMHSA and the Centers for Disease Control (CDC). This funding enabled Indiana's state disaster mental health plan to be developed and implemented in 2003. The disaster mental health plan from 2003 was

found to lack some of the necessary components once implemented in the field and needed to be changed to adjust to lessons learned during disaster response. The involvement of Indiana in responding to Hurricane Katrina and several disasters within Indiana highlighted many areas of weakness in Indiana's plan and called for changes. The most recent revisions and the plan used in this study were completed in 2007 . The 2008 flooding in Indiana was the first opportunity to test the new plan. This plan outlined how local responders would deploy with the support and help of each District Disaster Mental Health Response Team. 
Kansas Health Solutions was not involved in developing the original mental health disaster response plan for Kansas but has since added an addendum to address the state response. The Kansas State Plan was written by Kansas State University in 2006, revised in 2007, and a state addendum was added in May 2009. The state of Kansas does not require each Community Mental Health Center to have a disaster mental health plan. The state representative emphasized that "there is no contractual obligation so [the contract has] eight of 27 [Community Mental Health] centers that have completed the [disaster mental health] plan.” The Kansas state representative hoped that the requirement of having a disaster mental health plan at each Center will be mandated as part of future contracts. The Kansas representative summed up her need for guidance from the field of disaster mental health by stating that "some sort of standardized response would be ideal."

The first state plan in Mississippi was completed in June 2006, after Hurricane Katrina. The Mississippi state representative clearly stated that the impact of Hurricane Katrina stimulated the need for a state disaster mental health plan. The plan submitted for the current study was last revised in 2007. The Mississippi representative explained that "the plan is set up, especially the version that you have, it's more set up than what, operationally what it is the Department of Mental Health does." The plan is under current revision to add more content on local, state, and federal response and training in the state. In addition to the Mississippi State plan, each Community Mental Health Center is required to have a disaster response plan that is reviewed yearly by the Mississippi Department of Mental Health.

\section{Disaster Mental Health Responder Training}

This section on disaster mental health responder training requirements focuses on what states have been doing to prepare responders for disaster mental health response. The training 
program should outline what disaster mental health responders need to know before going into the field. The training allows states to maintain consistency in responders and insure quality services are provided.

The disaster mental health responder training and response section addresses 27 of the identified best practices (\#9-11, 21-24, 26-28, 31, 41-51, 53-56, 59). These best practices address the need to have a training program that certifies responders by requiring specific education, documentation, clinical training such as Psychological First Aid, coping, response to trauma, and training that addresses the quality of response in the field. This section also assesses the procedures for deployment in the field. The key areas identified for this subtopic include state training, clinical training, disaster preparedness training, special needs populations, and program manuals.

\section{State Training}

The training section refers to what specific training or requirements are in place for individuals to be considered appropriate for disaster mental health response. These requirements may be clinical or administrative in nature or may address possible limitations for responders.

\section{State Plans}

Indiana's All-Hazards Advisory Committee has established minimum standards for individuals participating in State and District Disaster Mental Health Response Teams (DDMHRT). All qualifying members of the District Disaster Mental Health Response Teams must be listed on an active roster by each district (Indiana Plan, p. 20). Indiana requires that all District Disaster Mental Health Response Team members meet the following requirements:

1. Successfully completed National Incident Management Systems (NIMS) 100, 200, 700, and any subsequent training 
2. Completed IDMHA approved Psychological First Aid (PFA) training

3. Become a member of the District Disaster Mental Health Response Team

4. Adhered to District Disaster Mental Health Response Teams Code of Ethics

5. Adhered to District Disaster Mental Health Response Teams Code of Conduct

6. Shown the ability to complete the job duties in the job description of the position held (Team Member, Team Leader, Clinical Director)

7. Become NIMS compliant and followed incident command system In addition to the requirements for members to be on the District Disaster Mental Health Response Teams, Team Leaders, Clinical Directors, and Chaplains must complete the NIMS 800 and have the required experience, education, and training to fulfill the job duties and job descriptions (Indiana Plan, pp. 58-59).

The Kansas plan specified that the Kansas Department of Social and Rehabilitation Services (SRS), the state agency involved in disaster mental health response, should work towards minimum competencies for disaster mental health responders (Kansas Plan, p.36). The only requirement of responders in Kansas was the completion of the Kansas All-Hazards Behavioral Health (KAHBH) Program core training.

The Mississippi plan did not address any clinical training for community responders. However, it did require state level disaster coordinators and state level disaster mental health response team members to complete NIMS training. The Disaster Coordinator was also required to complete the web-based Emergency Operation Center (EOC) Program training.

\section{Interviews with State Representatives}

In Indiana, the Indiana All-hazards Committee is responsible for identifying the required training of responders. Once the All-hazards Committee has identified areas of training, the 
training itself is completed in each district. All 10 district team members are required to have completed an application, a background check, completed NIMS 100, NIMS 200, NIMS 400, NIMS 800 and Psychological First Aid. In addition, the all-hazards committee requires special needs training for responders in every district. This requirement was initiated by the relationship with the Indiana Department of Health and the agreement with them to work with special needs populations in the disaster response.

Indiana has monthly phone conferences that are held with team leaders so updates on new information, including training and best practices, can be discussed. In addition, there is a yearly retreat where the state brings in the 10 district team leaders and clinical directors to get input from them on team communication and training. Each district disaster mental health team is mandated to meet within their district at least quarterly.

Furthermore, Indiana has contracted with the ASPIN Education Network to develop an all-hazards disaster mental health website where information will be posted and virtual on-line training will be available. The ASPIN Education Network is certified to provide continuing education credits for several clinical disciplines and offers access to clinical providers in over 50 locations throughout the state of Indiana. This website is expected to be available in November 2009.

Through a state grant, and in coordination with the Kansas Department of Health and Environment, Kansas has developed a database of potential responders for medical and mental health disaster response. This database is called $\mathrm{K}$-serve and is also part of the Kansas Health Alert Network (HAN). The Kansas representative explained that the database allows "anybody, those who are licensed in behavioral health to just Joe Schmo on the street, to volunteer. K-serve then verifies their credentials, if they are a credentialed provider, and also breaks it down by 
county." K-serve will also record any training responders have completed related to disaster response. Such training would include Psychological First Aid, NIMS, and FEMA/SAMHSA core training. All administrative coordinators at Community Mental Health Centers in Kansas have been given access to this database and are able to search the database for suitable responders in a given county or region. The procedure for contacting volunteers is either by phone, e-mail, and/or texting.

Kansas was working on a training junket that includes training on the Kansas State Crisis Counseling Program (KSCCP), FEMA core training (NIMS 100, NIMS 200, NIMS 400, NIMS 800), and Psychological First Aid. This training was intended to be delivered to designated disaster response coordinators at each Community Mental Health Center and any volunteers on K-serve who would like to have this training. The FEMA core training and the Psychological First Aid training will be offered on KS-Train. KS-Train is a web-based learning resource for public health workers and can be found at https://ks.train.org/. All training sessions are videotaped and can be viewed by all responders. The Kansas representative reported that K-serve and KS Train provide all types of training for the state. The Kansas State Crisis Counseling Program (KSCCP) training and a basic training on Kansas disaster mental health response will also be available to help everyone understand the state plan and their role in disaster mental health response. Everyone who completes the training will log-in with their name and the training will be recorded on the K-serve site. It is essential to note that the FEMA core training and Psychological First Aid were recommended but were not required at the time of the interview. Any live trainings completed in Kansas were based on volunteer services. During the Greensburg disaster mental health response, all responders were required to be trained in the Kansas All-Hazards Behavioral Health Program Core Training; over 400 individuals were 
trained by either live presentations or via the web on KS-Train. The Kansas state representative reiterated that "the trainings are not mandated, and the Community Mental Health Centers are not required to respond." The fact that training was not funded or mandated by the state was seen as a huge limitation by the Kansas state representative.

Mississippi's most recent goal was to develop a list of eligible responders who could be called during a disaster mental health response event. In collaboration with the Mississippi Department of Health, the state was utilizing the Volunteers in Preparedness Registry (VIPR) system to create a list of individuals who are willing to respond and have been trained in Psychological First Aid and the National Incident Management System (NIMS) classes. The VIPR system recognizes any licenses or degrees that an individual has received. The Department also used this system to compile a list of workers for medical responses and required all people who plan to respond in any type of disaster to be trained in Psychological First Aid and NIMS. The system is able to filter criteria to search for mental health professionals or specifically identify individuals who have Psychological First Aid or other trainings. Mississippi did not offer web-based training to responders.

\section{Clinical Training}

Clinical training refers to a training that is given to mental health disaster responders to aid in their skills to provide behavioral health care post-disaster.

\section{State Plans}

The Indiana plan was the only state plan that required any type of crisis counseling training for their disaster responders in their state plan. The requirement of Psychological First Aid accounts for meeting all the clinical requirements in the outlined best practices. However, the Kansas plan was clinically inclusive and identified examples and training on all similar 
clinical best practices, such as in Psychological First Aid, with the added component of family intervention.

\section{Interviews with State Representatives}

Indiana reported that Psychological First Aid was their clinical choice for their disaster mental health response. This decision came after much analysis of other models that were available. Both National Organization of Victim Assistance (NOVA) and Critical Incident Stress Management (CISM) were considered before the decision was made. Dr. Brian Flynn, who was the Rear Admiral and Assistant Surgeon General in the U.S. Public Health Service, was involved in the development of the disaster mental health best practices published by NIMH in 2002 . He was part of the development of the initial Indiana plan recommending that Psychological First Aid was a component of the disaster mental health plan in 2003.

Psychological First Aid was offered one to two times per year in each of the 10 Indiana districts. It was the responsibility of the District Team leaders to keep their members up to date on training. Presently, Indiana had a Psychological First Aid Intervention Guide that was given to all responders to use as a reminder of what needs to be addressed in the field. Indiana had online trainings for responders that could be launched within 48 hours post-disaster to train new responders.

Kansas was completing their first Psychological First Aid training for the state and the plan was to videotape the training to make it available on the website to train others. The decision to use Psychological First Aid was due to one team member who was very passionate about Psychological First Aid and strongly encouraged this training with the incentive that he could perform the training. The Kansas state representative stated, "It's not necessarily that we 
are using this at the exclusion of any others. It's just that at this moment, this is what's available and right now our big push is to coordinate the training and publicize what we are doing."

Mississippi reported that Psychological First Aid was their clinical choice of disaster mental health response in the field. The decision to use Psychological First Aid was a two year process that involved work with the University of Mississippi Medical Center Department of Psychiatry and the State Health Department, which had a strong history with Critical Incident Stress Management (CISM). The Mississippi representative explained that "it was our [DMH] stand to move away from that [CISM] model and move more towards utilizing PFA, and even working with our partners at the health department, it took us over two years to detach the old structure from the model." After much discussion and research, it was decided to use Psychological First Aid. The National Organization of Victim Assistance (NOVA) model was considered and it was determined that there were similar components to Psychological First Aid. The Mississippi state representative stated, "You must have responders with and without mental health backgrounds trained in Psychological First Aid.” Mississippi had a Psychological First Aid Intervention Guide that as provided to all responders to use as a reminder of what needs to be addressed in the field.

\section{Disaster Preparedness Training}

Disaster preparedness training is experiential training that is used to simulate a disaster response in order to prepare responders for deployment.

\section{State Plans}

No information was provided in the state plans that addressed this theme.

\section{Interviews with State Representatives}


Indiana has several ways that disaster preparedness was addressed. First was the involvement in several tabletop exercises throughout the year. These tabletop exercises involve both state and local response. There was a yearly state-wide training response that involved first responders, health support, and mental health support in a fabricated site at Camp Mascatatuk to help the state prepare for a mass causality and a mass response effort.

In addition, after being involved in several nationally declared disasters, the Indiana state representative noticed that many responders knew the mental health components of disaster mental health response but did not know the basics of how to deploy to the field. With the possibility of earthquakes and other disasters in Indiana, the Department of Mental Health and Addiction wanted to ensure other locations could deploy for a longer period of time without using resources from the local community. Indiana began to "provide field-ready training in how to deploy in the field, what to bring, and how to do that. One of the things we have been able to do through our grants is to purchase equipment, such as tents and cots and sleeping bags. So, our teams are pretty self contained teams and they can be deployed after 3 or 4 days without any type of outside assistance, which is something we are very proud of." This training was developed by the Indiana Department of Mental Health and Mission Ready Consultants (independent consultants). This training was intended to train teams to be self-deployed. They learn what they should bring to a deployment, what things they will need to know about the location, how to set up and sleep in tents, eat Meals Ready to Eat (MRE), build a field latrine, and other disaster logistics. The state of Indiana purchased enough tents, cots, sleeping bags and supplies to deploy teams into affected areas. Indiana included Psychological First Aid training and practice and team-building exercises during this training. Initially, this training was developed by mental 
health responders but has grown to include first responders and the Indiana Department of Health responders.

Finally, there were 12 people in Indiana who had become part of the Indiana Mortuary Emergency Response Team (IMERT). These members respond to bring the mental health component to the mass casualty sector of response. It was the plan for all Indiana mental health responders to have mass fatality training through the Indiana Department of Homeland Security.

With the present contract being held by Kansas Health Solutions beginning in January 2009, they had little disaster preparedness training in the months prior to the interview. They had quarterly meetings with the core response team where they organize information flow and communication logistics. They also planned tabletop exercises that coordinate with the Kansas Department of Health and Environment in addressing training with hospitals and Community Mental Health Centers, if they choose to participate.

Mississippi participated with the Mississippi Emergency Management Agency (MEMA) in both tabletop and full scale drills. When referring to the Department of Disaster Response, the Mississippi representative stated, "We don't do a lot of preparedness work. Pretty much we participate in the state drills that are initiated by the State Emergency Management Agency." Mississippi also runs the Grandgulf Drill, which is a radiological drill. Generally, there were two drills per year with MEMA. In addition, the Mississippi Department of Mental Health also participated in points of distribution (POD) exercises with the State Department of Health to prepare for prophylactic distribution in cases of medical outbreaks.

\section{Special Needs Populations}

Special needs populations include any identified group of individuals or persons that may need extra assistance before, during, or after a disaster to maintain safety or return to pre-disaster 
conditions. This group may include the physically or mentally disabled, elderly, children, institutionalized populations, and individuals with a mental illness.

\section{State Plans}

All three plans addressed special needs populations and outlined the procedure for being involved in a special needs shelter. Each plan addressed special needs populations with increased priority and recognized that their needs may be somewhat different than others who are affected individuals. The Mississippi plan outlined most specifically the evacuation and placement procedure of clients to special needs shelters in their state, including staffing requirements and responsibilities.

\section{Interviews with State Representatives}

The Indiana All-hazards committee required special needs training for responders in every district. This requirement was initiated by the relationship with the Department of Health and their agreement with them to work with special needs populations post disaster.

Kansas did not identify any specific training to address special populations during the interview, but there were aspects of special needs assistance outlined in the state disaster mental health response plan.

Mississippi has started to increase the training requirements for special populations and added a component on special populations to the VIPR training. Although this training is more of an overview, the state developed a special population work group that meets to have roundtable discussions to "look at what are the needs of our special populations and our at risk populations and how can we better prepare to meet those needs." 


\section{Program Manuals}

The possession of a program manual in itself implies fore-thought and planning. The manual offers guidance and clarification for those responding. Disaster mental health best practices encourage each state to have a manual that contains definitions, clarity of outreach, counseling methods and services, and available referral information accessible to each responder.

\section{State Plans}

None of the state plans reviewed mentioned any type of field guide or program manual available for the responders. Indiana did provide a directory of definitions and job descriptions at the end of their disaster state plan to help understand some of the disaster lingo and abbreviated words.

\section{Interviews with State Representatives}

No information was provided in the interviews that addressed this theme.

\section{Local Disaster Mental Health Response}

Local disaster mental health response refers to what happens in each pre-designated Community Mental Health Center's catchment area when a disaster occurs. This is often the first mental health response and the first assessment of the mental health needs in the affected community. This section is discussed in four sections: initial response, needs assessment, clinical teams, and responder safety.

\section{Initial Response}

The initial response describes what disaster mental health response is planned and expected in local areas during the first hours post disaster.

\section{State Plans}


The Indiana plan detailed contracts with 92 counties to provided mental health response in their area. This response plan may or may not include financial support. Indiana made all local jurisdictions responsible for their initial response to the disaster. In Indiana, this response included the District Disaster Mental Health Response Team Leaders collaborating with local Community Mental Health Centers (Indiana Plan, p. 18). The Indiana Department of Mental Health and Addiction will oversee the local response and gauge the need for increased assistance. Indiana maintains the safety of victims by coordinating care with first responders. Indiana ensures basic necessities by working with local shelters and by directing those affected to areas where support and assistance can be found.

The Kansas Department of Social and Rehabilitation Services did not require the 26 Community Mental Health Centers in the state to respond to a disaster, nor did it require Community Mental Health Centers to be involved in any training or preparation. Furthermore, the Kansas Department of Social and Rehabilitation Services did not require Community Mental Health Centers to have a disaster mental health plan for their agency. A pre-established relationship with American Red Cross has enabled Kansas to aid in the ability to provide food and shelter if local areas are involved in the response request. This plan did outline the importance of keeping families together and maintaining support for those affected. The use of family support was mentioned only within the Kansas plan (Kansas Plan, p.22).

The Mississippi plan mentioned several times that Community Mental Health Centers are responsible for disaster mental health response in their jurisdiction, but there is no reference to any agreement between the Mississippi Department of Mental Health and local Community Mental Health Centers. Mississippi required all Community Mental Health Centers to have an active disaster mental health plan in their facilities. It was written that all Community Mental 
Health Centers are responsible for deployment of their plan and it is their responsibility to complete a needs assessment of their response region post disaster.

\section{Interviews with State Representatives}

Initial disaster mental health response in Indiana was provided by the District Disaster Mental Health Response Teams. District disaster mental health responders may or may not be employees of the Community Mental Health Centers, but all responders were required to be a part of the district team and comply with the team training standards. Each Community Mental Health Center was expected to have a county comprehensive emergency mental health management plan that was submitted to the Indiana Department of Mental Health and Addiction to guide the district disaster mental health response teams. The district can contact the state if extra assistance is needed. If a federal disaster declaration is made, and a Crisis Counseling Program application is submitted, the state will hire disaster mental health responders to assume the responsibilities for completing the full 12-month Crisis Counseling Program, where local responders cannot continue.

In Kansas, each Community Mental Health Center was asked, but not required, to respond to any immediate disaster in their catchment area. Theoretically, each "CMHC [has] a mutual aid agreement with other surrounding Community Mental Health Centers that would immediately respond within the first 24 hours.” In addition, Kansas Health Solutions has coordinated a core team made up of 10 Masters-level mental health responders who are ready to respond to anywhere in the state within 24 hours, after the disaster declaration. Once the request has been made to the Kansas Department of Social and Rehabilitation Services (SRS) by the Kansas Division of Emergency Management (KDEM), the core team is expected to be on site within 24 hours. The initial response is supposed to provide services immediately but also 
initiate the preliminary assessment to determine and plan for the long-term disaster mental health response.

After the Greensburg tornado, the Kansas state representative noted that she was made aware that Community Mental Health Centers did respond; however, she did not know to what extent they were involved in the disaster mental health response. She noted that the fact that local response was not mandated was a great limitation to Kansas disaster mental health response and limited future growth in local areas. Ideally, Kansas Health Solutions would like to have a dedicated group of responders in each Community Mental Health Center who meet regularly, have attended SAMHSA/FEMA Crisis Counseling Training in Emmittsburg, MD, are up to date on FEMA required training, and have a budget for their disaster response.

Initial disaster mental health response in Mississippi was identified as the responsibility of the local Community Mental Health Centers. After Hurricane Katrina, the Mississippi representative explained "[the Community Mental Health Centers] started working in the shelters. First, they tried to locate clients, because they were very concerned. Secondly, they began to work with the people who were in the shelter regardless of whether or not they were clients." Each Community Mental Health Center was to have a disaster plan that was mandated by Mississippi Department of Mental Health standards. Coordination among Community Mental Health Centers and the state of Mississippi was somewhat disjointed and it was the hope of the state representative that, with the involvement of mandated training, more interactive responses will occur in the future.

\section{Needs Assessment}

The needs assessment section was based on four best practices (\#2, 25, 29, and 30) that evaluate the acknowledgement of completing a needs assessment for both individual and 
community needs. A needs assessment is an evaluation of an affected area that gathers information to be utilized in planning an organized response to a disaster affected area. Information gathered during the needs assessment includes, but is not limited to, the following: population affected; description of the area affected, including size and type of setting; number of people affected; number of fatalities; location of survivors; description of mental health needs of population; external agency response in the area; and number and type of response that is needed.

\section{State Plans}

All three state plans outlined the process of completing a needs assessment. All states reported that it was the responsibility of the district/county to first recognize the need for external support or resources. In Indiana, it was the responsibility of the clinical director of the district disaster mental health team to evaluate the needs of the district. In larger responses, the Deputy Director of Disaster Preparedness and Response will complete a needs assessment in the affected areas and will work with other agencies as the mental health needs of workers and survivors are determined.

The Kansas plan identified that it is the responsibility of the Team Leader at the Community Mental Health Center to evaluate the needs of the affected area. State level support was available and able to assist with the needs assessment in larger responses. The Public Safety Officer monitored the environment to ensure responder safety throughout the response (Kansas Plan, p. 38).

The Mississippi plan stated that it was the responsibility of local Community Mental Health Centers to respond to initial local disasters and complete the initial needs assessments. 
The Mississippi Department of Mental Health was able to provide additional support to areas and aid in the completion of a needs assessment in that area.

\section{Interviews with State Representatives}

In 2008, Indiana faced its largest disaster mental health response when severe flooding occurred over the entire state. This was the first time the revised version of the state disaster mental health plan was tested. Mental health teams were in the field within 24-48 hours serving their communities in shelters and other recovery areas, as well as providing support for first responders. The Indiana state representative reported that local teams were "more or less called out by their local district. Shortly before I called them, they had already been deployed." Indiana "actually had people placed into shelters and other recovery areas a day or two after the storm." Due to the implementation of the "Blue Book," a book developed by the Indiana team designed to help Indiana responders with accurate data collection, responders were able to record everything they did and contacts they made. Indiana was able to obtain $\$ 20,000$ from SAMHSA as reimbursement for interim costs from the work done from the day of the storm until the initial SAMHSA Crisis Counseling Program grant was approved. This was an unusual achievement in the field of disaster mental health response. The concept of regional multifaceted teams, that included medical, first responders, emergency management, and mental health, was very successful and enabled quick and precise deployment of teams.

The needs assessment in Indiana reflected that of their disaster plan. The regional teams completed the initial needs assessment sending in local teams of mental health workers where support was needed. Communicating needs during the deployment went directly to the state level representative, who directed feedback and assignments from state and local agencies to the teams in the field. It was reported that constant needs assessments were being completed at the state 
and local levels. The Indiana state representative explained that "a lot of times I will send a team leader on the ground in the county of the disaster and I will have that leader call me back. Last year, when this thing was so big, I was doing a lot of responses myself. Going down to Shelby County and going down to Terre Haute and just making sure that our folks were okay."

In 2007, Kansas responded to a catastrophic disaster when providing support to responders and survivors of the Greensburg tornado. This response was coordinated by Kansas State University who, at that time, held the contract in the state of Kansas for disaster mental health response. The identified state disaster mental health plan that was used in this study was written by those involved in that original contract. Unfortunately, at the time of data collection for the present study, the identified state level individual who had been involved in the Greensburg disaster mental health response left her position at the Kansas Department of Social and Rehabilitation Services and was no longer available to participate in this study. Since the current disaster mental health contractor (Kansas Health Solutions) does not possess the knowledge of the actual response to the Greensburg tornado, this area of the data collection is lacking for the state of Kansas. The information used when referencing this response is third party information gained through conversations with the Kansas state representative.

Since Kansas Health Solutions obtained the grant beginning in January 2009 to provide disaster mental health support to the state, they have not responded to any disasters. It is their plan that local Community Mental Health Centers will complete the initial needs assessment with additional aid coming from the core response team sent in within the first 24 hours post disaster declaration. The Kansas state representative reported that the "base team that goes out and provides the immediate services within that 24 hour period and does the needs assessment, will give us [the state] back an estimate of what they think we need [for the disaster mental 
health response]: so many lay people, so many Master's level, [Bachelor level] case management [providers]." This assessment would determine who the state would deploy into the field in regard to the number of mental health and support workers. It would also address the financial needs and other necessary concerns identifying where specific support is needed.

In 2005, Mississippi responded to Hurricane Katrina, the country's largest and most expensive disaster to date. The Mississippi state representative stated that at that time, they "were still unclear on what the role of mental health is, when mental health comes in, the difference among crisis counseling and mental health treatment.” After Hurricane Katrina, the state was unable to get in contact with the local Community Mental Health Center in the hardest hit area and all transportation routes were down. Three days after the impact, Community Mental Health Center workers began to look for clients who had been displaced and began working in shelters. "[The Community Mental Health Centers] were providing some basic crisis intervention because at that time the PFA field guide didn't exist or wasn't out yet." Communication was "hairy," before cell phone coverage was restored; cell phones and text messaging were the primary means of communication.

After Hurricane Katrina hit, Mississippi reported that "in terms of needs assessment, it pretty much [we] did the standardized needs assessment, which we would normally have to use for the Crisis Counseling Program. So, we were looking at the preliminary damage assessments that were coming out of the state EOC [Emergency Operations Center] and taking them at face value. As you know, damage assessment after Katrina was a nightmare in and of itself." The Mississippi state representative stated that during Hurricane Katrina, "We had patients relocated throughout the state, something that we never imagined we would have to do." One facility was 
completely evacuated and two other facilities had severe building damage, which was an

overwhelming experience for the mental health response in the state of Mississippi.

\section{Clinical Teams}

Clinical teams refer to the disaster mental health responders that deploy to the field and the logistics of the team.

\section{State Plans}

No information was provided in the state plans that addressed this theme.

\section{Interviews with State Representatives}

Indiana had a program within their district disaster mental health teams that identifies volunteers ready to respond to local disasters within 24 hours after the disaster has occurred. As seen in minor to moderate disasters, this was quite efficient. A more formal statewide team and smaller numbers of responders who are ready to respond within 24 hours may be a good plan for areas where team numbers are small or destruction is extensive.

Kansas established the idea of a state wide "core team" that can respond anywhere in the state within 24 hours after the disaster declaration. This concept was the key to quick and consistent disaster mental health response. The 10 team members were all volunteers and were ready to respond at a moment's notice. This core team was also the first state team sent out to the disaster location once declared. However, the question of responding to a large tornado that has affected multiple areas may not be met by this particular team. In addition, what response occurs between the time of the disaster and the state or federal declaration was not clearly addressed because the core team does not respond until a declaration is received. 


\section{Responder Safety}

Responder safety involves the physical safety of those responding to a disaster, including disaster mental health responders, location and environment monitoring. It also involves the mental health safety of those responding to ensure proper debriefing takes place post intervention. Although everyone involved in a disaster is affected by the disaster, the effects should not inhibit a responders' ability to help themselves or others.

\section{State Plans}

The Indiana plan explicitly outlined that no district disaster mental health team shall enter an impacted area until their safety can be assured by local emergency management responders (Indiana Plan, p. 12). The relationship with Emergency Management and the State Health Department enables Indiana to keep informed of any environmental concerns that may affect mental health responders' safety.

Both the Indiana and Kansas plans reported being involved with daily meetings and updated on progress and area needs. The Kansas plan specifically outlined how responders will be "debriefed" at the end of each day or shift to assess for not only physical safety but mental health safety. The Mississippi plan did not specifically describe how responder safety will be addressed throughout the disaster timeline.

\section{Interviews with State Representatives}

Indiana placed the responsibility of debriefing first responders on local district disaster mental health teams. The district teams and disaster mental health responders identified the needs of the first responders, which were then directed to local teams for intervention.

Although the current Kansas team has not responded to a disaster, their expectation was that there would be "a morning briefing telling [the responders] what is going on. Then at the end 
of the day there is actually a debriefing of first responders as they come out of the field." This is consistent with the procedures described in the Kansas plan.

After Hurricane Katrina, no mental health intervention was arranged for first responders by the Mississippi Department of Mental Health. Other agencies and Community Mental Health Centers may have been providing this service. According to the Mississippi state representative, it was expected that during initial disaster response, these types of services will be handled by the Community Mental Health Centers.

\section{Mental Health Screening}

The use of mental health screeners allows for a standardized assessment to be utilized in the field and increases the consistency and accuracy of evaluations by responders. The subtopic of Mental Health Screening was developed based on two indentified best practices (\#1, 52). The first best practice outlines the use of a PTSD screener to identify individuals or groups that are considered high risk for PTSD. The second identifies the use of a clinical assessment using valid and reliable measures.

\section{State Plans}

No state plans outlined any type of screening tool or formal clinical assessment to identify individuals or groups who are considered high risk for PTSD. It must be noted that when a state is involved in a federal response and a Crisis Counseling Program is being utilized, the SAMHSA Assessment and Referral Tool has to have a built in screening tool for PTSD. The Posttraumatic Stress Disorder Rating Interview (SPRINT) has been utilized in the SAMHSA Crisis Counseling Program Assessment and Referral Tool and has been shortened to four questions which enable the assessment to be quickly and easily used. In addition, the use of Psychological First Aid techniques and the Crisis Counseling Program model increases the 
awareness of clinical needs in the field. Although no formal clinical assessment was used by the states, each worker was provided with the clinical tools to identify high risk persons and refer to more formal therapeutic services.

\section{Interviews with State Representatives}

Indiana and Kansas did not report using a PTSD screener in the field unless it was part of the Crisis Counseling Program (CCP) Assessment and Referral process. The Kansas representative reported that "any of the documents we are using once we hit the ground are essentially the FEMA Crisis Counseling Program Toolkit forms.” In the past, Indiana considered some screening measures, but the state has never committed to using one.

Mississippi was very informed on PTSD assessment tools utilized by SAMHSA as part of the Adult Referral and Assessment Tool when a CCP has been implemented. The Short Posttraumatic Stress Disorder Rating Interview (SPRINT) has been incorporated into CCP assessments. The Mississippi state representative also reported she is familiar with the Primary Care PTSD screener (PCPTSD), which is a 4 question screening measure that can be easily utilized in a disaster setting, and which Mississippi would consider implementing during a response.

\section{Disaster Communication Methods}

This section identifies how each state distributes information to the public. This includes utilizing current technology for the community to access information, selection of hard copy materials that will be provided to the affected community, and identifying who will be in charge of general information dissemination throughout the disaster mental health response. With survivors grasping for news from media and responders, it is essential to provide accurate and 
timely information. As stated in the best practices addressed (\#32-37, 57), information can calm the population or cause havoc. It is a very important part of disaster mental health response.

\section{Mode of Communication}

This section addresses the specific use of technology for information exchange with the community.

\section{State Plans}

No information was provided in the state plans that addressed this theme.

\section{Interviews with State Representatives}

Indiana had a 1-800 number that was utilized during responses and they were able to have that number ready within 24 hours post-disaster. The number has been advertised on every Project Aftermath handout and the same number will be kept for use in future disaster responses. According to the Indiana state representative, Indiana "made up business cards that [had] our toll-free number and our web-site on them. So, we can just very easily pass that out to folks," which allows for easy distribution to survivors. Handouts for Project Aftermath were kept in a library at the Indiana Department of Mental Health and Addiction (INDMHA) and are easily accessible to responders when needed.

According to the Kansas state representative, within 24 hours of the Governor of Kansas' declaration, a 1-800 number was established to help survivors gain information about the disaster response and provide information about available services. This line also served as a crisis contact number. Each declaration will have the same 1-800 number for consistency across disaster events. The 1-800 number will not go into effect until state or federal disaster declarations have been made. The Kansas state representative stated that the Kansas Department of Social and Rehabilitation Services will be in charge of public relations and information dissemination as well as communicating this information directly to the field. Any materials 
provided during the response were preauthorized items that the KARE Program (the name for the Kansas Crisis Counseling Program) utilized in the past. Any other information will be downloaded from the FEMA library on the internet.

Regarding communication with the response team, it appears experience from the Greensburg tornado has indicated the use of radio communication as opposed to cell phone communication. Because Kansas is a rural state, cell phone towers cover large areas and can affect communication for some time. Although radios may be more consistent for smaller responses, this type of communication may have limitations for state-wide communication. Mississippi had a 1-800 number that was staffed through the Office of Constituency Services, which was open 24 hours a day and was a contact point for individuals attempting to find out information about the disaster response or services in general. This office received information about the disaster response from the Department of Disaster Preparedness and Response. During Mississippi’s Project Recovery, another 1-800 number was established just for disaster related issues. The same Project Recovery number can be used in future disaster responses. In addition to this contact number, Mississippi offered updated information on their Department of Mental Health website.

All three state representatives mentioned the importance of having a website with updated information for the affected communities. However, in spite of the agreement of importance, none of the states to date have used the website as a main form of information dissemination. All three states planned to have a web-based training program that can be accessed from across the state at any time. 


\section{Information Dissemination}

Information dissemination includes ways to address media demands and information distribution, as well as how information will be delivered in the disaster affected areas.

\section{State Plans}

The Indiana plan indicated that a library of materials was maintained at the Indiana Department of Mental Health and Addiction. These can be utilized during a disaster mental health response (Indiana Plan, p. 24). The Indiana Plan outlined that material dispersion should be done through outreach efforts in the community by actually handing out written materials. The Indiana disaster mental health response plan did propose efforts to use electronic technology but it did not detail how that may be implemented. The Indiana plan identified ways to incorporate new technologies and emerging best practices of mental health within its plan (Indiana Plan, p. 9). The Indiana plan outlined that the Department of Mental Health and Addiction will gather, analyze and disseminate information during a disaster mental health response (Indiana Plan, p. 24).

The Kansas plan stated that it is the responsibility of the Kansas All-Hazards Behavioral Health Program (previously at Kansas State University and now located at Kansas Health Solutions) to develop a compendium of on-line resources to use at community and regional levels (Kansas Plan, p. 36). The Kansas Mental Health Authority (KMHA) or the Kansas AllHazards Behavioral Health Program is responsible for dissemination of information to the public. This is to ensure that consistent and accurate information is released (Kansas Plan, p. 39). In addition, the Kansas All-Hazards Behavioral Health Program will identify a Public Information Officer (PIO) who will work with the Kansas All-Hazards Behavioral Health team to ensure accurate and timely information is released to the public (Kansas Plan, p. 39). 
The Kansas plan further outlined that the distribution of information should be dispersed in non-traditional ways, such as through outreach services (Kansas Plan, p. 21). Other resource areas included impacted areas, disaster shelters, meal sites, churches, and community centers (Kansas Plan, p. 21). Unfortunately, none of this information dissemination can be expected by Community Mental Health Centers, as they are not required to participate or respond to local disasters.

The Mississippi plan did not outline any community-based information dissemination. However, the Mississippi plan indicated the use of phone, radio, and websites as sources to relay information to families and support providers of those clients receiving services in state-operated facilities.

\section{Interviews with State Representatives}

No information was provided in the interviews that addressed this theme.

\section{Follow-Up Contact}

Follow-up contact is an essential component in disaster response, as it allows for crisis workers to monitor behaviors and mood over a period of time, and it allows the appropriate referral or treatment decisions to be made. Follow-up contact is when crisis workers plan to reevaluate, revisit, or refer a person due to concerns about safety, both physical and mental health-based. Follow-up contact was based on six indentified best practices (\#3-8) that outline the need for follow-up contact or interaction with those individuals who were identified as high risk and more vulnerable.

\section{State Plans}

The best practices recorded for follow-up contact were related to individuals experiencing the following: experiencing Acute Stress Disorder (ASD), bereavement, pre- 
existing mental illness, requiring medical care, prolonged exposure to disaster/trauma, or those who request a follow-up contact. Follow-up contact and referral is an essential component to Crisis Counseling Program and Psychological First Aid success. All three states had been involved in a Crisis Counseling Program. For more severe responses, the Crisis Counseling Program covers requirements for follow-up. However, only Indiana mandated Psychological

First Aid for all responders, and thus, was the only state that specifically addressed the importance of follow-up during local disaster mental health response.

\section{Interviews with State Representatives}

No information was provided in the interviews that addressed this theme.

\section{Research and Data Collection}

Most behaviorally-based disaster mental health response techniques have relied on research and clinical data collection to provide support for their process. With this in mind, it is important for the field of disaster mental health to continue to improve procedures with the use of both qualitative and quantitative research studies and increase the amount of useful data collected before, during, and after disaster mental health responses. These best practices encourage research to become an active component of disaster mental health response and planning.

In this section, the best practices set forth expectations that states should have a process for collecting data, evaluating the response, research initiation and research participation. This section contains seven best practices (\#12-15, 18-20) that address these areas related to research and data collection.

State Plans 
All states involved in the Crisis Counseling Program are required to collect data for SAMHSA, in the Data Collection Toolkit, which has very specific forms and reporting methods that are set forth by SAMHSA. Much of the data collected involves demographic information, areas of concern for the survivors, and referral information. None of the states identified any data collection tools that could be used for local disasters or disasters that lack the severity of a federal declaration.

All states involved in a Crisis Counseling Program are required to complete an After Action Report (AAR), which evaluates preparation and deployment during a disaster mental health response. This After Action Report is required by SAMHSA and would not be used in non-federally declared disasters. In both the Indiana and Kansas general response timeline, an After Action Report (as used by Indiana) or evaluation (as stated by Kansas) was noted as being completed during the recovery timeline of the disaster mental health response. It was also noted that after the evaluation is complete, recommendations will be made to improve all phases of the response for each state.

While the Crisis Counseling Program addressed the research and evaluation components of disaster mental health response, none of the three states involved in this study reported plans for completing their own research. No guidelines for obtaining Institutional Review Board (IRB) approval was seen in the disaster mental health response plans. The Indiana plan outlined that the All-Hazards Committee will establish pre-disaster baseline information on state and county mental health and substance abuse needs (Indiana Plan, p. 46). This information can be useful in determining any changes in the baseline post disaster. This for-thought of data collection could be used in research studies in the future, but only if the human subjects research protocols have been approved. 


\section{Interviews with State Representatives}

The Indiana state representative discussed that although the state of Indiana had not completed research studies, all of their data that was collected was for SAMHSA. The Indiana state representative reported that he had individuals inquire about future research and would consider it in future disaster responses. The Indiana state representative discussed that if they were ever deployed again in an out-of-state deployment, he would consider taking staff that could specifically provide the research component of the response, but he did not have a specific plan or ideas that would be implemented.

Indiana appeared to be the most advanced in data collection, as they had developed a procedure to collect data from the first moment of deployment for local, state, and federal disasters. The Indiana state representative reported that "one of the areas of concern that [Indiana] had was that of collecting data in a better way. That is why we came up with our Blue Book and adopted SAMHSA's guidelines for collecting data." Indiana made a decision as a committee to adopt SAMHSA's formula and format for collecting data and developed a field book, known as the "Blue Book." All disaster mental health responders carry this book that outlines what information needs to be collected in the field. This "Blue Book" enabled quick and easy collection of data that was given to team leaders and state level designees for accumulation and follow-up when needed. The Indiana state representative explained that "one of the things that we instituted in the current plan and with our current teams is that when they first go out, they're collecting data and they are keeping track of the people. Just like we would, if we were doing a Project Aftermath" (the Indiana Crisis Counseling Program response program for federally declared disasters). 
The state of Kansas was unaware of any research being completed by the state involving disaster mental health. This component was not in the present scope of the contract. In Kansas, the Kansas state representative had just returned from Emmetsburg, MD, where she completed the SAMHSA Crisis Counseling Program training and learned about required data collection for a crisis counseling program response. The Kansas state representative stated that the Crisis Counseling Program training will be a train-the-trainer type of model for future responders in data collection. When placed in the field, it was expected that each responder will use the SAMHSA/FEMA Toolkit. The SAMHSA/FEMA Toolkit was developed as one of several SAMHSA activities critical to its evidenced-based practice strategy and includes information sheets for stakeholders and a manual for practitioners. This toolkit was used by the $K A R E$ Program in responding to the Greensburg tornado.

The Mississippi state representative acknowledged "post Katrina research was not our focus. I think there is a time and a place, but your research and disaster mental health [response]; you need to have it set up front, you don't need to be trying to do [research] in the middle of responding." Planned research in disaster mental health needs to occur well in advance of any disaster mental health response. No research on disaster mental health response has been completed by the state of Mississippi.

During the initial response, the state of Mississippi knew they needed to collect data so they made the SAMHSA/FEMA Toolkit available to those who were in the field. Prior to the availability of the tool kit, Mississippi was "collecting individual counter logs, the brief contact information, they were beginning to collect that. Was that a refined process? Absolutely not." Mississippi funneled all mental health requests through their Department of Mental Health database, which logged calls and requests from organizations and individuals. Once the demand 
for assistance was evident, the Information Technology (IT) Department for the Mississippi Department of Mental Health formally set up the database to allow a more user-friendly interface. According to the Mississippi state representative, this process itself was overwhelming. Because at the same time the Mississippi Department of Mental Health was compiling information to get the Crisis Counseling Program's Immediate Service Program (ISP) started, they were also applying for a Supplemental Emergency Relief Grant (SERG). To receive SERG grant funding, areas must demonstrate that local resources are overwhelmed and the need is greater than what is being provided. Additionally the applicant must explain why other Federal funding does not meet their needs. In addition, the application for an Emergency Management Assistance Compact (EMAC) was being initiated. This is an interstate mutual aid request, which allows a state to request disaster response assistance from other states post disaster.

\section{External Organizations}

No organizations can respond effectively to a disaster without the support and relationship with others in the community and state. The acknowledgement of other agency involvement in disaster mental health response and in disaster response in general helps to support the infrastructure of a community and can make a heavy load seem bearable. Without the constant collaboration with other organizations in the community and state, disaster preparedness cannot fully occur. Within this section, five best practices $(\# 16,17,38-40)$ were identified that address the need for states to become involved with other organizations for consultation, collaboration, training, and mutual assistance.

\section{State Plans}

The Indiana plan detailed that the office of Emergency Preparedness and Response will liaise with other organizations that may provide disaster mental health response. Such agencies 
are the American Red Cross (ARC), Indiana Voluntary Organizations Active in Disaster (INVOAD), National Organization of Victims Assistance (NOVA), and local charitable and faith-based groups (Indiana Plan, p. 17). No formal Memoranda of Understanding were obtained among Indiana State level agencies. However, a listing of 18 supporting agencies was noted in the Indiana Disaster Mental Health Response Plan (Indiana Plan, p. 31). The relationships with organizations like the America Red Cross and the Salvation Army ensure that food, clothing and shelter resources are provided, as needed.

The Kansas plan stated that they will provide mutual aid to state agencies such as the FEMA Disaster Recovery Centers, Kansas phone hotlines, and the American Red Cross. Throughout the plan, a relationship among American Red Cross and the State of Kansas is evident, and these two agencies work together during a response, with Kansas responders supporting the American Red Cross and community infrastructure in the affected area.

The Mississippi plan outlined several agencies with which they have maintained interagency planning and communication (Mississippi Plan, p. 7). In the state plan, it explained the nature of each relationship to either the Mississippi Department of Health or to a stateoperated facility. Agencies identified in the state plan were the Mississippi Department of Health, Mississippi Emergency Management Agency (MEMA), hospitals, Native American Tribes, community health clinics and physicians, federal health and military facilities, local and regional emergency medical services, and law enforcement agencies (Mississippi Plan, pp. 7-8).

\section{Interviews with State Representatives}

Indiana worked closely with the Indiana Department of Homeland Security and the Indiana Department of Health to aid in mutual training, preparedness training, deployment, and post-deployment evaluations/activities. Many of the disaster mental health missions came 
directly from the Emergency Operations Center (EOC). Since the deployment for Hurricane Katrina, many other state agencies have been looking at the Department of Mental Health and the Health Department as an example of best practices for team development. During times of disaster, the Indiana Department of Homeland Security conducted daily briefings, which included the Department of Mental Health. Mental health assistance was offered to those requesting it from these response agencies.

The Indiana state representative stated that he felt much support by both local and state government agencies. His relationship with Indiana Homeland Security and the Department of Health was very strong. He reported that successful past responses have been a strong contributor to these successful relationships. He summed this up by saying, "I think one of the reasons why we are so successful here is that people know they can count on us. They know we will respond. They know we are a professional group."

In Kansas, mutual aid agreements were encouraged among existing Community Mental Health Centers but were not required. In addition, the state encouraged each Community Mental Health Center to become involved with their county's emergency management agency and local disaster responders, like the American Red Cross. This was outlined in the state disaster plan template for local response. Both the Kansas Department of Emergency Management (KDEM) and the Kansas Department of Health and Environment were closely involved with the Kansas Department of Social and Rehabilitation Services during previous disaster mental health preparedness and response activities. The information gained from this relationship has filtered down to Kansas Health Solutions for deployment direction.

Mississippi denied having a memorandum of understanding (MOU) with the Mississippi Department of Health as both agencies fall under the umbrella of the Family and Social Services 
Administration (FSSA). Mississippi also denied an MOU with the American Red Cross (ARC) or the Salvation Army. The Mississippi state representative acknowledged that without these relationships, both locally and statewide, the mental health program could not exist. Mississippi acknowledged the need for further relationship growth within local areas of emergency management and mental health. In regards to state level relationships, the relationship with the Mississippi Department of Health has grown since Hurricane Katrina into a mutually supportive and positive working relationship. The Mississippi state representative emphasized the importance of this relationship by stating it was a "critical relationship." Now, the Mississippi Department of Health, Department of Mental Health and Mississippi Emergency Management Agency collaborate with each other for disaster preparedness and response. The Mississippi state representative acknowledged that the Mississippi Department of Mental Health was not considered a lead agency, but other response agencies were aware of where they are located and their role in disaster response. The Mississippi state representative stated, when asked about communication, "You have to have that communication, because a lot of the times the health department and emergency response coordinators are my eyes and ears on the ground."

Although each state identified agencies that they will be involved with either through the FEMA Emergency Support Function-8 (ESF-8) or by mutual aid agreements, none of the states specifically identified activities that would occur within the disaster mental health response or how disaster response tasks would be specifically divided among the various agencies. Although with the nature of disaster, many needs may be unknown, there are many consistent requests involving shelters, information dissemination, and medical care that need to be identified prior to a disaster. A more descriptive outline of the relationship and expectation would be helpful in disaster planning. 


\section{Disaster Mental Health Response Timeline}

Elrod et al. (2006) strongly encouraged all disaster mental health plans to have a training component that addresses disaster response across the disaster timeline. It is important to acknowledge that the response in the first 24 hours is very different than the response two weeks post disaster. This section addresses preparation and deployment as well as long-term recovery.

\section{Preparation and Deployment Phases}

The transformation from searching for survivors to recovering the dead has a different toll on victims and responders alike. Acknowledging these differences and preparing teams for what to expect during different times post disaster is an important component of disaster mental health response. This best practice (\#58) was identified by Elrod et al. (2006) and addresses the need for responses to progress throughout the disaster timeline and acknowledges how the response changes across time.

\section{State Plans}

The Indiana plan outlined each level of response across a timeline addressing predisaster, during disaster, and post-disaster tasks (Indiana Plan, p. 26). In the pre-disaster phase of disaster mental health response, the Indiana plan addressed prevention and preparedness, which included strengthening of relationships with local and state organizations, plan development, training, and mock disaster mental health response activities. During the immediate disaster response, the timeline outlined needs assessments, deployment and points of contact for local and state agencies. In the post-disaster phase, the Indiana plan outlined monitoring of responders' mental health, implementing long term services to local areas, completing the After Action Report, and implementing corrective action plans as primary tasks (Indiana Plan, p. 36). 
The Kansas plan not only outlined responder reactions during each level of response, but it also included behavioral mental health reactions during each stage (Kansas Plan, p. 22). The Kansas plan outlined the timeline of response as preparedness, response, and recovery. During preparedness, the activities are designed to help save lives and minimize damage by preparing people to respond appropriately (Kansas Plan, p. 28). Response activities were described as activities that occur immediately after the disaster (Kansas Plan, p. 29). Recovery was outlined as activities that occur 6-12 months following the disaster (Kansas Plan, p. 34). Once again, due to local Community Mental Health Centers not being required to respond or prepare for disaster mental health response, the likelihood of adherence to these expectations was uncertain.

The Mississippi plan focused on planning for evacuation and the evacuation of stateoperated facilities. Although it acknowledged the presence of a timeline in disaster mental health response, it did not identify community-based needs or response activities within the various phases of disaster.

\section{Interviews with State Representatives}

No information was provided in the interviews that addressed this theme.

\section{Long-Term Recovery}

Long-term recovery refers to recovery that occurs 12 months after the disaster occurs. This type of recovery exists after the Crisis Counseling Program ends but need still exists in the affected areas.

\section{State Plans}

Indiana had a pre-identified relationship with Indiana Voluntary Organizations Active in Disasters (INVOAD), which helps in longer term recovery missions post disaster. Although the long-term plans involving this organization were not detailed, their involvement implies longterm recovery intervention. 
The Kansas state plan outlined responses throughout the phases of disaster including recovery, which goes up to 12 months post-disaster. No arrangement appears to be made to cover any response services extending past that time.

The Mississippi plan did not address long-term recovery.

\section{Interviews with State Representatives}

Indiana was involved with the Indiana Voluntary Organizations Active in Disasters (INVOAD) during the past several declared disasters. Among the relationship with the INVOAD agencies and the agreements with local Community Mental Health Centers, the gap of services after the Crisis Counseling Program has ended was minimal.

The Kansas state plan outlined response throughout the phases of disaster including recovery, which only goes up to 12 months post-disaster. This information was reiterated during the interview with The Kansas state representative, as she had not planned for services or referrals after the 12 month period. In the plan, it did establish a relationship with volunteer organizations and other groups, which can be utilized to cover extending needs beyond the plan or expected response dates. Volunteer groups identified for long-term services were encouraged to register as a disaster responder on the K-serve registry.

Mississippi did not address the long-term recovery of the state. With Mississippi still recovering from Hurricane Katrina, it was easy to identify the need for this type of response. Mississippi has depended on federal funding, grants, and volunteer organizations to help with the long-term recovery missions of the state.

\section{Special Issues}

This section addresses specific issues that each state has identified in their disaster mental health response. This section includes naming your state team, suicide prevention, spirituality 
and state-operated facilities. These areas are not specifically identified in the best practices categories, but the researcher believed they were important themes to include.

\section{Naming Your State Disaster Mental Health Team}

This section addresses what each state disaster mental health response team was named during their federal response and how they might have been identified during the response. This theme provides important information about developing an identity for the state disaster mental health team that is easily recognizable by both other disaster responders and community members.

\section{State Plans}

No information was provided in the state plans that addressed this theme.

\section{Interviews with State Representatives}

Indiana named their program "Project Aftermath." The Indiana state representative expressed that one of the most important things to have is a name for your team, as this lets others know who you are and with shirts that identify you, this can help people locate the disaster mental health responders. Project Aftermath shirts were always blue to aid in the consistency and recognizability of the response effort. The Indiana state representative reported that "everybody knows that we're the blue shirts. Whenever the people come together that are involved, they call and say, 'Are you going to have your blue shirt folks down there?' They pretty much know us."

Kansas had the "KARE Program: Kansas Assisting Recovery Efforts.” This team wore green shirts during their disaster responses.

Mississippi used the name "Project Recovery" before Hurricane Katrina and knew that this name could invoke both positive and possible negative associations. Mississippi responders wore blue shirts for their Hurricane Katrina response activities. 


\section{Suicide Prevention}

Suicide prevention addresses specialized training assessing the risk factors and interventions associated with suicidal intention post disaster.

\section{State Plans}

No information was provided in the state plans that addressed this theme.

\section{Interviews with State Representatives}

During the interview with the Mississippi representative, she stated that Mississippi has started to educate responders about the treatment of trauma and suicide prevention as part of their disaster response training. Due to the traumatic experience of a disaster with multiple loses in single families or communities, the state of Mississippi felt that this was an appropriate venue for such training. The Indiana and Kansas interviews did not provide information that addressed this theme.

\section{Spirituality}

Spirituality addresses the inclusion of spiritual content or intervention within the training program for disaster mental health responders.

\section{State Plans}

The Indiana plan outlined the inclusion of a chaplain as a member of their district disaster mental health team. This position included job description and specific qualifications to complete the job. No other states described the inclusion of spirituality in their state plans.

\section{Interviews with State Representatives}

Both in the Indiana plan and during the interview, the inclusion of a chaplain on the disaster mental health response teams was seen. By having an individual who specialized in this area, the Indiana state representative believed this was another resource to use in the field to aid 
survivors in healing and dealing with stress. The Kansas and Mississippi interviews did not provide information that addressed this theme.

\section{State-Operated Facilities (SOF)}

A state-operated facility is a component of each state's mental health services. These facilities include inpatient mental health treatment facilities and residential facilities of varying levels. These treatment facilities are run by each state and require a specific level of care requirements to be established. Many of these facilities maintain the highest level of care, housing the most severe patients with mental illness in the state. With the degree of illness and need for care in these facilities, these individuals are seen as a vulnerable population during disaster response.

\section{State Plans}

When referring to state-operated facilities (SOF), the Indiana plan stated that a representative from each facility should be a member on the district disaster mental health team (Indiana Plan, p. 11). This would ensure that each facility is familiar with the district disaster mental health response and would be able to coordinate their disaster mental health plan in accordance with the district response.

The Kansas plan outlined that each Kansas Mental Health Authority (KMHA) facility have a disaster plan, which includes evacuation, staffing, and emergency contact information (Kansas Plan, p. 42). The Kansas plan clearly made recommendations of what should be in the plan but left logistics and the writing of the plan up to the state facilities.

The Mississippi plan clearly defined what should happen when a state-operated facility has been involved in a disaster or may be involved in the disaster response. The plan itself was a step-by-step instructional guide of what needs to be done, who needs to be called, and where and 
when evacuations should take place. This plan was a detailed guide for the evacuation of any state-operated facility.

\section{Interviews with State Representatives}

No information was provided in the interviews that addressed this theme.

\section{Overall State Summary}

In summary, all three states have responded to large federally declared disasters. The interviews provide a wealth of knowledge about how their disaster mental health response has been and should be conducted in future disaster responses. Each interview explained how the disaster mental health plans are put into reality in the field and described their expectations of the

response. By reviewing the state plans, more insight about the state response and planning can be gained and used to further explore how each state encompasses best practices in the field of disaster mental health. The data from each of the three state plans will be reviewed next.

\section{Indiana}

The Indiana plan was a very complex plan that encompassed a multi-layer approach to disaster mental health response. This plan clearly outlined the duties of each level of response throughout the disaster timeline. This plan exhibited a thorough training program and strengths were seen in logistic planning, training, and state-wide involvement and coordination. Areas for improvement exist in expectations of completing research, information dissemination, family togetherness, and emphasis on core elements of self efficacy, hope and the promotion of calmness. Overall, this plan scored a $73 \%$ on compliance with best practices based on the 59 best practices with which the plan was evaluated.

Kansas 
The Kansas plan was very clinically focused and showed strength in including core elements of family, self-efficacy, hope, and calmness. This plan showed further insight by describing the detailed role and responsibilities of the Public Information Officer. This plan lacked the research component of disaster mental health response and mandated training for disaster responders, including Psychological First Aid. With local responses not being mandated, much of the plan did not cover all local and state responses and was evaluated as being deficient in these areas. Overall, this plan scored a $51 \%$ on compliance with best practices based on the 59 best practices with which the plan was evaluated.

\section{Mississippi}

The Mississippi plan by far had the most inclusive evacuation plans for state-operated facilities of any of the three plans. This plan included such fore-thought as using an Officer of Public Information and the use of diverse technology to inform the families of individuals in State-operated Facilities. However, this plan did not include a detailed community disaster mental health response. This plan neglected state mental health responder training, including the use of Psychological First Aid, and lacked clinical input. Overall, this plan scored a 12\% on compliance with best practices based on the 59 best practices with which the plan was evaluated. 


\section{CHAPTER 5- Discussion}

The purpose of this qualitative study was to review state disaster mental health response plans and actual disaster mental health responses in three states to examine not only adherence to best practices, but also to highlight procedures being performed during deployment of disaster mental health response teams. This research study was developed to gain a thorough understanding of disaster mental health response in both the planning and implementation phases. Interviews with three state disaster mental health officials were completed and a review of each state's disaster mental health state plan was completed. The study investigated the conclusiveness of state plans and their adherence to published best practices in three post 9/11 disasters: 2005 Hurricane Katrina response in Mississippi; 2007 Greensburg, Kansas tornado; and 2008 Indiana flooding. Two of the state representatives in this research study had an existing relationship with the researcher and were the heads of their state mental health disaster response programs. The third person interviewed was selected by the state to represent that state for this study. The semi-structured interviews provided information about the experiences of state disaster mental health officials. These interviews allowed the researcher to collect information about actual disaster mental health responses in each state and allowed state representatives to express their views on their disaster mental health response to these disasters. In addition, the research procedure included the review of the written state disaster mental health plans for each state, which investigated each the state plan's adherence to best practices set forth by experts in the field of disaster mental health response (Elrod et al., 2006; Hobfoll et al., 2007; NIMH, 2002). 
This chapter provides a comprehensive review of the knowledge gained from reviewing each state's disaster mental health plan and analysis of the interviews with each state representative. The study outcomes will be described in five areas: review of the findings, limitations of the study, implications for future research, implications for the field of marriage and family therapy, and recommendations.

\section{Review of the Findings}

The following areas of discussion are based on the themes that developed from the data collection process. These themes were identified throughout the research and have been identified by the states involved as being an important component to their disaster mental health response. The themes identified were: state plans and best practices, disaster mental health state training, additional training options, local disaster mental health response, program manuals, mental health screening, needs assessment, responder safety, communication, research and data collection, external organizations, and long-term recovery.

\section{State Plans and Best Practices}

Professional literature (Elrod et al., 2006; Hobfoll et al., 2007; NIMH, 2002) focuses on what practices need to occur before, during, and after a disaster mental health response. There were 59 disaster mental health best practices outlined in this study (Appendix C). One component of this study was to assess each state disaster mental plan's compliance with these identified best practices. Each of the three disaster plans reviewed were influenced by each state's prior disaster mental health response experience. Indiana scored $73 \%$ on compliance with best practices. Indiana was strong clinically in responders, with a longer history of disaster planning and preparation, and their plan catered to the mandated training, roles, duties, and incident command of a response. Kansas scored a $51 \%$ on compliance with best practices. 
Kansas, with less clinical support in surrounding Community Mental Health Centers and no mandated training for their responders, put more importance on the clinical aspects of their plan. Mississippi scored a $12 \%$ on compliance with best practices. Mississippi had responded to Hurricane Katrina where many facilities were not evacuated; consequently, they did not want to repeat this experience and made evacuation preparation the main part of their disaster mental health plan.

Although the state disaster plans were evident on paper, in most cases, they were not consistent with the actual disaster response deployed in the field, based on the state representative interviews. It was observed that as plans became more compliant with best practices in disaster mental health response, their reported disaster response activities were more symmetrical to their disaster mental health response plan. For example, Indiana scored $73 \%$ compliance with best practices and, during the interview, reported a very consistent response in accordance to their state disaster mental health plan. Mississippi scored $12 \%$ compliance with best practices when reviewing the state plan, but Mississippi was much more compliant with these best practices in their actual response, based on the interview data. In addition, it was observed that although the intent of the disaster mental health response plan was to guide the response, often the response itself was more compliant to the best practices than that of the written state plan. It appears that there is an obvious difference in what is being put into the disaster mental health response plan versus what is occurring during the actual disaster mental health response. Ironically, if each state had included in their plan what they actually had done in the field, higher scores on compliance with best practices for all three states would have been seen. 
The scores for each state do not represent the success of the actual disaster mental health response. The scores are simply a numerical representation of the compliance of the disaster mental health state plans submitted for this study. There are several reasons that scores may not reflect each state response accurately. First, each plan must be submitted and approved by numerous individuals in upper state level positions. Due to this time lapse, the plan may take several months to obtain all needed signatures, yet the actual response planning continues to improve and modify itself across time. Therefore, the plan represents one specific time in the past and may not be an accurate account of present disaster mental health activities. Second, the emphasis of the plan is not symmetrical to the emphasis of the response. Each state plan was written to meet a specific need (e.g., state government regulations), whereas the actual disaster mental health response in the field is aimed at different needs and demands (e.g., meeting community based needs). Thus, inconsistencies between the state plans (which are static documents) and actual disaster response (which is a continuously changing process) would be expected. Third, disaster mental health is an ever changing field with ever changing demands and many people find it difficult to attempt to predict all responses necessary for a successful deployment; thus, all elements of their response would not be included in their written disaster mental health plans. The plans themselves do not reflect what is actually occurring during a disaster mental health response.

Elrod et al. (2006) emphasized the importance for states to have a disaster response plan with the disaster mental health response being an integral piece of the response. Elrod et al. (2006) further emphasized that a written disaster mental health response plan would help to ensure consistency among disaster responses. Upon reviewing each state's disaster mental health plan, it was evident that each state places a priority in different areas. 


\section{Disaster Mental Health State Training}

Training is an essential component to prepare states for disaster response. Training ensures a consistent and higher quality response with responders who are prepared and know what to do to best help survivors. The lack of such training puts responders at risk of unintended harm towards survivors (NIMH, 2002). Training for responders should include National Incident Management System (NIMS) training, some type of clinical response training like Psychological First Aid, and state response training about how the particular state should respond and collect data. Responder team membership should include a code of ethics and a code of conduct. States should also engage in preparedness activities to improve and refresh skills needed to respond successfully and to improve collaboration and interagency relationships.

\section{Psychological First Aid}

When renowned professionals in the field of disaster mental health gathered in October of 2001 to discuss disaster mental health response, Psychological First Aid was placed in the best practices for disaster mental health response (NIMH, 2002). There is consensus among international disaster mental health experts and researchers that PFA can help alleviate painful emotions and reduce further harm that could result from initial reactions to disasters (Norris et al., 2006b). Unfortunately in 2009, we are still struggling with the full acceptance of Psychological First Aid into the training programs. Although money, past history, or training may be barriers within states, states need to become compliant with this primary recommendation.

Although the states in the current study were committed to providing good mental health response, the lack of mandated clinical training hindered the ability to meet this need. Mississippi was in the process of mandating Psychological First Aid training, and Indiana 
already required this training for all disaster mental health responders. Kansas still struggles with the lack of upper level mandates and financial restraints, so Kansas was unable to require that all responders complete the training. To ensure consistent and safe disaster mental health response, it is essential that mandated training is supported from upper state authority and throughout the disaster mental health response. Without the mandated clinical training, it will be difficult for states to ensure consistent care is being included in their response.

\section{NIMS Training}

Nothing identified in the literature supports the need for responders to adhere to mandated NIMS training. However, all states involved in this study have acknowledged the need to have NIMS training as a part of their mandated training. This requirement appears to be mandated by federal regulations and may be tied with financial dispersion to states after disasters. Further inquiry needs to be completed on this issue before more in-depth discussion can occur.

\section{Preparedness}

Mental health training has been successfully utilized to prepare community responders without formal mental health experience (North \& Hong, 2000). During this pre-incident time, many states utilize tabletop and reenactment training to help sharpen their skills to prepare for responding to a disaster. Pre-disaster training, which includes disaster preparedness that utilizes tabletop exercises, disaster response planning sessions, and role plays, were highlighted by research completed by Elrod et al. (2006). All states involved in the present study reported to be involved or plan to be involved in such exercises with their state teams or responders. All three states teamed up with other state agencies, such as the health department, to aid in the training of 
responders. Due to funding limitations and the establishment of good working relationships among response agencies, this collaboration appears to work well.

In addition to general tabletop exercises with the health department, Mississippi participated in points of distribution (POD) training in coordination with the health department to prepare for mass prophylactic distribution. They also participated in a radiological disaster drill where mass evacuation would be required. Such training aids in the preparation for response and increases the strength of relationships among multiple disaster response agencies.

Indiana was involved with a mass casualty response at Camp Mascatatuk that involves many state agencies and simulated deployment. Indiana, with the help of Mission Ready Consultants, compiled a field training that prepares mental health teams for self-deployment into the field. This training prepares responders to be able to care for themselves and others while being deployed. Indiana purchased enough outdoor equipment to have teams self-deploy, when necessary. With the urgency for teams to be more self-reliant in the field, this training is unique and a forerunner in the field of disaster mental health.

Preparedness activities not only help responders learn and gain experience in the field, they also create bonds and relationships that are essential during a response. Indiana acknowledged the need to have teams come together during the preparedness stage of response to allow for increased team cohesion.

\section{Naming Your State Disaster Mental Health Program}

By naming the state disaster mental health program, states allow the response to become more recognizable. It also creates ownership of the team and its processes. All states evaluated in this project named their disaster mental health programs. All responders involved also wore specific shirt colors to help those in the community and other responders identify who they were 
and their role in the disaster response. This consensus supports the concept of having a name and an identity as an important component of disaster response.

\section{Additional Training Options}

The following training programs were seen in different state plans or were identified during interviews with state representatives. These additional areas for specialized training may be considered an addendum to existing disaster mental health responses.

\section{Special Needs}

All three states, either within their state plans or during the interviews, discussed the inclusion of special needs training as part of their response preparation. This emphasis on those who may need more support during disaster response is seen as an important aspect of disaster preparation. Becker (2007) showed support for preparing professions to adapt to differing needs of children and other special needs populations. With the frequent necessity of relocating special populations pre and post-disaster, the need to have a solid plan seems evident. However, little research at this time has been conducted on this issue.

\section{Spirituality}

Spirituality has been studied in association with trauma and can either aid in dealing with a traumatic event, or hinder those involved depending on the person (Conner, Davidson, \& Lee, 2003). Many people find comfort in their faith during times of despair, and it is these faith-based groups that often respond throughout the disaster and remain once state and federal agencies have left. Bulling (2006) contends that chaplain care during disaster response plays an important part in helping disaster-affected individuals. The involvement of a chaplain in a disaster response setting was something that Indiana included that other states did not. Although the implications of this component are unclear, the addition of a spiritual component would aid in the healing of 
those who find it beneficial. Indiana is to be commended for including non-traditional responders in the response program.

\section{Suicide}

Chou et al. (2003) reported a significant increase in persons committing suicide post disaster. The Centers for Disease Control (CDC) reported that suicide rates increase 13\% post disaster and emphasized the need for disaster mental health intervention (Moore, 1998). This alarming result should lead disaster mental health response training to include specific suicide prevention interventions. However, Mississippi was the only state that included such training as part of their disaster mental health response preparation. This type of preventative measure should be a component of all disaster mental health response training.

\section{Local Disaster Mental Health Response}

In each state, there was a heavy reliance on local resources to respond to disaster mental health needs during the initial phases of a response. Without a select group of individuals who have been identified as responders, who have an agreement of some type to respond in their area, and who have been trained appropriately, no beneficial response is guaranteed. The lack of response can decrease the sense of safety within victims and leave basic needs unmet as survivors struggle with the disaster (Gard \& Ruzek, 2006). Local response for any size disaster should be a priority and a building block for all disaster mental health responses. Although the necessity of a local disaster mental health plan has not been established, the need for having a guaranteed response is obvious.

\section{Program Manuals}

Program manuals need to be developed to outline the roles of the outreach workers, the counselors, and the referral procedure (Elrod et al., 2006). Indiana and Mississippi both possess 
Psychological First Aid field guides that help responders in the field identify appropriate tasks throughout the response timeline. These guides increase the consistency of care given and ensure that time lapses between disasters will have minimal effects on remembering Psychological First Aid components. Such guides would be beneficial for all responders to use and should be promoted nationally.

\section{Mental Health Screening}

The exclusion of a screening tool for PTSD is not consistent with the disaster mental health best practices. Though each state was aware that the Crisis Counseling Program has a component of a mental health screening tool within it, they acknowledged these programs did not begin until several weeks after the disaster's impact. Each state representative reported that they did not specifically include an assessment during the local or initial response.

Research on PTSD does not support the need for a PTSD screener in the early phases of mental health disaster response, as most individuals will return to pre-event levels of functioning within days or weeks after the trauma (McNally et al., 2003). Most individuals will respond with hyper-arousal immediately after the disaster and these symptoms will decrease over time. With symptoms needing to present for a minimum of one month to diagnose PTSD, early screening may not be necessary as many false positives may be identified (Schiraldi, 1999).

The purpose in early disaster mental health response is to help decrease the likelihood of long-term effects of the traumatic experience. The use of screening tools throughout the disaster mental health response needs to be addressed and may be more appropriate during later phases, when the difference between general coping and significantly impaired distress may be seen. This screening should be a part of training so that all responders, within the crisis counseling model or not, will have the best knowledge and ability to help survivors. 


\section{Needs Assessment}

All states involved in this study performed a needs assessment in all areas affected by the impact of a disaster. Although this needs assessment was being completed by the states, the only needs assessment that was standardized was the needs assessment involved in the Crisis Counseling Program grant requests. There is a need for more education and consistency in conducting needs assessments that should be a part of the response team leader training.

\section{Responder Safety}

The emotional impact of disaster is especially strong for workers if contact with survivors is prolonged (Harvey \& Bryant, 1998; Moynihan et al., 2005). All responders must be aware of the consequences of secondary traumatic stress that may manifest as a result of being exposed to other's traumatic experiences (Pulido, 2007). Each state in the current study addressed the importance of responder safety. Disaster mental health teams should have an arrangement to help with first responders and to care for their own disaster mental health team members.

\section{Communication}

Communication is the process of exchanging or delivering information to the community post disaster, with the responders during the response, and with key players through all phases of disaster response. The issue of how to communicate basic information to the community and the responders has been a growing concern as technology increases our options. Additionally, by identifying who will control the distribution of information can contribute to increased calm throughout the disaster. Two key themes developed from this study: information dissemination and information officers.

\section{Information Dissemination}

States have begun to utilize more technological forms of information dissemination. Cell phones, satellite phones, 1-800 numbers, two-way radios, text messaging, internet and websites 
are various ways agencies are communicating to the public about where help is located and offering crisis contact numbers for survivors to call. Indiana used a business type card that they distributed to people in the disaster area. This card is small and can be easily stored and kept for times when help is needed. The card identifies websites and crisis phone numbers that can be used to help with distress post-disaster. The ability to have a 1-800 number supporting the public within 24 hours is a great asset to states, as they can utilize the same toll free number for each disaster to create consistency between incidents. Kansas reported that two-way radios were most beneficial in mass disasters, because many cell phone towers may be down and two-way radios are essential. All teams should establish a reliable mode of communication prior to a disaster and all responders should be aware of the method of communication to be used in the response.

\section{Information Officers}

In the past, the lack of consistent communication has been a very stressful and hindering part of disaster mental health response (Elrod et al., 2006). Best practices clearly identify the benefits of having control over information dissemination post-disaster. Increasing the likelihood that correct information is being given in a timely manner will increase survivors' ability to remain calm and reduce feelings of fear and powerlessness (Hobfoll et al., 2007; NIMH, 2002). During this research, two states identified a person within the response who would be responsible for information dissemination. Whether it is the Public Information Officer or the Public Safety Officer, this role is essential in disaster mental health response.

\section{Research and Data Collection}

Hobfoll et al. (2007) published an article outlining the absence of evidence-based consensus supporting immediate and mid-term post disaster mental health response. The topic of research itself created an emotional reaction during the interviews. The Mississippi state 
representative stated that "there is a time and a place for research, you need to have it set up in front, you don't need to be trying to do it in the middle of responding." There appears to be a consistent agreement that research is important, but it needs to be done outside of the response itself. The Indiana state representative was open to having a research team involved with their responses but acknowledged it must be in addition to the response, not part of the response.

NIMH (2002) reported, "When the optimal forms of intervention are unknown, there is an ethical duty to conduct scientifically valid research to improve prevention, assessment, intervention, and treatment" (p. 10). The National Center for Post-Traumatic Stress Disorder (NCPTSD) has encouraged further disaster mental health research and basic education. Such organizations, with the aid of partnerships such as private researchers, including universities, will be the best way to increase the number and quality of studies being completed in the field of disaster mental health.

NIMH (2002) also encouraged the development of a national strategy to aid in data collection and research throughout the disaster response. Indiana has developed a training tool to use during deployment and to aid in the proper collection of disaster mental health data so that accurate information can be used by SAMHSA. This small book easily fits in a pocket or purse and can be utilized by all responders. The forms developed were based on the SAMHSA forms used during Crisis Counseling Programs and data can be easily adapted from local to state or federal responses. This tool is something that all states would benefit from using and has financially supported some of Indiana's early responses with reimbursement of federal money for services performed prior to the SAMHSA Crisis Counseling Program approval.

\section{External Organizations}

It is critical to build relationships with other organizations prior to working together in a disaster setting (Elrod et al., 2006). By increasing interactions and developing effective working 
relationships between disaster response agencies prior to disasters and being part of other state agencies' disaster planning and response, mental health teams will gain respect and increase the strength of collaborative relationships in the process. While all three states evaluated in the current study included external organizations in their state plans and discussed the importance of these relationships in the interviews, there remain areas for improvement in establishing new relationships and strengthening current relationships with other local and state response organizations.

\section{Long-Term Recovery}

Long-term recovery refers to recovery that occurs 12 months after the disaster occurs. All three states involved in this study recognized the need for longer recovery plans but there has been no consistency among the states in how that may be accomplished. Literature does not address the long-term care of disaster-affected areas in the United States. Other countries have been involved in disaster response for years post disaster, utilizing non-profit and volunteer organizations, like the International Red Cross and Red Crescent Society. After Hurricane Katrina, Mississippi utilized grant funding and volunteers to continue treatment and rebuilding of the Gulf Coast area. The concept of long-term recovery should be addressed more in-depth in disaster mental health state plans.

\section{Limitations of the Study}

Limitations of this study are discussed in the following section. Limitations include issues related to researcher bias, sample size and selection, the researcher's limited experience, and the state representatives interviewed. 


\section{Researcher Bias}

This researcher had a prior relationship with two of the states involved in this study. Because in qualitative research, the researcher plays such an important role in data collection and interpretation, potential bias must be recognized. This researcher attempted to control bias by using a structured interview to guide the research to a full and thorough understanding of each state's disaster response and by transcribing the interviews to allow for a more objective observation. Further, the researcher attempted to control bias by utilizing a written evaluation of best practices from the literature (Elrod et al., 2006; Hobfoll et al., 2007; NIMH, 2002) for the state plan review.

\section{Sample Size and Selection}

This research utilized purposeful sampling to allow for the best quality of disaster responders to be involved in the study. Although purposeful sampling was utilized, this study could have been more generalizable with increased numbers of participants. Due to time and the nature of qualitative studies, however, the decision to use three representative states appeared to be the best compromise for this study.

The participants in this study were selected for two reasons. First, these states did represent a purposeful sample of diversity that would be beneficial to the study. Indiana had been involved in state and federal responses, which commonly involved flooding, tornadoes, and earthquakes. Kansas' experience with tornadoes and flooding had allowed them to respond to major disasters in recent years. Lastly, Mississippi, with the Hurricane Katrina disaster and other smaller state responses, had gained the experience needed to be an avid part of disaster mental health response. 
Second, states were chosen to participate in this study due to their accessibility to the researcher and the committee. This researcher had a prior professional relationship with the representatives in Indiana and Mississippi. This opened a door for the research opportunity. In addition, the chair of the researcher's dissertation supervisory committee was involved in the Kansas disaster mental health response in Greensburg in 2007 and was the author of the original Kansas All-Hazards Behavioral Health Plan. This relationship provided access for Kansas to be involved in this study.

A third limitation of state selection was that even though all three states were involved in federal disaster responses, each state experience was very different. Each state had a differing timeline, degree of damage, geographical location, and number of people affected. For instance, Hurricane Katrina occurred in 2005, and in 2009, they are still in the recovery and rebuilding stage of disaster response and, until this year, were still receiving federal funding for recovery efforts. The Indiana flooding in 2008 covered a large area with a shorter recovery timeline, while the Greensburg, KS tornado in 2007 was much localized with total devastation that affected a smaller community.

\section{Researcher's Limited Experience}

One limitation of this study was the researcher's inexperience in designing and conducting qualitative research. However, the researcher had been involved in multiple research studies at the graduate level and had taken two graduate research classes, which included qualitative research methodology. To address this issue, the researcher relied heavily on the dissertation committee's guidance during the proposal period and utilized the experience and knowledge of the committee members involved in this study. This researcher utilized her clinical 
skills to gain a thorough understanding of concepts during the interview and was able to enhance interviewee comfort throughout the interview.

\section{State Representative Interviewed}

During the initial planning for this study, the intent was to include all state level personnel who had been involved in the last nationally declared disaster response involved in this study. However, prior to interviewing the representative from Kansas and after interviewing both Indiana and Mississippi, the identified person in Kansas left her position and no replacement was available. The Kansas Department of Social and Rehabilitation Services (SRS) recommended the special projects coordinator who was managing the contract for disaster response to be involved

in the study. Although this representative knew little of the Greensburg tornado disaster mental health response, she was very knowledgeable about the direction of the current response in Kansas and what was being done to prepare Kansas for their next disaster. However, both Indiana and Mississippi were able to provide more in-depth knowledge based on their direct experiences responding to federally-declared disasters. In addition, because the interviews were conducted with state directors, rather than with direct responders in the field (e.g., the disaster mental health program coordinators running the local response), the information on the response may have been different. It is possible that what state-level directors report happening in the field and what response team members report happening are very different. Future research that includes responders and personnel at various response levels (e.g., local, state, federal agencies) would be beneficial.

\section{Implications for Future Research}

As noted by NIMH (2002), more research needs to be completed in the area of disaster mental health. Further investigation exploring best practices in disaster mental health response 
needs to occur to ensure responders are providing the best quality response possible. The question of the implementation of disaster research concurrent with the disaster mental health response is still an issue. Developing a process of collecting data utilizing present instruments in existing tools to gain more quality information for research needs to be done. The use of the current SAMHSA Crisis Counseling Program model is being utilized for research but more can be done. The effectiveness of various disaster mental health programs needs to be further explored.

Research on disaster mental health best practices in the field of disaster mental health would be effective. Evaluating the compliance to best practices of actual disaster mental health responses would add to the understanding of what best practices are being completed in the field. More research that explores the gap between state disaster mental health plans and disaster mental health response would allow an in-depth understanding of what contributes to this difference in compliance. Utilizing multiple disaster mental health focus groups across the country and engaging them in what they are doing throughout their responses would add great knowledge to the literature. Larger studies involving more states would allow disaster mental health responders to see what is working in other states and possibly add components to their own plans. Reviewing all state plans and identifying possible strengths and areas for improvement would be extremely helpful to the field of disaster mental health and those who are coordinating plans and responses in each state.

Research that further explores the competencies of state disaster mental health training needs to occur. The proficiency of Psychological First Aid is an important aspect of future research and should be a priority. Further investigation to identify what federal regulations are mandated for states should be assessed and explained. Exploration into how disaster preparation 
training affects the disaster mental health responders' performance in the field should also be addressed.

More proficient means of gaining the knowledge of the mental health needs a community has post-disaster and the type of response activities that would be most beneficial are still unknown. The need to establish guidelines for local responders to assess their own needs should be a priority. In addition, multiple specialists involved with disaster mental health response teams could be beneficial to the field. Many questions still need to be posed, such as: What type of team is most resilient to the effects of disaster response? What disaster mental health responder qualities are most resilient? Is different preparation needed for local, state, or federal disaster responses? What effect does team cohesion have on disaster mental health response? Do multi-faceted teams that include medical, emergency responders, and mental health responders have the ability to reduce long-term effects of disaster trauma more than mental health teams alone? Are non-clinical disaster mental health responders as effective as clinical responders in providing disaster mental health services?

The themes identified in this study and the NIMH (2002) best practices need to be further explored empirically. How does the inclusion of a spiritual component affect disaster mental health response outcomes? How does additional training in such areas as suicide prevention and special needs training impact the effectiveness of the disaster mental health response? Does having a Psychological First Aid Field Guide or other program manuals have an impact on consistency and program effectiveness during the response? Does having mandated training increase the quality of services provided? Does preparedness training increase the confidence and effectiveness of disaster mental health responders? 
The field of disaster mental health response is still new to the area of research. Disaster researchers today have begun to lay the foundation for future research in the field. Clinicians in the field need to understand the importance of research and become active participants in developing and implementing research studies. It is encouraged that evaluation research be completed by those who use various disaster response techniques. Universities can be a great area of support for the development of future research.

\section{Implications for the Field of Marriage and Family Therapy}

The National Institute of Mental Health (2002) identified the American Association for Marriage and Family Therapy (AAMFT) as a resource organization for disaster mental health responders. This alone is an honor that is under-utilized in our field. With the emphasis on family systems concepts, marriage and family therapists should be active and involved in disaster mental health response. Our field can identify the benefits of family involvement post-crisis and understand the concepts of how disasters disrupt the systemic equilibrium of social structures. Family therapists are trained to see the holistic picture of a situation and can use this training to aid in the healing of those affected by disaster.

One major limitation in the field of disaster mental health is the lack of theory based intervention and philosophy. With the acknowledgement on non-linear interactions in disaster mental health, the door is open for more relational or systemic research and theory development to be conducted. Marriage and family therapists should use their theory base to stabilize disaster mental health intervention and to further address the relationships between interventions and outcomes.

In addition, marriage and family therapists should identify the need for evidence-based intervention support in the field of disaster mental health and find support for such interventions. 
Psychological First Aid needs to be transitioned from evidence-informed practice to evidencebased practice. The research opportunities for MFTs in the area of disaster mental health is wide open.

\section{Recommendations}

Based on the current study results, several recommendations for state disaster mental health administrators and responders can be provided:

1. All individuals involved in disaster mental health work should be familiar with the identified disaster mental health best practices and practices should be included in their disaster mental health response and plans. These best practices should be utilized as the primary guide for developing effective disaster mental health response at the local, state and national levels.

2. All states should have required training that includes a clinical framework, like Psychological First Aid, the NIMS core trainings, data collection training module, code of ethics, code of conduct, and special needs population training. Responders should be compliant with these trainings and states need to have a tracking system in place to ensure training compliance occurs.

3. All states should be involved in preparedness training at all levels of disaster mental health response. Preparedness activities (e.g., tabletop exercises, coordination with other disaster response agencies) should occur at the local, state and federal levels.

4. Each state should develop a name for their program for local, state, and federal disaster mental health responses. This program name provides for consistent recognition of the disaster mental health responders, team unity, and clarity of responder roles.

5. All states should establish disaster mental health response plans that cover all degrees of disaster response at the local, state, and federal levels. These plans should include an 
outline of who will respond to the disaster in a given area with a plan to ensure a disaster mental health response will occur, even if the event does not reach the level of a state or federal disaster declaration.

6. Each state should plan communication methods prior to a disaster. States must plan for worst case scenarios (e.g., no internet, no cell phone coverage) to ensure communication will not be lost during disaster mental health response.

7. All state disaster mental health plans should address long-term recovery that goes beyond the 12 month plan of the FEMA/SAMHSA Crisis Counseling Program. The plan should identify resources and additional funding that may be utilized by those who need longer term services and support.

\section{Conclusion}

Each state brings unique attributes and experiences to their disaster mental health response, which helps to mold the response to the state needs. As increased knowledge is gained from other state disaster mental health responses, more knowledge and expertise will contribute to disaster mental health preparedness across the county.

This research will serve as a guide for those developing disaster mental health plans and encourage further thought in disaster mental health response. Researchers and responders are encouraged to examine the findings in this study and continue to utilize the core best practices in their disaster mental health preparedness and response. This knowledge will add to the quality and effectiveness of services provided during disaster mental health responses. 


\section{Appendix A-Glossary of Acronyms}

AAMFT

AAR

APA

ARC

ARC DMHS

ASD

CCP

$\mathrm{CDC}$

CISD

CISM

$\mathrm{CMHC}$

CMHS

DDMHRT

$\mathrm{DMH}$
American Association for Marriage and Family Therapy

After Action Report

American Psychiatric Association

American Red Cross

American Red Cross Disaster Mental Health Services

Acute Stress Disorder

Crisis Counseling Program

Centers for Disease Control

Critical Incident Stress Debriefing

Critical Incident Stress Management

Community Mental Health Center

Center for Mental Health Services

District Disaster Mental Health Response Teams

Department of Mental Health 
DSM

EMAC

EMDR

EOC

ESF

FEMA

FSSA

HAN

HFMA

IMERT

INDMHA

INVOAD

IRB

ISP

IT
Diagnostic and Statistical Manual of Mental Disorders

Emergency Management Assistance Compact

Eye Movement Desensitization and Reprocessing

Emergency Operations Center

Emergency Support Function

Federal Emergency Management Agency

Family and Social Services Administration

Health Alert Network

Healthcare Financial Management Association

Indiana Mortuary Emergency Response Team

Indiana Department of Mental Health and Addictions

Indiana Voluntary Organizations Active in Disasters

Institutional Review Board

Immediate Service Program

Information Technology 
KAHBHP

KARE

KDEM

KHS

KMHA

KSCCP

MDMH

MEMA

MFT

MOU

MRE

NCPTSD

NCTSN

NIMH

NIMS

NOVA
Kansas All-Hazards Behavioral Health Program

Kansas Assisting Recovery Efforts

Kansas Division of Emergency Management

Kansas Health Solutions

Kansas Mental Health Authority

Kansas State Crisis Counseling Program

Mississippi Department of Mental Health

Mississippi Emergency Management Agency

Marriage and Family Therapy

Memorandum of Understanding

Meals Ready to Eat

National Center for Post-Traumatic Stress Disorder

National Child Traumatic Stress Network

National Institute of Mental Health

National Incident Management System

National Organization of Victim Assistance 


$\begin{array}{ll}\text { PCPTSD } & \text { Primary Care Post Traumatic Stress Disorder Screener } \\ \text { POD } & \text { Points of Distribution } \\ \text { PFA } & \text { Psychological First Aid } \\ \text { PTSD } & \text { Post Traumatic Stress Disorder } \\ \text { RSP } & \text { Regular Service Program } \\ \text { SAMHSA } & \text { Substance Abuse and Mental Health Services Administration } \\ \text { SERG } & \text { Supplemental Emergency Relief Grant } \\ \text { SOF } & \text { State-Operated Facility } \\ \text { WOAD } & \text { Posttraumatic Stress Rating Interview } \\ \text { SPRINT } & \text { Worluntary Organizations Active in Disasters } \\ \text { VIPR } & \text { Social and Rehabilitation Services } \\ \text { SUV } & \text { Spontaneous Uninvited Volunteers } \\ & \end{array}$




\title{
Appendix B- Semi-Structured Interview for State Representatives
}

\author{
Interview Questions
}

Before beginning the interview it will be explained that this interview will be taped and the tape will be used as data for my dissertation.

Background of Interviewee

Describe the position you currently hold in regards to disaster mental health.

How long have you held this position? Is all of your FTE dedicated to disaster mental health?

Describe the history of your organization related to disaster mental health response in your state.

At what point did your organization develop a disaster mental health plan?

Did your state experience any disaster that expedited or changed your disaster model?

\section{Background of Disaster Mental Health Plan}

Was your state's disaster mental health plan developed according to the NIMH (2002) best practices for disaster mental health?

How does your state set up and prepare for disaster mental health response?

Describe how your disaster mental health plan is followed during a disaster?

What clinical approach for disaster mental health response does your state use (CISM, PFA, NOVA)? Why did your organization move towards that model?

\section{Preparation for Disasters}

Describe your disaster mental health response training plan.

Is training mandated for all responders?

Does your training plan include training in vulnerable/high risk populations?

Describe how you identify disaster mental health responders.

Do you have a pre-identified list of Mental Health responders?

What makes them eligible responders?

How do you ensure communication with other organizations responding to the disasters?

Do any Memoranda of Understanding exist prior to a disaster?

Do you have an existing crisis number to use in case of disaster? 


\section{$\underline{\text { Best Practices }}$}

Describe the assessment methods used to assess the need for different services or interventions? Is a Clinical assessment tool utilized (describe)?

Describe how communication with staff occurs and how information is disseminated to your response team(s).

Describe what information you provide to survivors. In what ways does your staff protect victims from further harm from the disaster? How does your organization work to keep families together after a disaster?

Describe the support available to first responders, including your disaster mental health responders.

How do you monitor and ensure quality services are being provided by your staff?

Evaluation/Implementation of the Plan during a Crisis Counseling Program

Related to the (XX) disaster when your state implemented a federal Crisis Counseling Program:

How did your plan play out the first 48 hours of response? How did you evaluate needs/demands?

Do you believe your state's response has had a positive impact on those you have been in contact with?

Did you feel supported by your organization/federal government during your past disaster mental health responses? What were some of the rewards/ limitations of the Crisis Counseling Program?

How did your program organize long-term care of those affected after the CCP was completed?

What are some of the mistakes that you saw in the field during the response?

Fran Norris noted that one of the biggest limitations from state representative was the breakdown of communication. How did communication affect you response?

What do you feel is a must for any mental health team responding to a disaster?

If money was not an issue, what would you add to your program? Is there anything else that you would like to share about your disaster mental health program in (xx state)? 


\title{
Appendix C- Best Practices Evaluation Sheet
}

\author{
Best Practices of Disaster Mental Health Response
}

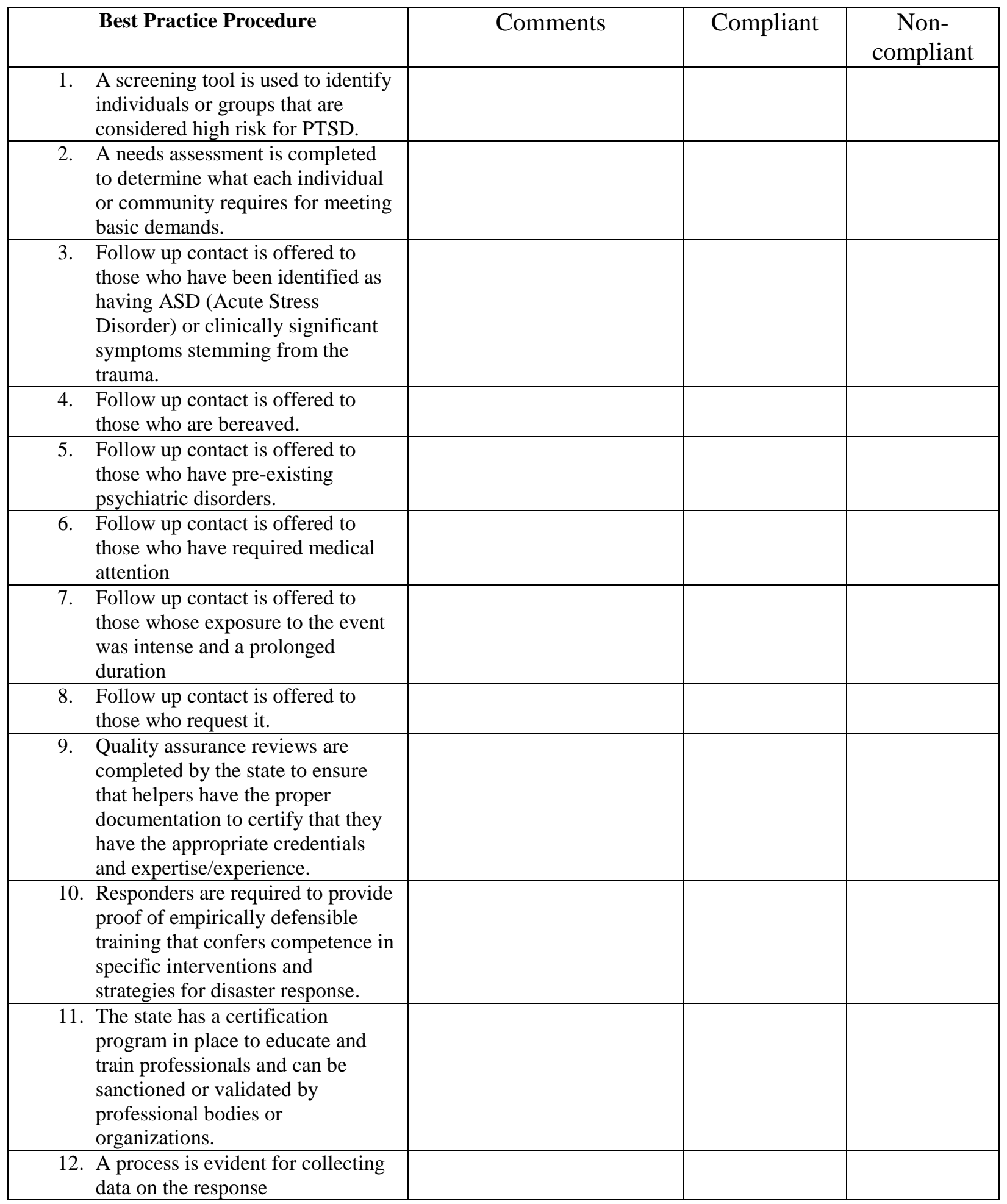




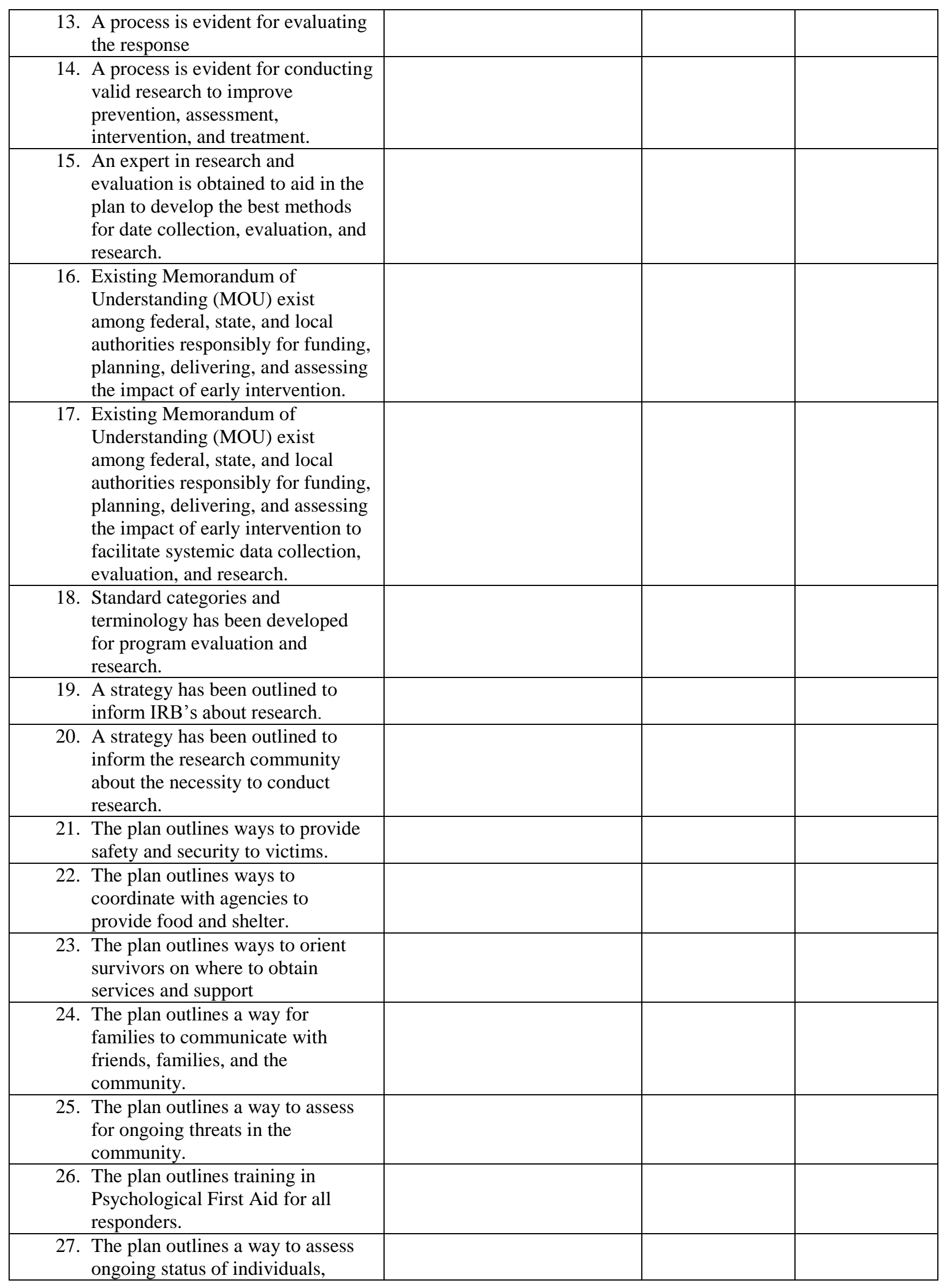




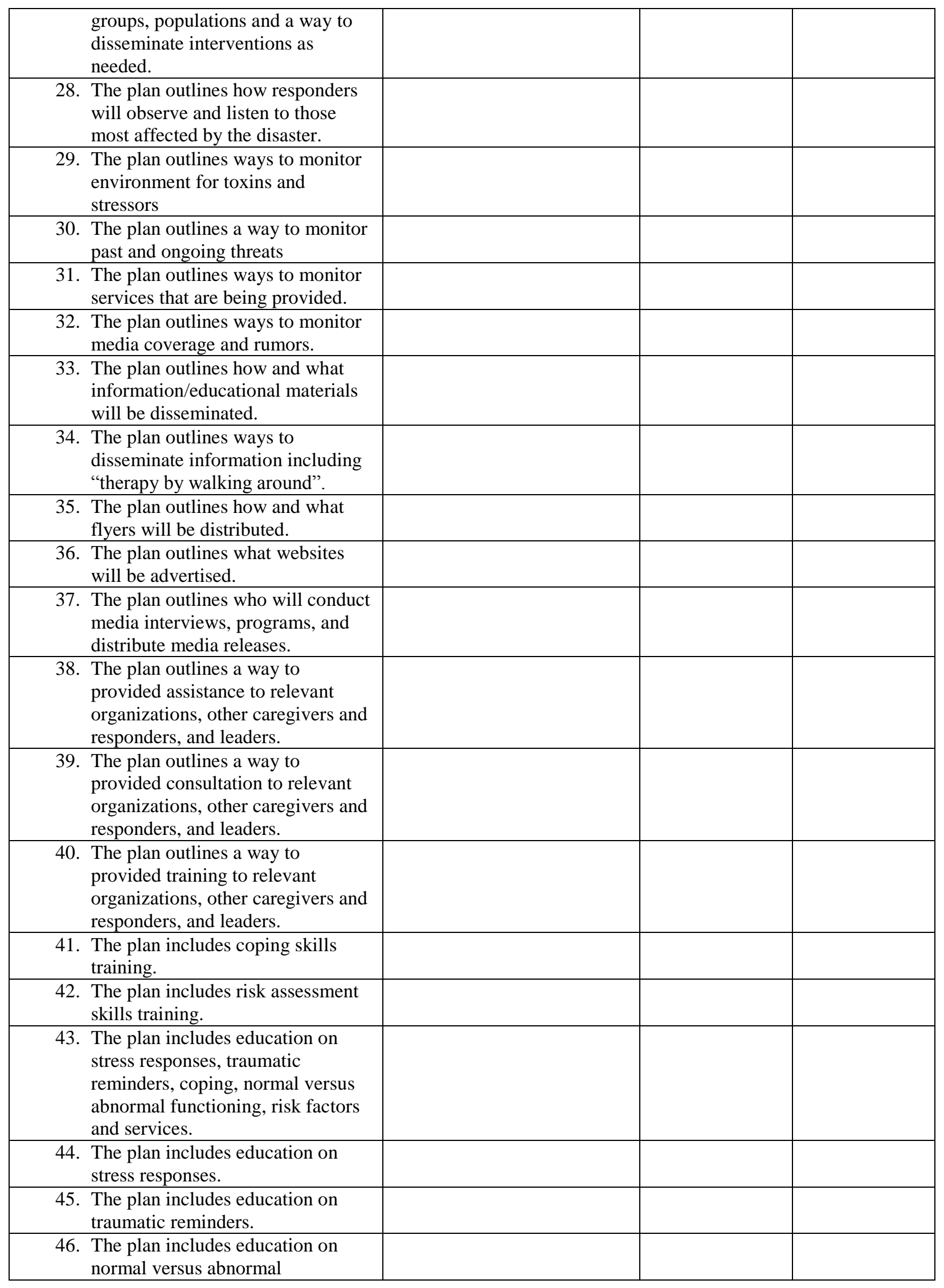




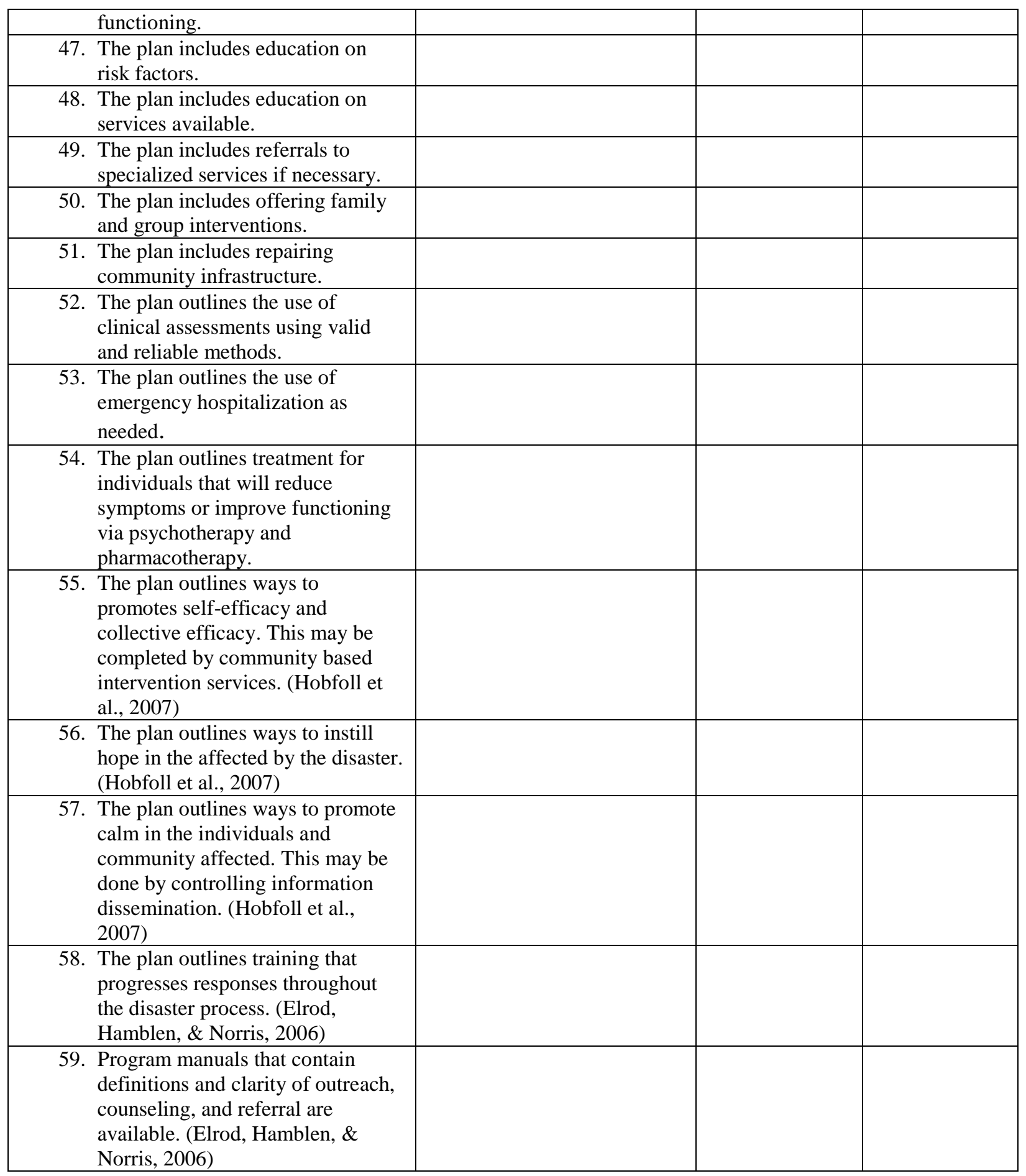




\title{
Appendix D- Best Practices Evaluation Sheet - Indiana
}

\author{
Best Practices of Disaster Mental Health Response \\ Indiana
}

The following is a legend of the themes of best practices. Each best practice category is highlighted in a specific color to help identify the category.

$\begin{array}{ll}\text { Mental Health Screening } & \text { Green } \\ \text { Needs Assessment best practices } & \text { Gray } \\ \text { Follow Up Contact } & \text { Red } \\ \text { Disaster Mental Health Training and Response } & \text { Purple } \\ \text { Research and Data Collection } & \text { Orange } \\ \text { External Organizations } & \text { Royal blue } \\ \text { Information Dissemination } & \text { Merlot } \\ \text { Training Across the Response Timeline } & \text { Black }\end{array}$

\begin{tabular}{|c|c|c|c|c|}
\hline & Best Practice Procedure & Comments & Compliant & $\begin{array}{l}\text { Non- } \\
\text { compliant }\end{array}$ \\
\hline 1. & $\begin{array}{l}\text { A screening tool is used to } \\
\text { identify individuals or groups } \\
\text { that are considered high risk for } \\
\text { PTSD }\end{array}$ & $\begin{array}{l}\text { Part of CCP A\&R. None used } \\
\text { for local intervention. }\end{array}$ & & $\mathrm{X}$ \\
\hline 2. & $\begin{array}{l}\text { A needs assessment is completed } \\
\text { to determine what each } \\
\text { individual or community } \\
\text { requires for meeting basic } \\
\text { demands. }\end{array}$ & $\begin{array}{l}\text { Each region is responsible for } \\
\text { district assessments. Need to } \\
\text { notify state if assistance is } \\
\text { needed-team leader }\end{array}$ & $\mathrm{X}$ & \\
\hline & $\begin{array}{l}\text { Follow up contact is offered to } \\
\text { those who have been identified } \\
\text { as having ASD (Acute Stress } \\
\text { Disorder) or clinically } \\
\text { significant symptoms stemming } \\
\text { from the trauma. }\end{array}$ & $\begin{array}{l}\text { Part of CCP and PFA for } \\
\text { responders. }\end{array}$ & $X$ & \\
\hline & $\begin{array}{l}\text { Follow up contact is offered to } \\
\text { those who are bereaved. }\end{array}$ & $\begin{array}{l}\text { Part of CCP and PFA for } \\
\text { responders }\end{array}$ & $X$ & \\
\hline & $\begin{array}{l}\text { Follow up contact is offered to } \\
\text { those who have pre-existing } \\
\text { psychiatric disorders. }\end{array}$ & $\begin{array}{l}\text { Part of CCP and PFA for } \\
\text { responders }\end{array}$ & $X$ & \\
\hline & $\begin{array}{l}\text { Follow up contact is offered to } \\
\text { those who have required medical } \\
\text { attention }\end{array}$ & $\begin{array}{l}\text { Part of CCP and PFA for } \\
\text { responders }\end{array}$ & $\mathrm{X}$ & \\
\hline & $\begin{array}{l}\text { Follow up contact is offered to } \\
\text { those whose exposure to the } \\
\text { event was intense and a } \\
\text { prolonged duration }\end{array}$ & $\begin{array}{l}\text { Part of CCP and PFA for } \\
\text { responders }\end{array}$ & $\mathrm{X}$ & \\
\hline
\end{tabular}




\begin{tabular}{|c|c|c|c|c|}
\hline & $\begin{array}{l}\text { Follow up contact is offered to } \\
\text { those who request it. }\end{array}$ & $\begin{array}{l}\text { Part of CCP and PFA for } \\
\text { responders }\end{array}$ & $\mathrm{X}$ & \\
\hline & $\begin{array}{l}\text { Quality assurance reviews are } \\
\text { completed by the state to ensure } \\
\text { that helpers have the proper } \\
\text { documentation to certify that } \\
\text { they have the appropriate } \\
\text { credentials and } \\
\text { expertise/experience. }\end{array}$ & $\begin{array}{l}\text { P 19. Done extensively. Part } \\
\text { of DDMHRT, } 10 \text { regions that } \\
\text { have mandated training and } \\
\text { list of responders. Check } \\
\text { credentials, t raining, PFA, } \\
\text { NIMS, code of ethics, code of } \\
\text { conduct, job descriptions. }\end{array}$ & $\mathrm{X}$ & \\
\hline 10. & $\begin{array}{l}\text { Responders are required to } \\
\text { provide proof of empirically } \\
\text { defensible training that confers } \\
\text { competence in specific } \\
\text { interventions and strategies for } \\
\text { disaster response. }\end{array}$ & $\begin{array}{l}\text { Indiana uses PFA that is } \\
\text { empirically informed by best } \\
\text { practices in the field of } \\
\text { disaster mental health. }\end{array}$ & $\mathrm{X}$ & \\
\hline & $\begin{array}{l}\text { The state has a certification } \\
\text { program in place to educate and } \\
\text { train professionals and can be } \\
\text { sanctioned or validated by } \\
\text { professional bodies or } \\
\text { organizations. }\end{array}$ & $\begin{array}{l}\text { There is a state registry and all } \\
\text { responders must be part of the } \\
\text { district disaster response teams } \\
\text { and be on their roster of team } \\
\text { members. Overseen by DMH } \\
\text { and trainings are mandated by } \\
\text { state. Very specific guidelines. }\end{array}$ & $X$ & \\
\hline 12. & $\begin{array}{l}\text { A process is evident for } \\
\text { collecting data on the response }\end{array}$ & $\begin{array}{l}\text { Use SAMHSA forms to } \\
\text { collect data during CCP. Does } \\
\text { not specifically in disaster } \\
\text { plan what is used for local } \\
\text { responses. }\end{array}$ & & $\mathrm{X}$ \\
\hline 13. & $\begin{array}{l}\text { A process is evident for } \\
\text { evaluating the response }\end{array}$ & $\begin{array}{l}\text { Use AAR for state, federal and } \\
\text { local responses. }\end{array}$ & $\mathrm{X}$ & \\
\hline 14. & $\begin{array}{l}\text { A process is evident for } \\
\text { conducting valid research to } \\
\text { improve prevention, assessment, } \\
\text { intervention, and treatment. }\end{array}$ & $\begin{array}{l}\text { IN does not collect its own } \\
\text { data. They collect data for } \\
\text { SAMHSA but do not plan the } \\
\text { study or get IRB approval. } \\
\text { They do get baseline data. }\end{array}$ & & $\mathrm{X}$ \\
\hline 15. & $\begin{array}{l}\text { An expert in research and } \\
\text { evaluation is obtained to aid in } \\
\text { the plan to develop the best } \\
\text { methods for date collection, } \\
\text { evaluation, and research. }\end{array}$ & No & & $\mathrm{X}$ \\
\hline 16. & $\begin{array}{l}\text { Existing Memorandum of } \\
\text { Understanding (MOU) exist } \\
\text { between federal, state, and local } \\
\text { authorities responsibly for } \\
\text { funding, planning, delivering, } \\
\text { and assessing the impact of early } \\
\text { intervention. }\end{array}$ & $\begin{array}{l}\text { P 32. Between state and } \\
\text { DMHA. ESF } 8 \text { umbrella. List } \\
\text { multiple organizations they } \\
\text { work with. }\end{array}$ & $\mathrm{X}$ & \\
\hline 17. & $\begin{array}{l}\text { Existing Memorandum of } \\
\text { Understanding (MOU) exist } \\
\text { between federal, state, and local } \\
\text { authorities responsibly for } \\
\text { funding, planning, delivering, } \\
\text { and assessing the impact of early } \\
\text { intervention to facilitate } \\
\text { systemic data collection, } \\
\text { evaluation, and research. }\end{array}$ & & & $\mathrm{X}$ \\
\hline
\end{tabular}




\begin{tabular}{|c|c|c|c|c|}
\hline & $\begin{array}{l}\text { Standard categories and } \\
\text { terminology has been developed } \\
\text { for program evaluation and } \\
\text { research. }\end{array}$ & & & $\mathrm{X}$ \\
\hline 19. & $\begin{array}{l}\text { A strategy has been outlined to } \\
\text { inform IRB's about research. }\end{array}$ & & & $\mathrm{X}$ \\
\hline 20. & $\begin{array}{l}\text { A strategy has been outlined to } \\
\text { inform the research community } \\
\text { about the necessity to conduct } \\
\text { research. }\end{array}$ & & & $\mathrm{X}$ \\
\hline 21. & $\begin{array}{l}\text { The plan outlines ways to } \\
\text { provide safety and security to } \\
\text { victims. }\end{array}$ & $\begin{array}{l}\text { Plan state initial response } \\
\text { relies on first responders, } \\
\text { Local response helps keep } \\
\text { people informed, shelters. P } \\
12\end{array}$ & $\mathrm{X}$ & \\
\hline 22. & $\begin{array}{l}\text { The plan outlines ways to } \\
\text { coordinate with agencies to } \\
\text { provide food and shelter. }\end{array}$ & $\begin{array}{l}\text { Coordinates with ARC and } \\
\text { Salvation Army to help with } \\
\text { food and shelter for victims. } \\
\text { Human support section. P } 26\end{array}$ & $X$ & \\
\hline 23. & $\begin{array}{l}\text { The plan outlines ways to orient } \\
\text { survivors on where to obtain } \\
\text { services and support }\end{array}$ & PFA, A\&R & $\mathrm{X}$ & \\
\hline 24. & $\begin{array}{l}\text { The plan outlines a way for } \\
\text { families to communicate with } \\
\text { friends, families, and the } \\
\text { community. }\end{array}$ & & & $\mathrm{X}$ \\
\hline 25. & $\begin{array}{l}\text { The plan outlines a way to assess } \\
\text { for ongoing threats in the } \\
\text { community. }\end{array}$ & $\begin{array}{l}\text { Needs assessment done locally } \\
\text { and at state level }\end{array}$ & $\mathrm{X}$ & \\
\hline 26. & $\begin{array}{l}\text { The plan outlines training in } \\
\text { Psychological First Aid for all } \\
\text { responders. }\end{array}$ & $\begin{array}{l}\text { Part of mandated training } \\
\text { response. }\end{array}$ & $X$ & \\
\hline 27. & $\begin{array}{l}\text { The plan outlines a way to assess } \\
\text { ongoing status of individuals, } \\
\text { groups, populations and a way to } \\
\text { disseminate interventions as } \\
\text { needed. }\end{array}$ & $\begin{array}{l}\text { P 24. Outlines constant } \\
\text { assessments, outreach in } \\
\text { DRC's, in community }\end{array}$ & $\mathrm{X}$ & \\
\hline 28. & $\begin{array}{l}\text { The plan outlines how } \\
\text { responders will observe and } \\
\text { listen to those most affected by } \\
\text { the disaster. }\end{array}$ & $\begin{array}{l}\text { PFA outlines behavioral } \\
\text { response }\end{array}$ & $\mathrm{X}$ & \\
\hline 29. & $\begin{array}{l}\text { The plan outlines ways to } \\
\text { monitor environment for toxins } \\
\text { and stressors }\end{array}$ & $\begin{array}{l}\text { Needs assessment throughout } \\
\text { the response. }\end{array}$ & $\mathrm{X}$ & \\
\hline 30. & $\begin{array}{l}\text { The plan outlines a way to } \\
\text { monitor past and ongoing threats }\end{array}$ & Needs assessments & $\mathrm{X}$ & \\
\hline 31. & $\begin{array}{l}\text { The plan outlines ways to } \\
\text { monitor services that are being } \\
\text { provided. }\end{array}$ & $\begin{array}{l}\text { Daily meetings, data } \\
\text { collection, feedback from } \\
\text { responders }\end{array}$ & $\mathrm{X}$ & \\
\hline 32. & $\begin{array}{l}\text { The plan outlines ways to } \\
\text { monitor media coverage and } \\
\text { rumors. }\end{array}$ & $\begin{array}{l}\text { Plan does mention that the } \\
\text { state will handle information } \\
\text { dissemination but does not } \\
\text { discuss media coverage in } \\
\text { detail. No mention of PIO. }\end{array}$ & & $\mathrm{X}$ \\
\hline 33. & The plan outlines how and what & Information is gathered and & & \\
\hline
\end{tabular}




\begin{tabular}{|c|c|c|c|}
\hline $\begin{array}{l}\text { information/educational } \\
\text { materials will be disseminated. }\end{array}$ & $\begin{array}{l}\text { held in a Library at DMHA. } \\
\text { Available to responders. P } 24\end{array}$ & $\mathrm{X}$ & \\
\hline $\begin{array}{l}\text { 34. The plan outlines ways to } \\
\text { disseminate information } \\
\text { including "therapy by walking } \\
\text { around". }\end{array}$ & $\begin{array}{l}\text { Outreach, part of CCP, part of } \\
\text { DDMHRT p } 47\end{array}$ & $\mathrm{X}$ & \\
\hline $\begin{array}{l}\text { 35. The plan outlines how and what } \\
\text { flyers will be distributed. }\end{array}$ & $\begin{array}{l}\text { The plan discusses a library of } \\
\text { information but does not } \\
\text { specify what flyers will be } \\
\text { handed out. Does identify } \\
\text { materials for dispersion }\end{array}$ & $\mathrm{X}$ & \\
\hline $\begin{array}{l}\text { 36. The plan outlines what websites } \\
\text { will be advertised. }\end{array}$ & $\begin{array}{l}\text { Not in plan. Does mention } \\
\text { electronic means but not in } \\
\text { detail. }\end{array}$ & & $X$ \\
\hline $\begin{array}{l}\text { 37. The plan outlines who will } \\
\text { conduct media interviews, } \\
\text { programs, and distribute media } \\
\text { releases. }\end{array}$ & P 24. No mention of PIO & & $\mathrm{X}$ \\
\hline $\begin{array}{l}\text { 38. The plan outlines a way to } \\
\text { provided assistance to relevant } \\
\text { organizations, other caregivers } \\
\text { and responders, and leaders. }\end{array}$ & PFA. & $\mathrm{X}$ & \\
\hline $\begin{array}{l}\text { 39. The plan outlines a way to } \\
\text { provided consultation to relevant } \\
\text { organizations, other caregivers } \\
\text { and responders, and leaders. }\end{array}$ & $\begin{array}{l}\text { FSSA, Dept. of Homeland } \\
\text { Security, Dept. of Health }\end{array}$ & $\mathrm{X}$ & \\
\hline $\begin{array}{l}\text { 40. The plan outlines a way to } \\
\text { provided training to relevant } \\
\text { organizations, other caregivers } \\
\text { and responders, and leaders. }\end{array}$ & $\begin{array}{l}\text { P 70. outlines what the } \\
\text { DMHA will do in regards to } \\
\text { training, outreach, to all } \\
\text { community, survivors, } \\
\text { responders, organizations }\end{array}$ & $\mathrm{X}$ & \\
\hline $\begin{array}{l}\text { 41. The plan includes coping skills } \\
\text { training. }\end{array}$ & PFA & $\mathrm{X}$ & \\
\hline $\begin{array}{l}\text { 42. The plan includes risk } \\
\text { assessment skills training. }\end{array}$ & $\begin{array}{l}\text { P } 67 \text { be able to assess } \\
\text { community needs, special } \\
\text { population training }\end{array}$ & $\mathrm{X}$ & \\
\hline $\begin{array}{l}\text { 43. The plan includes education on } \\
\text { stress responses, traumatic } \\
\text { reminders, coping, normal } \\
\text { versus abnormal functioning, } \\
\text { risk factors and services. }\end{array}$ & PFA. P 13 & $\mathrm{X}$ & \\
\hline $\begin{array}{l}\text { 44. The plan includes education on } \\
\text { stress responses. }\end{array}$ & P 13 point 4 & $X$ & \\
\hline $\begin{array}{l}\text { 45. The plan includes education on } \\
\text { traumatic reminders. }\end{array}$ & P 13 point 2 & $X$ & \\
\hline $\begin{array}{l}\text { 46. The plan includes education on } \\
\text { normal versus abnormal } \\
\text { functioning. }\end{array}$ & P 13 yes & $\mathrm{X}$ & \\
\hline $\begin{array}{l}\text { 47. The plan includes education on } \\
\text { risk factors. }\end{array}$ & P 13 point 1 & $X$ & \\
\hline $\begin{array}{l}\text { 48. The plan includes education on } \\
\text { services available. }\end{array}$ & P 13 PFA & $X$ & \\
\hline 49. The plan includes referrals to & CCP, PFA & & \\
\hline
\end{tabular}




\begin{tabular}{|c|c|c|c|c|}
\hline & specialized services if necessary. & & $\mathrm{X}$ & \\
\hline & $\begin{array}{l}\text { The plan includes offering } \\
\text { family and group interventions. }\end{array}$ & PFA & $\mathrm{X}$ & \\
\hline & $\begin{array}{l}\text { The plan includes repairing } \\
\text { community infrastructure. }\end{array}$ & $\begin{array}{l}\text { Does not obviously say } \\
\text { repairing infrastructure. }\end{array}$ & & $X$ \\
\hline & $\begin{array}{l}\text { The plan outlines the use of } \\
\text { clinical assessments using valid } \\
\text { and reliable methods. }\end{array}$ & & & $\mathrm{X}$ \\
\hline & $\begin{array}{l}\text { The plan outlines the use of } \\
\text { emergency hospitalization as } \\
\text { needed. }\end{array}$ & PFA & $X$ & \\
\hline & $\begin{array}{l}\text { The plan outlines treatment for } \\
\text { individuals that will reduce } \\
\text { symptoms or improve } \\
\text { functioning via psychotherapy } \\
\text { and pharmacotherapy. }\end{array}$ & $\begin{array}{l}\text { Referral to CMHC, outline } \\
\text { about services that area } \\
\text { available. Part of PFA and } \\
\text { CCP }\end{array}$ & $X$ & \\
\hline 55. & $\begin{array}{l}\text { The plan outlines ways to } \\
\text { promotes self-efficacy and } \\
\text { collective efficacy. This may be } \\
\text { completed by community based } \\
\text { intervention services. (Hobfoll et } \\
\text { al., 2007) }\end{array}$ & $\begin{array}{l}\text { Use community based services } \\
\text { that rely on people to perform } \\
\text { to their ability. }\end{array}$ & $\mathrm{X}$ & \\
\hline & $\begin{array}{l}\text { The plan outlines ways to instill } \\
\text { hope in the affected by the } \\
\text { disaster. (Hobfoll et al., 2007) }\end{array}$ & Not mentioned specifically. & & $\mathrm{X}$ \\
\hline 57. & $\begin{array}{l}\text { The plan outlines ways to } \\
\text { promote calm in the individuals } \\
\text { and community affected. This } \\
\text { may be done by controlling } \\
\text { information dissemination. } \\
\text { (Hobfoll et al., 2007) }\end{array}$ & $\begin{array}{l}\text { None identified. State does } \\
\text { disseminate info but not PIO is } \\
\text { used in this plan. }\end{array}$ & & $\mathrm{X}$ \\
\hline & $\begin{array}{l}\text { The plan outlines training that } \\
\text { progresses responses throughout } \\
\text { the disaster process. (Elrod, } \\
\text { Hamblen, \& Norris, 2006) }\end{array}$ & $\begin{array}{l}\text { Extremely detailed in this } \\
\text { area. List of what needs to be } \\
\text { done in each phase and who } \\
\text { will do it. }\end{array}$ & $X$ & \\
\hline 59. & $\begin{array}{l}\text { Program manuals that contain } \\
\text { definitions and clarity of } \\
\text { outreach, counseling, and } \\
\text { referral are available. (Elrod, } \\
\text { Hamblen, \& Norris, 2006) }\end{array}$ & $\begin{array}{l}\text { No program manuals } \\
\text { mentioned in the plan } \\
\text { Although they are available to } \\
\text { state responders. They do have } \\
\text { definitions in their state plan. }\end{array}$ & & $\mathrm{X}$ \\
\hline
\end{tabular}

Score: $43 / 59=73 \%$ 


\title{
Appendix E- Best Practices Evaluation Sheet - Kansas
}

\author{
Best Practices of Disaster Mental Health Response
}

Kansas

The following is a legend of the themes of best practices. Each best practice category is highlighted in a specific color to help identify the category.

$\begin{array}{ll}\text { Mental Health Screening } & \text { Green } \\ \text { Needs Assessment best practices } & \text { Gray } \\ \text { Follow Up Contact } & \text { Red } \\ \text { Disaster Mental Health Training and Response } & \text { Purple } \\ \text { Research and Data Collection } & \text { Orange } \\ \text { External Organizations } & \text { Royal blue } \\ \text { Information Dissemination } & \text { Merlot } \\ \text { Training Across the Response Timeline } & \text { Black }\end{array}$

\begin{tabular}{|c|c|c|c|c|}
\hline & Best Practice Procedure & Comments & Compliant & $\begin{array}{c}\text { Non- } \\
\text { compliant }\end{array}$ \\
\hline 1. & $\begin{array}{l}\text { A screening tool is used to identify } \\
\text { individuals or groups that are } \\
\text { considered high risk for PTSD }\end{array}$ & $\begin{array}{l}\text { None identified. Part of Crisis } \\
\text { Counseling Program when } \\
\text { program is running. }\end{array}$ & & $X$ \\
\hline 2. & $\begin{array}{l}\text { A needs assessment is completed } \\
\text { to determine what each individual } \\
\text { or community requires for meeting } \\
\text { basic demands. }\end{array}$ & $\begin{array}{l}\text { Done by Community Mental } \\
\text { Health Center for each area. }\end{array}$ & $\mathrm{X}$ & \\
\hline 3. & $\begin{array}{l}\text { Follow up contact is offered to } \\
\text { those who have been identified as } \\
\text { having ASD (Acute Stress } \\
\text { Disorder) or clinically significant } \\
\text { symptoms stemming from the } \\
\text { trauma. }\end{array}$ & & & $\mathrm{X}$ \\
\hline & $\begin{array}{l}\text { Follow up contact is offered to } \\
\text { those who are bereaved. }\end{array}$ & & & $X$ \\
\hline & $\begin{array}{l}\text { Follow up contact is offered to } \\
\text { those who have pre-existing } \\
\text { psychiatric disorders. }\end{array}$ & & & $X$ \\
\hline & $\begin{array}{l}\text { Follow up contact is offered to } \\
\text { those who have required medical } \\
\text { attention }\end{array}$ & & & $X$ \\
\hline & $\begin{array}{l}\text { Follow up contact is offered to } \\
\text { those whose exposure to the event } \\
\text { was intense and a prolonged } \\
\text { duration }\end{array}$ & & & $\mathrm{X}$ \\
\hline
\end{tabular}




\begin{tabular}{|c|c|c|c|c|}
\hline & $\begin{array}{l}\text { Follow up contact is offered to } \\
\text { those who request it. }\end{array}$ & & & $X$ \\
\hline 9. & $\begin{array}{l}\text { Quality assurance reviews are } \\
\text { completed by the state to ensure } \\
\text { that helpers have the proper } \\
\text { documentation to certify that they } \\
\text { have the appropriate credentials } \\
\text { and expertise/experience. }\end{array}$ & $\begin{array}{l}\text { No review of responder } \\
\text { training }\end{array}$ & & $X$ \\
\hline 10. & $\begin{array}{l}\text { Responders are required to provide } \\
\text { proof of empirically defensible } \\
\text { training that confers competence in } \\
\text { specific interventions and } \\
\text { strategies for disaster response. }\end{array}$ & None at this time. & & $\mathrm{X}$ \\
\hline 11. & $\begin{array}{l}\text { The state has a certification } \\
\text { program in place to educate and } \\
\text { train professionals and can be } \\
\text { sanctioned or validated by } \\
\text { professional bodies or } \\
\text { organizations. }\end{array}$ & & & $\mathrm{X}$ \\
\hline 12. & $\begin{array}{l}\text { A process is evident for collecting } \\
\text { data on the response }\end{array}$ & $\begin{array}{l}\text { During Crisis Counseling } \\
\text { Program but not during local } \\
\text { responses. }\end{array}$ & & $\mathrm{X}$ \\
\hline 13. & $\begin{array}{l}\text { A process is evident for evaluating } \\
\text { the response }\end{array}$ & $\begin{array}{l}\text { P } 35 \text { evaluation and implement } \\
\text { revisions }\end{array}$ & $X$ & \\
\hline 14. & $\begin{array}{l}\text { A process is evident for conducting } \\
\text { valid research to improve } \\
\text { prevention, assessment, } \\
\text { intervention, and treatment. }\end{array}$ & & & $\mathrm{X}$ \\
\hline 15. & $\begin{array}{l}\text { An expert in research and } \\
\text { evaluation is obtained to aid in the } \\
\text { plan to develop the best methods } \\
\text { for date collection, evaluation, and } \\
\text { research. }\end{array}$ & & & $\mathrm{X}$ \\
\hline 16. & $\begin{array}{l}\text { Existing Memorandum of } \\
\text { Understanding (MOU) exist } \\
\text { between federal, state, and local } \\
\text { authorities responsibly for funding, } \\
\text { planning, delivering, and assessing } \\
\text { the impact of early intervention. }\end{array}$ & Mutual Aid agreements & $\mathrm{X}$ & \\
\hline 17. & $\begin{array}{l}\text { Existing Memorandum of } \\
\text { Understanding (MOU) exist } \\
\text { between federal, state, and local } \\
\text { authorities responsibly for funding, } \\
\text { planning, delivering, and assessing } \\
\text { the impact of early intervention to } \\
\text { facilitate systemic data collection, } \\
\text { evaluation, and research. }\end{array}$ & & & $\mathrm{X}$ \\
\hline 18. & $\begin{array}{l}\text { Standard categories and } \\
\text { terminology has been developed } \\
\text { for program evaluation and } \\
\text { research. }\end{array}$ & & & $\mathrm{X}$ \\
\hline 19. & $\begin{array}{l}\text { A strategy has been outlined to } \\
\text { inform IRB's about research. }\end{array}$ & & & $X$ \\
\hline 20. & A strategy has been outlined to & & & \\
\hline
\end{tabular}




\begin{tabular}{|c|c|c|c|c|}
\hline & $\begin{array}{l}\text { inform the research community } \\
\text { about the necessity to conduct } \\
\text { research. }\end{array}$ & & & $\mathrm{X}$ \\
\hline & $\begin{array}{l}\text { The plan outlines ways to provide } \\
\text { safety and security to victims. }\end{array}$ & $\begin{array}{l}\text { Monitor environment, use of } \\
\text { Public Safety Officer. Not in } \\
\text { local response although. }\end{array}$ & & $\mathrm{X}$ \\
\hline 22. & $\begin{array}{l}\text { The plan outlines ways to } \\
\text { coordinate with agencies to } \\
\text { provide food and shelter. }\end{array}$ & $\begin{array}{l}\text { Strong relationship with ARC } \\
\text { and shelter response. Not } \\
\text { mandated in local responses. }\end{array}$ & & $\mathrm{X}$ \\
\hline 23. & $\begin{array}{l}\text { The plan outlines ways to orient } \\
\text { survivors on where to obtain } \\
\text { services and support }\end{array}$ & $\begin{array}{l}\text { During a declarations response } \\
\text { yes but during local response } \\
\text { no. The Community Mental } \\
\text { Health Center's are not } \\
\text { required to respond or have a } \\
\text { disaster plan in place. }\end{array}$ & & $\mathrm{X}$ \\
\hline 24. & $\begin{array}{l}\text { The plan outlines a way for } \\
\text { families to communicate with } \\
\text { friends, families, and the } \\
\text { community. }\end{array}$ & $\begin{array}{l}\text { This plan outlines the need to } \\
\text { keep families together and } \\
\text { stresses the need for } \\
\text { relationship post disaster. P } 22\end{array}$ & $X$ & \\
\hline 25. & $\begin{array}{l}\text { The plan outlines a way to assess } \\
\text { for ongoing threats in the } \\
\text { community. }\end{array}$ & Public Safety officer. P 38 & $X$ & \\
\hline 26. & $\begin{array}{l}\text { The plan outlines training in } \\
\text { Psychological First Aid for all } \\
\text { responders. }\end{array}$ & & & $\mathrm{X}$ \\
\hline 27. & $\begin{array}{l}\text { The plan outlines a way to assess } \\
\text { ongoing status of individuals, } \\
\text { groups, populations and a way to } \\
\text { disseminate interventions as } \\
\text { needed. }\end{array}$ & $\begin{array}{l}\text { Needs assessments, outreach, } \\
\text { and non-traditional methods of } \\
\text { info dissemination not } \\
\text { mandated in local responses. }\end{array}$ & & $\mathrm{X}$ \\
\hline 28. & $\begin{array}{l}\text { The plan outlines how responders } \\
\text { will observe and listen to those } \\
\text { most affected by the disaster. }\end{array}$ & & & $\mathrm{X}$ \\
\hline 29. & $\begin{array}{l}\text { The plan outlines ways to monitor } \\
\text { environment for toxins and } \\
\text { stressors }\end{array}$ & $\begin{array}{l}\text { Ongoing needs assessment in } \\
\text { the field by Community Mental } \\
\text { Health Center's, those in the } \\
\text { field. Other state agencies. Not } \\
\text { in local response plan. }\end{array}$ & & $\mathrm{X}$ \\
\hline 30. & $\begin{array}{l}\text { The plan outlines a way to monitor } \\
\text { past and ongoing threats }\end{array}$ & $\begin{array}{l}\text { Public Safety Officer. P. } 38 . \\
\text { Only for larger response—-not } \\
\text { local. }\end{array}$ & & $\mathrm{X}$ \\
\hline 31. & $\begin{array}{l}\text { The plan outlines ways to monitor } \\
\text { services that are being provided. }\end{array}$ & $\begin{array}{l}\text { During Crisis Counseling } \\
\text { Program yes but not during } \\
\text { local responses. }\end{array}$ & & $\mathrm{X}$ \\
\hline 32. & $\begin{array}{l}\text { The plan outlines ways to monitor } \\
\text { media coverage and rumors. }\end{array}$ & Public Safety Officer. P 39 & $X$ & \\
\hline 33. & $\begin{array}{l}\text { The plan outlines how and what } \\
\text { information/educational materials } \\
\text { will be disseminated. }\end{array}$ & $\begin{array}{l}\text { P 36. Information will be } \\
\text { gathered by K-state }\end{array}$ & $X$ & \\
\hline 34. & $\begin{array}{l}\text { The plan outlines ways to } \\
\text { disseminate information including } \\
\text { "therapy by walking around". }\end{array}$ & $\begin{array}{l}\text { Non-traditional methods and } \\
\text { locations. P } 21\end{array}$ & $\mathrm{X}$ & \\
\hline 35. & $\begin{array}{l}\text { The plan outlines how and what } \\
\text { flyers will be distributed. }\end{array}$ & $\begin{array}{l}\text { P } 36 \& 37 \text { Resources will be } \\
\text { available through Kansas All- }\end{array}$ & $\mathrm{X}$ & \\
\hline
\end{tabular}




\begin{tabular}{|c|c|c|c|}
\hline & Hazards Behavioral Health & & \\
\hline $\begin{array}{l}\text { 36. The plan outlines what websites } \\
\text { will be advertised. }\end{array}$ & None mentioned in plan. & & $X$ \\
\hline $\begin{array}{l}\text { 37. The plan outlines who will conduct } \\
\text { media interviews, programs, and } \\
\text { distribute media releases. }\end{array}$ & Public Safety Officer P 39 & $\mathrm{X}$ & \\
\hline $\begin{array}{l}\text { 38. The plan outlines a way to } \\
\text { provided assistance to relevant } \\
\text { organizations, other caregivers and } \\
\text { responders, and leaders. } \\
\end{array}$ & Mutual Aid response & $\mathrm{X}$ & \\
\hline $\begin{array}{l}\text { 39. The plan outlines a way to } \\
\text { provided consultation to relevant } \\
\text { organizations, other caregivers and } \\
\text { responders, and leaders. }\end{array}$ & Not outlined & & $\mathrm{X}$ \\
\hline $\begin{array}{l}\text { 40. The plan outlines a way to } \\
\text { provided training to relevant } \\
\text { organizations, other caregivers and } \\
\text { responders, and leaders. }\end{array}$ & Not outlined & & $\mathrm{X}$ \\
\hline $\begin{array}{l}\text { 41. The plan includes coping skills } \\
\text { training. }\end{array}$ & $\begin{array}{l}\text { P 18. Mentions coping skills } \\
\text { but would not term it training. }\end{array}$ & & $\mathrm{X}$ \\
\hline $\begin{array}{l}\text { 42. The plan includes risk assessment } \\
\text { skills training. }\end{array}$ & $\begin{array}{l}\text { Aspects of risk behaviors but } \\
\text { not enough for formal training. }\end{array}$ & & $\mathrm{X}$ \\
\hline $\begin{array}{l}\text { 43. The plan includes education on } \\
\text { stress responses, traumatic } \\
\text { reminders, coping, normal versus } \\
\text { abnormal functioning, risk factors } \\
\text { and services. }\end{array}$ & $\begin{array}{l}\text { P } 18 \text { has some education on } \\
\text { this in the plan. }\end{array}$ & $\mathrm{X}$ & \\
\hline $\begin{array}{l}\text { 44. The plan includes education on } \\
\text { stress responses. }\end{array}$ & Examples. P 18-19 & $\mathrm{X}$ & \\
\hline $\begin{array}{l}\text { 45. The plan includes education on } \\
\text { traumatic reminders. }\end{array}$ & $\begin{array}{l}\text { Criteria, anniversary } \\
\text { highlighted. }\end{array}$ & X & \\
\hline $\begin{array}{l}\text { 46. The plan includes education on } \\
\text { normal versus abnormal } \\
\text { functioning. }\end{array}$ & P 19 & $\mathrm{X}$ & \\
\hline $\begin{array}{l}\text { 47. The plan includes education on } \\
\text { risk factors. }\end{array}$ & $\begin{array}{l}\text { More clinically based. Easy to } \\
\text { understand this clinical section. } \\
\text { Good examples that can be } \\
\text { understood to responders. }\end{array}$ & $\mathrm{X}$ & \\
\hline $\begin{array}{l}\text { 48. The plan includes education on } \\
\text { services available. }\end{array}$ & $\begin{array}{l}\text { For local response this is left } \\
\text { up to Community Mental } \\
\text { Health Center's } \\
\text { recommendations made of } \\
\text { what they should do, no } \\
\text { mandate. During Crisis } \\
\text { Counseling Program this would } \\
\text { be available. }\end{array}$ & & $\mathrm{X}$ \\
\hline $\begin{array}{l}\text { 49. The plan includes referrals to } \\
\text { specialized services if necessary. }\end{array}$ & $\begin{array}{l}\text { Explains expectation of normal } \\
\text { recovery and that some will } \\
\text { need more formal therapeutic } \\
\text { services. }\end{array}$ & $\mathrm{X}$ & \\
\hline $\begin{array}{l}\text { 50. The plan includes offering family } \\
\text { and group interventions. }\end{array}$ & $\begin{array}{l}\text { Mentions family on several } \\
\text { occasions. P } 7\end{array}$ & X & \\
\hline 51. The plan includes repairing & P 7. Very impressed about & & \\
\hline
\end{tabular}




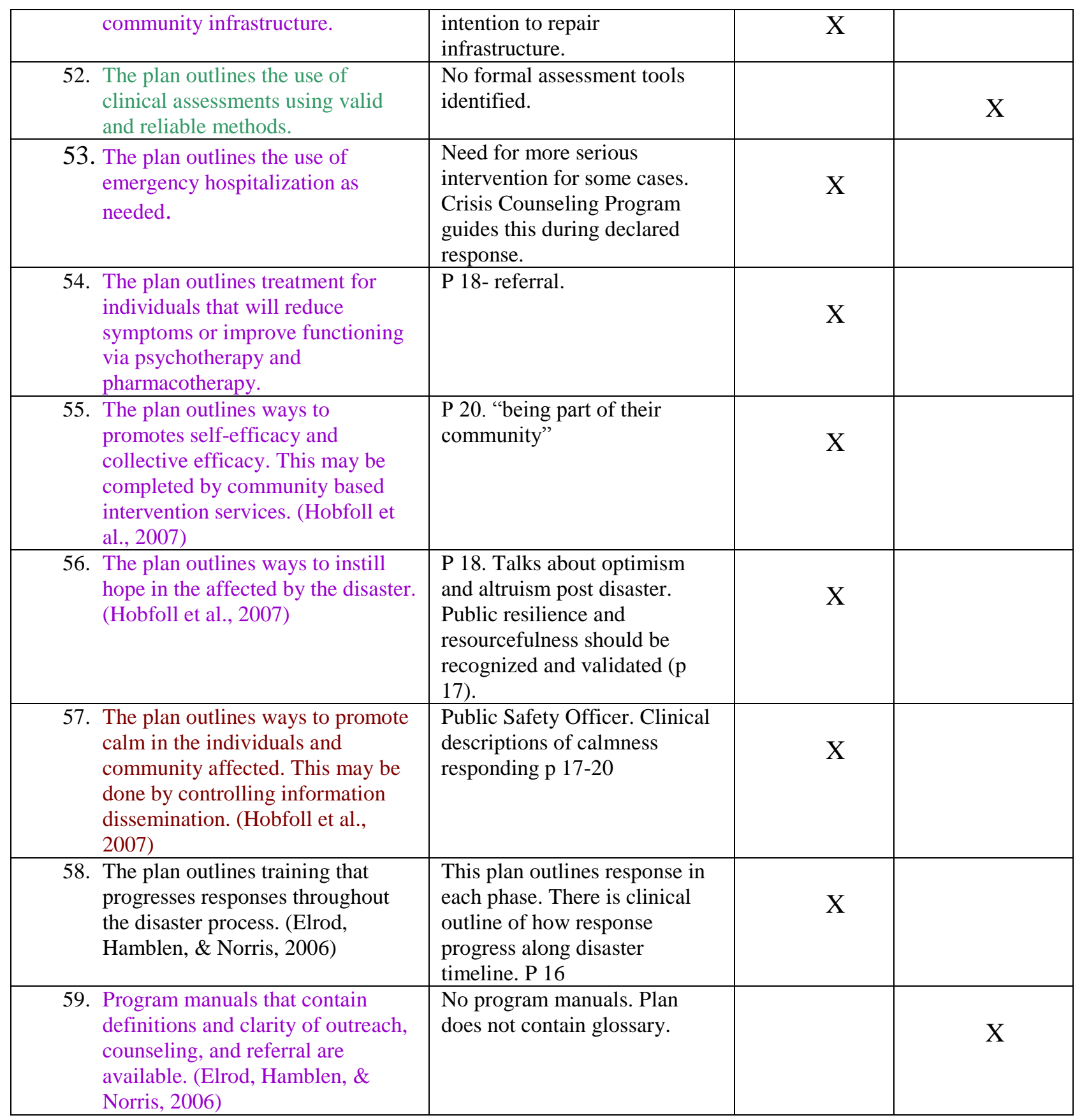

Score $30 / 59=51 \%$ 


\title{
Appendix F- Best Practices Evaluation Sheet - Mississippi
}

\author{
Best Practices of Disaster Mental Health Response \\ Mississippi
}

The following is a legend of the themes of best practices. Each best practice category is highlighted in a specific color to help identify the category.

$\begin{array}{ll}\text { Mental Health Screening } & \text { Green } \\ \text { Needs Assessment best practices } & \text { Gray } \\ \text { Follow Up Contact } & \text { Red } \\ \text { Disaster Mental Health Training and Response } & \text { Purple } \\ \text { Research and Data Collection } & \text { Orange } \\ \text { External Organizations } & \text { Royal blue } \\ \text { Information Dissemination } & \text { Merlot } \\ \text { Training Across the Response Timeline } & \text { Black }\end{array}$

\begin{tabular}{|c|c|c|c|c|}
\hline & Best Practice Procedure & Comments & Compliant & $\begin{array}{c}\text { Non- } \\
\text { compliant }\end{array}$ \\
\hline 1. & $\begin{array}{l}\text { A screening tool is used to identify } \\
\text { individuals or groups that are } \\
\text { considered high risk for PTSD }\end{array}$ & $\begin{array}{l}\text { During CCP- ISP or RSP. } \\
\text { Not for local responses. }\end{array}$ & & $X$ \\
\hline 2. & $\begin{array}{l}\text { A needs assessment is completed } \\
\text { to determine what each individual } \\
\text { or community requires for meeting } \\
\text { basic demands. }\end{array}$ & $\begin{array}{l}\text { A needs assessment is } \\
\text { completed by CMHC's } \\
\text { and state can help if } \\
\text { needed. }\end{array}$ & $X$ & \\
\hline 3. & $\begin{array}{l}\text { Follow up contact is offered to } \\
\text { those who have been identified as } \\
\text { having ASD (Acute Stress } \\
\text { Disorder) or clinically significant } \\
\text { symptoms stemming from the } \\
\text { trauma. }\end{array}$ & & & $X$ \\
\hline 4. & $\begin{array}{l}\text { Follow up contact is offered to } \\
\text { those who are bereaved. }\end{array}$ & & & $X$ \\
\hline & $\begin{array}{l}\text { Follow up contact is offered to } \\
\text { those who have pre-existing } \\
\text { psychiatric disorders. }\end{array}$ & & & $\mathrm{X}$ \\
\hline 6 . & $\begin{array}{l}\text { Follow up contact is offered to } \\
\text { those who have required medical } \\
\text { attention }\end{array}$ & & & $X$ \\
\hline 7. & $\begin{array}{l}\text { Follow up contact is offered to } \\
\text { those whose exposure to the event } \\
\text { was intense and a prolonged } \\
\text { duration }\end{array}$ & & & $\mathrm{X}$ \\
\hline 8. & Follow up contact is offered to & & & \\
\hline
\end{tabular}




\begin{tabular}{|c|c|c|c|c|}
\hline & those who request it. & & & $\mathrm{X}$ \\
\hline & $\begin{array}{l}\text { Quality assurance reviews are } \\
\text { completed by the state to ensure } \\
\text { that helpers have the proper } \\
\text { documentation to certify that they } \\
\text { have the appropriate credentials } \\
\text { and expertise/experience. }\end{array}$ & $\begin{array}{l}\text { No training program in } \\
\text { plan. }\end{array}$ & & $\mathrm{X}$ \\
\hline & $\begin{array}{l}\text { Responders are required to provide } \\
\text { proof of empirically defensible } \\
\text { training that confers competence in } \\
\text { specific interventions and } \\
\text { strategies for disaster response. }\end{array}$ & & & $\mathrm{X}$ \\
\hline & $\begin{array}{l}\text { The state has a certification } \\
\text { program in place to educate and } \\
\text { train professionals and can be } \\
\text { sanctioned or validated by } \\
\text { professional bodies or } \\
\text { organizations. }\end{array}$ & & & $\mathrm{X}$ \\
\hline & $\begin{array}{l}\text { A process is evident for collecting } \\
\text { data on the response }\end{array}$ & & & $X$ \\
\hline 13. & $\begin{array}{l}\text { A process is evident for evaluating } \\
\text { the response }\end{array}$ & & & $\mathrm{X}$ \\
\hline 14. & $\begin{array}{l}\text { A process is evident for conducting } \\
\text { valid research to improve } \\
\text { prevention, assessment, } \\
\text { intervention, and treatment. }\end{array}$ & & & $\mathrm{X}$ \\
\hline 15. & $\begin{array}{l}\text { An expert in research and } \\
\text { evaluation is obtained to aid in the } \\
\text { plan to develop the best methods } \\
\text { for date collection, evaluation, and } \\
\text { research. }\end{array}$ & & & $X$ \\
\hline 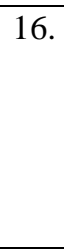 & $\begin{array}{l}\text { Existing Memorandum of } \\
\text { Understanding (MOU) exist } \\
\text { between federal, state, and local } \\
\text { authorities responsibly for funding, } \\
\text { planning, delivering, and assessing } \\
\text { the impact of early intervention. }\end{array}$ & P 7. & $\mathrm{X}$ & \\
\hline & $\begin{array}{l}\text { Existing Memorandum of } \\
\text { Understanding (MOU) exist } \\
\text { between federal, state, and local } \\
\text { authorities responsibly for funding, } \\
\text { planning, delivering, and assessing } \\
\text { the impact of early intervention to } \\
\text { facilitate systemic data collection, } \\
\text { evaluation, and research. }\end{array}$ & & & $\mathrm{X}$ \\
\hline 18. & $\begin{array}{l}\text { Standard categories and } \\
\text { terminology has been developed } \\
\text { for program evaluation and } \\
\text { research. }\end{array}$ & & & $\mathrm{X}$ \\
\hline & $\begin{array}{l}\text { A strategy has been outlined to } \\
\text { inform IRB's about research. }\end{array}$ & & & X \\
\hline 20. & $\begin{array}{l}\text { A strategy has been outlined to } \\
\text { inform the research community } \\
\text { about the necessity to conduct }\end{array}$ & & & $\mathrm{X}$ \\
\hline
\end{tabular}




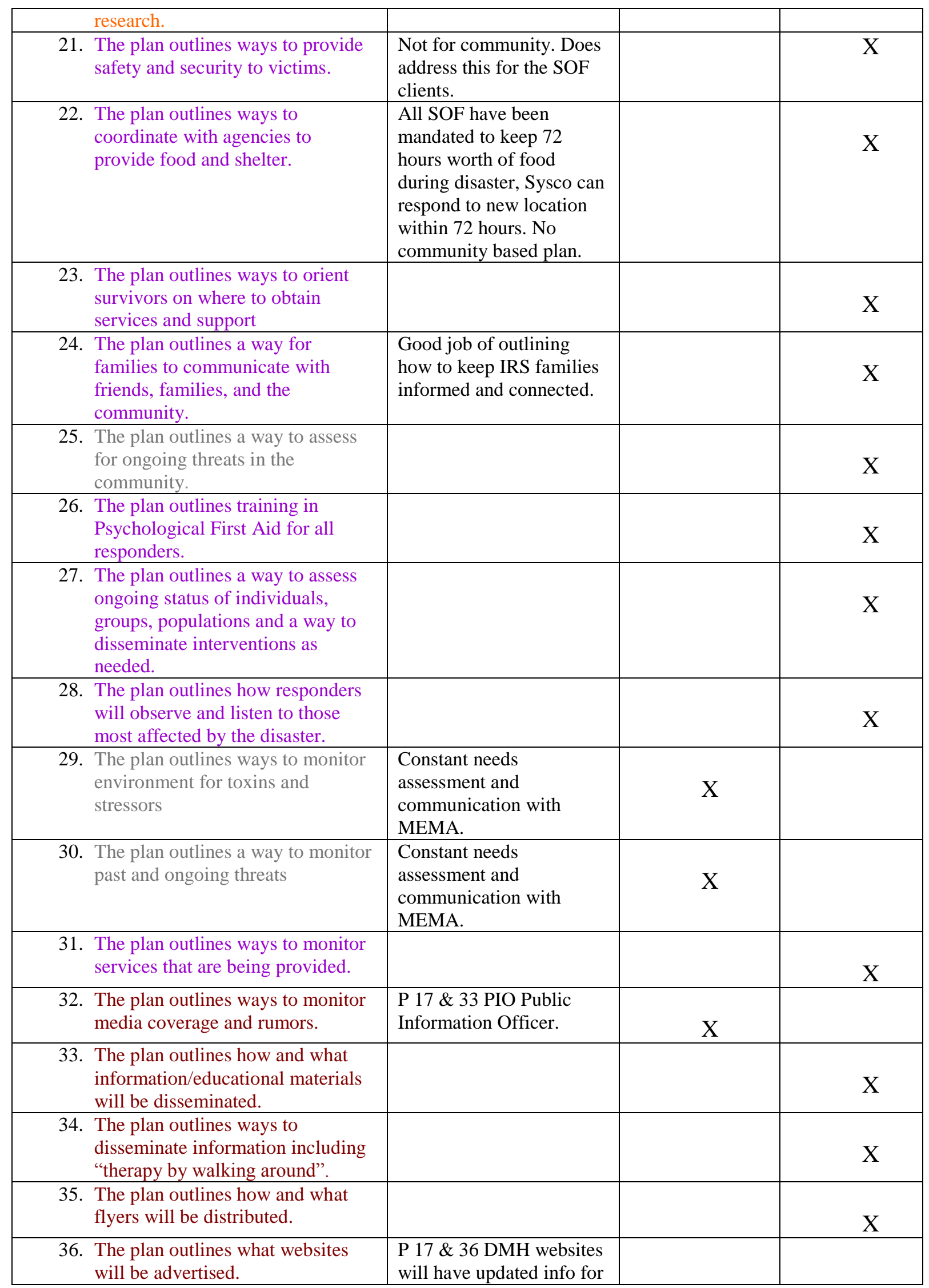




\begin{tabular}{|c|c|c|c|}
\hline & $\begin{array}{l}\text { the community and } \\
\text { families. }\end{array}$ & $\mathrm{X}$ & \\
\hline $\begin{array}{l}\text { 37. The plan outlines who will conduct } \\
\text { media interviews, programs, and } \\
\text { distribute media releases. }\end{array}$ & PIO P $17 \& 33$ & $\mathrm{X}$ & \\
\hline $\begin{array}{l}\text { 38. The plan outlines a way to } \\
\text { provided assistance to relevant } \\
\text { organizations, other caregivers and } \\
\text { responders, and leaders. }\end{array}$ & & & $\mathrm{X}$ \\
\hline $\begin{array}{l}\text { 39. The plan outlines a way to } \\
\text { provided consultation to relevant } \\
\text { organizations, other caregivers and } \\
\text { responders, and leaders. }\end{array}$ & & & $\mathrm{X}$ \\
\hline $\begin{array}{l}\text { 40. The plan outlines a way to } \\
\text { provided training to relevant } \\
\text { organizations, other caregivers and } \\
\text { responders, and leaders. }\end{array}$ & & & $\mathrm{X}$ \\
\hline $\begin{array}{l}\text { 41. The plan includes coping skills } \\
\text { training. }\end{array}$ & & & $\mathrm{X}$ \\
\hline $\begin{array}{l}\text { 42. The plan includes risk assessment } \\
\text { skills training. }\end{array}$ & & & X \\
\hline $\begin{array}{l}\text { 43. The plan includes education on } \\
\text { stress responses, traumatic } \\
\text { reminders, coping, normal versus } \\
\text { abnormal functioning, risk factors } \\
\text { and services. }\end{array}$ & & & $\mathrm{X}$ \\
\hline $\begin{array}{l}\text { 44. The plan includes education on } \\
\text { stress responses. }\end{array}$ & & & X \\
\hline $\begin{array}{l}\text { 45. The plan includes education on } \\
\text { traumatic reminders. }\end{array}$ & & & $X$ \\
\hline $\begin{array}{l}\text { 46. The plan includes education on } \\
\text { normal versus abnormal } \\
\text { functioning. }\end{array}$ & & & $\mathrm{X}$ \\
\hline $\begin{array}{l}\text { 47. The plan includes education on } \\
\text { risk factors. }\end{array}$ & & & $X$ \\
\hline $\begin{array}{l}\text { 48. The plan includes education on } \\
\text { services available. }\end{array}$ & & & X \\
\hline $\begin{array}{l}\text { 49. The plan includes referrals to } \\
\text { specialized services if necessary. }\end{array}$ & & & X \\
\hline $\begin{array}{l}\text { 50. The plan includes offering family } \\
\text { and group interventions. }\end{array}$ & & & X \\
\hline $\begin{array}{l}\text { 51. The plan includes repairing } \\
\text { community infrastructure. }\end{array}$ & & & X \\
\hline $\begin{array}{l}\text { 52. The plan outlines the use of } \\
\text { clinical assessments using valid } \\
\text { and reliable methods. }\end{array}$ & & & $\mathrm{X}$ \\
\hline $\begin{array}{l}\text { 53. The plan outlines the use of } \\
\text { emergency hospitalization as } \\
\text { needed. }\end{array}$ & & & $\mathrm{X}$ \\
\hline $\begin{array}{l}\text { 54. The plan outlines treatment for } \\
\text { individuals that will reduce }\end{array}$ & & & X \\
\hline
\end{tabular}




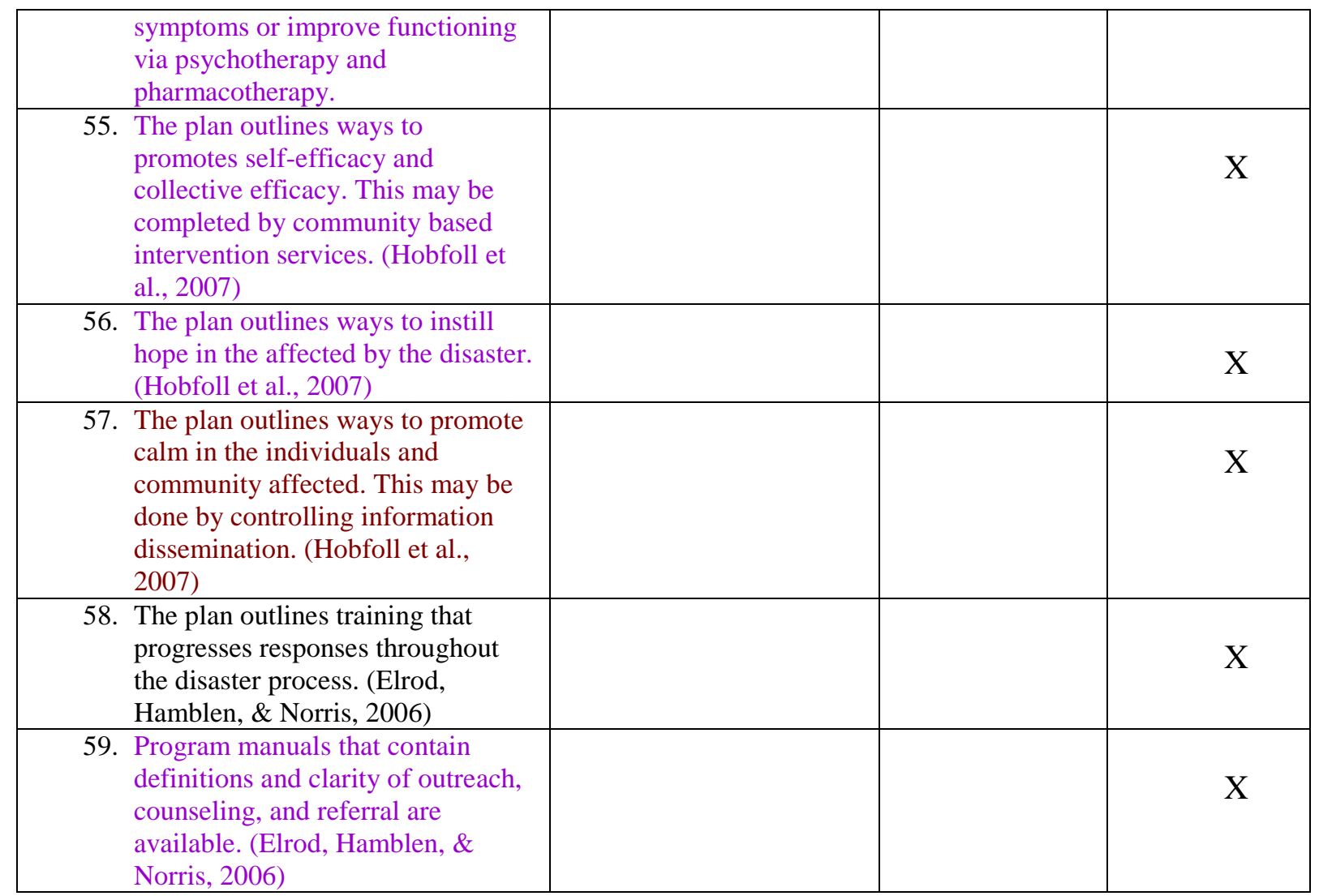

Score $7 / 59=12 \%$ 


\section{References}

American Psychiatric Association (2000). Diagnostic and statistical manual of mental disorders ( $4^{\text {th }}$ ed., Text Revision). Washington, DC: Author.

Antonovsky, A. (1979). Health stress and coping. San Francisco: Josey-Bass.

Apanovitch, A. M., Hobfoll, S E., \& Salovey, P. (2002). The effects of social influence on perceptual and affective reactions to scenes of sexual violence. Journal of Applied Social Psychology, 32(3), 443-464.

Arata, C., Picou, J., Johnson, G., \& McNally, T. (2000). Coping with a technological disaster: An application of the conservation of resources model to Exxon Valdez oil spill. Journal of Traumatic Stress, 13(1), 23-29.

Archives of General Psychiatry (2005). Psychopathology among New York City public school children 6 months after September 11. Arch General Psychiatry, 62, 545-551.

Bassuk, E. L., Mickelson, K. D., \& Perloff, J. N. (2002). Role of kin and non-kin support in the mental health of low-income women. American Journal of Orthopsychiatry, 72(2), $39-49$.

Becker, S. M. (2007). Psychosocial care for adult and child survivors of the tsunami disaster in India. Journal of Child and Adolescent Psychiatric Nursing, 20(3), 148-155.

Benight, C. C. (2004). Collective efficacy following a series of natural disasters. Anxiety, Stress, and Coping, 17(4), 401-420.

Benight, C. C., \& Harper, M. L. (2002). Coping self-efficacy perceptions as a mediator between acute stress response and long-term distress following natural disasters. Journal of Traumatic Stress, 15(3), 177-186.

Biglan, A. C., \& Craker, D. (1982). Effects of pleasant-activities manipulation on depression. Journal of Consulting and Clinical Psychology, 50, 436-438.

Bledsoe, B. E. (2003). EMS Myth \#3: Critical incident stress management (CSIM) is effective in managing EMS-related stress. Accessed October 12, 2008. www.publicsafety.com/article/article.jsp?id=2026\&siteSection=8

Bleich, A., Gelkopf, M., \& Solomon, Z. (2003). Exposure to terrorism, stress-related mental health symptoms, and coping behaviors among a nationally representative sample in Israel. Journal of the American Medical Association, 290(5), 612-620.

Borja, S., Callahan, J. L., \& Long, P. J. (2006). Positive and negative adjustment and social support of sexual assault survivors. Journal of Traumatic Stress, 19(6), 905-914. 
Bryant, R. A., Harvey, A. G., Guthrie, R. M., \& Moulds, M. L. (2003). Acute psychophysiological arousal and posttraumatic stress disorder: A two-year prospective study. Journal of Traumatic Stress, 16(5), 439-443.

Bulling, D. J. (2006). Prayed up: A qualitative exploration of disaster chaplaincy. Ph.D. dissertation, The University of Nebraska, United States: Nebraska. Retrieved September 16, 2008, from ProQuest (Publication No. 3233743).

Burnham, J. (2007). Children's fears: A pre-9/11 and post-9/11 comparison using the American fear survey schedule for children. Journal of Counseling and Development, 85(4), 461-466.

Burton, J. (2008). Crisis not over for hurricane victims. Environmental Health Perspectives, $114(8), 462$.

Bussolari, C. J., \& Goodell, J. A. (2009). Chaos theory as a model for life transitions counseling: Nonlinear dynamics and life's changes. Journal of Counseling and Development, 87, 98-107.

Carver, C. S., \& Scheier, M. R. (1998). On the self regulation of behavior. New York: Cambridge University Press.

Castellano, C., \& Pilonis, E. (2006). Comparative analysis of the three crisis intervention models applied to law enforcement first responders during 9/11 and Hurricane Katrina. Brief Treatment and Crisis Intervention, 6(4), 326-336.

Centers for Disease Control (2004). Mental health status of World Trade Center rescue and recovery workers and volunteers-New York City, July 2002-August 2004. Accessed 10/21/08. www.cdc.gov/mmwr/preview/mmwrhtml/mm5335a2.htm

Chou, Y. J., Huang, N., Lee, C. H., Tsai, S. L., Tsay, J. H., Chen, L. S., \& Chou, P. (2003). Suicide after the 1999 Taiwan earthquake. International Journal of Epidemiology, 32(6), 1007-1014.

Cohan, C., \& Cole, S. (2002). Life course transitions and natural disaster: Marriage, birth, and divorce following Hurricane Hugo. Journal of Family Psychology, 16, 14-25.

Collogan, L. K., Tuma, F., Dolan-Sewell, R., Borja, S., \& Fleishman, A. R. (2004). Ethical issues pertaining to research in the aftermath of disaster. Journal of Traumatic Stress, 17(5), 363-372.

Conner, K. M., Davidson, J. R. T., \& Lee, L. (2003). Spirituality, resilience, and anger in survivors of violent trauma: A community survey. Journal of Traumatic Stress, 16(5), 487-498. 
Creamer, M., Burgess, P., \& McFarlane A. C. (2001). Posttraumatic stress disorder: Findings from the Australian National Survey of Mental Health and Well-Being. Psychological Medicine, 31(7), 1237-1247.

Creswell, J. W. (2009). Research Design: Qualitative, Quantitative, and Mixed Methods Approaches. Thousand Oaks, CA: Sage.

Cwikel, J. G., Havenaar, J. M., \& Bromet, E. J. (2002). Understanding the psychological and societal response of individuals, groups, authorities, and media to toxic hazards. Plenum series on stress and coping (pp. 39-65). New York: Kluwer Academic/Plenum Publishers.

Department of Mental Health (DMH), (no date). DMH Executive Division. Retrieved on 5/29/09 from http://www.dmh.state.ms.us/Executive_Division.htm

Devilly, G., Gist, R., \& Cotton, P. (2006). Ready! Fire! Aim! The status of psychological debriefing and therapeutic interventions: In the workplace after disasters. Review of General Psychology, 10, 318-345.

DeWolfe, D. J. (2000). Training manual for mental health and human service workers in major disasters. DHHS Publication No. ADM 90-538.

Edwards, M. L. K. (1998). An interdisciplinary perspective on disasters and stress: The promise of an ecological framework. Sociological Forum, 13(1), 115-132.

Elrod, C. L., Hamblen, J. L., \& Norris, F. H. (2006). Challenges in implementing disaster mental health programs: State program directors' perspectives. Annals of the American Academy, 604, 152-170.

Farberow, N. L. (1978). Training manual for human services in major disasters. DHHS Pub. No. (ADM) 83-538, Rockville, MD: Center for Mental Health Services.

Federal Emergency Management Agency (FEMA)(nd). About FEMA: Helping people before, during, and after disasters, "FEMA History." Retrieved on 10/18/08 from http://www.fema.gov/about/history.htm

FEMA (2007a). Greensburg six month anniversary recovery update. Retrieved on 5/29/09 from http://www.fema.gov/news/newsrelease.fema?id=41597

FEMA (2007b). Robert T. Stafford Disaster Relief and Emergency Act (Public Law 93-288) as amended, and related authorities. Retrieved on 8/18/08 from www.fema.gov/about/stafact

FEMA (2008). Disaster crisis counseling: What it is and what it is not. Retrieved 10/18/08 from www.fema.gov/media/fact_sheets/crisis_counseling.shtm 
Finnegan, C. (2003). Social welfare and visual politics: The story of survey graphic. New Deal Network: Columbia University. Retrieved November 15, 2008 from http://newdeal.feri.org/sg/essay01.htm.

Fleischman, A. R., Collogan, L. \& Tuma, F. (2006). Ethical issues in disaster research. In F. H. Norris, S. Galea, M. J. Friedman, \& P. J. Watson, (Eds.), Methods for Disaster Mental Health Research (pp. 78-92). New York: Guilford Press.

Foa, E. B. (1997). Psychological processes related to recovery from a trauma and an effective treatment for PTSD. In R. Yehuda \& A. C. McFarlane (Eds.), Psychobiology of posttraumatic stress disorder (pp. 410-424). New York: New York Academy of Scientists.

Foa, E. B., \& Meadows, E. A. (1997). Psychosocial treatment for posttraumatic stress disorder: A critical review. Annual Review of Psychology, 48, 449-480.

Freedy, J. R., \& Simpson, W. M. (2007). Disaster-related physical and mental health: A role for the family physician. American Family Physician, 75 (6), 841-851.

Gaffney, D., Barry, D., Chiocchi, N., \& Theis, J. (2005). A disaster of unspeakable proportions. Journal of Forensic Nursing, 1, 145-196.

Gard, B. A., \& Ruzek, J. I., (2006). Community mental health response to crisis. Journal of Clinical Psychology, 62(8), 1029-1041.

Geonjian, A. K., Karayan, I., Pynoos, R. S., Minassian, D., Najarian, L. M., Steinberg, A. M., et al. (1997). Outcomes of psychotherapy among early adolescents after trauma. American Journal of Psychiatry, 154, 536-542.

Geonjian, A. K., Walling, D., Steinberg, A. M., Karavan, I., Najarian, L. M., \& Pynoos, R. (2005). A prospective study of posttraumatic stress and depressive reactions among treated and untreated adolescents 5 years after a catastrophic disaster. American Journal of Psychiatry, 162, 2302-2308.

Ginexi, E. M., Weihs, K., Simmens, S. J., \& Hoyt, D. R. (2000). Natural disasters and depression: A prospective study of reactions to the 1993 Midwest floods. American Journal of Community Psychology, 28(4), 495-518.

Goodman, R. D., \& West-Olatunji, C., (2008). Transgenerational trauma and resilience: Improving mental health counseling for survivors of Hurricane Katrina. Journal of Mental Health Counseling, 30(2), 121-136.

Greiger, T. A., Fullerton, C. S., \& Ursano, R. J. (2003). Posttraumatic stress disorder, alcohol use, and perceived safety after the terrorist attack on the Pentagon. Psychiatric Services, 54(10), 1380-1382. 
Groh, C. J. (2007). Poverty, mental health, and women: Implication for psychiatric nurses in primary care settings. American Psychiatric Nurses Association Journal, 13(5), 267-274.

Harvey, A. G., \& Bryant, R. A. (1998). The relationship between acute stress disorder and posttraumatic stress disorder: A prospective evaluation of motor vehicle accident survivors. Journal of Consulting and Clinical Psychology, 66, 507-512.

Healthcare Financial Management Association (HFMA) (2007). Mental health providers in New Orleans are facing soaring caseloads, burnout two years after Hurricane Katrina. Healthcare Financial Management, 61(10), 12.

Hensley, L., \& Varela, E. (2008). PTSD symptoms and somatic complaints following Hurricane Katrina: The role of trait anxiety and anxiety sensitivity. Journal of Clinical Child and Adolescent Psychology, 37(3), 542-552.

Hobfoll, S. E., Watson, P., Bell, C. C., Bryant, R. A., Brymer, M. J., Friedman, M. J., et al. (2007). Five essential elements of immediate and mid-term mass trauma intervention: Empirical evidence. Psychiatry, 70(4), 283-315.

Hodges, H. F., Keeley, A. C., \& Troyan, P. J. (2008). Professional resilience in baccalaureateprepared acute care nurses: First steps. Nursing Education, 29(2), 80-89.

Hurricane Katrina Relief (nd.) Hurricane Katrina FAQs. Retrieved 3/9/09 from http://www.hurricanekatrinarelief.com.

Institute of Medicine (2007). Crossing the chasm. A new health system for the 21st century. Washington, DC: National Academy Press.

International Federation of Red Cross and Red Crescent Societies and the Centre for Research on the Epidemiology of Disasters (1993). World disaster report. Norwell, Mass: Kluwer Academic Publishers.

Ironside, G., Wynings, C. D., Breznitz, S., Figley, C., Folkman, S., Green, B. L., et al. (1997). Post-traumatic stress symptoms, intrusive thoughts, loss, and immune function after Hurricane Andrew. Psychosomatic Medicine, 59, 128-141.

Iseksen, S. G., Dorval, K. B., \& Treffinger, D. J. (1998). Creative problem solving. Sarasota, FL: Center for Creative Learning.

Jackson, G., \& Cook, C. (1999). Disaster mental health: Crisis counseling programs for rural community. (DHHS Publication No. SMA 99-3378). Rockville, MD: US Department of Health and Human Services Substance Abuse and Mental Health Services Administration, Center for Mental Health Services. 
Jacobs, G. A. (1995). The development of a national plan for disaster mental health. Professional Psychology: Research and Practice, 26(6), 543-549.

Johnson, P. B., \& Richter, L. (2003). The impact of 9/11 and its aftermath on substance use and psychological functioning: An overview. Fordham Urban Law Journal, 30(4), 14551464.

Johnson, S. D., North, C. S., \& Smith, E. M. (2002). Psychiatric disorders among victims of a courthouse shooting spree: A three year follow-up study. Community Mental Health Journal, 38(3), 181-194.

Kaniasty, K., \& Norris, F. (1993). A test of the support deterioration model in the context of natural disaster. Journal of Personality and Social Psychology, 64, 395-408.

Kaniasty, K., \& Norris, F. (1997). Social support dynamics in adjustment to disasters. In S. Duck (Ed.). Handbook of personal relationships: Theory, research, and interventions $\left(2^{\text {nd }}\right.$ ed.) (pp. 595-619). Hoboken, NJ: John Wiley \& Sons Inc.

Kaufmann, S. A. (1995). At home in the universe. New York: Oxford University Press.

Kessler, R.C., Sonnega, A., Bromet, E., Hughes, M., \& Nelson, C.B. (1995). Posttraumatic stress disorder in the National Comorbidity Survey. Archives of General Psychiatry, 52(12), 1048-1060.

Kiser, L., Heston, J., Hickerson, S., Millsap, P., Nunn, W., \& Pruitt, D. (1993). Anticipatory stress in children and adolescents. The American Journal of Psychiatry, 150(1), 87-92.

Klatte, A. P. (2007). Rev. Andrew Klatte. Retrieved on 5/29/09 from http://www.zoominfo.com/people/Klatte_Andrew_428217413.aspx

Lamberg, L. (2006). Katrina survivors strive to reclaim their lives. Journal of the American Medical Association, 296, 499-502.

Lawyer, S. R., Resnick, H., Galea, S., Ahern, J., Kilpatrick, D., \& Vlahov, D. (2006). Predictors of peritraumatic reactions and PTSD following the September 11th terrorist attacks. Psychiatry: Interpersonal and Biological Processes, 69, 130-141.

Levine, C. (2004). The concept of vulnerability in disaster research. Journal of Traumatic Stress, $17(5), 395-402$.

Levine, L. J., Whalen, C. K., Henker, B., \& Jamner, L. D. (2005). Looking back on September 11, 2001: Appraised impact and memory for emotions in adolescents and adults. Youth Studies Australia, 24(3), 61.

Litz, B. T., \& Gray, M. J. (2002). Early intervention for mass violence: What is the evidence? What should be done? Cognitive and Behavioral Practice, 9(4), 266-272. 
Loganovsky, K., Havenaar, J. M., Tintle, N. L., \& Guey, L. T. (2008). The mental health cleanup 18 years after the Chernobyl accident. Psychological Medicine, 38(4), 481-488.

Lustad, M. (1985). Innovative mental health services for child disaster victims. Children Today, $14,13-17$.

Madrid, P.A., \& Grant, R. (2008). Meeting mental health needs following a natural disaster: Lessons from Hurricane Katrina. Professional Psychology: Research and Practice, 39(1), 86-92.

Malcolm, A. S., Seaton, J., Perera, A., Sheehan, D. C., \& Van Hasselt, V. B. (2005). Critical incident stress debriefing and law enforcement: An evaluation review. Brief Treatment and Crisis Intervention, 5(3), 261-278.

Marshall, C., \& Rossman, G. B. (2006). Designing qualitative research (4 ${ }^{\text {th }} \mathrm{ed}$.). Thousand Oaks, CA: Sage.

Marsee, M. A. (2008). Reactive aggression and posttraumatic stress in adolescents affected by Hurricane Katrina. Journal of Clinical Child and Adolescent Psychology, 37(3), 519-529.

McCarthy, M. A., \& Butler, L. (2003). Responding to traumatic events on campuses: A case study and assessment of student postdisaster anxiety. Journal of College Counseling, 6(1), 90-96.

McCaslin, M. L., \& Scott, K. W. (2003). The five-question method for framing a qualitative research study. The Qualitative Report, 8(3), 447-461.

McDermott, B. M., Lee, E. A., Judd, M., \& Gibbon, P. (2005). Posttraumatic stress disorder and general psychopathology in children and adolescents following a wildfire disaster. Canadian Journal of Psychiatry, 50(3), 137-143.

McNally, R. J., Bryant, R. A., \& Elhers, A. (2003). Does early psychological intervention promote recovery from posttraumatic stress? Psychological Science for the Public Interest, 4(2), 45-79.

Miller, J. (2002). Affirming flames: Debriefing survivors of the World Trade Center attack. Brief Treatment and Crisis Intervention, 2(1), 85-94.

Mitchell, J. T. (2003). Crisis intervention \& CISM: A research summary. International Critical Incident Stress Foundation. Ellicott, Maryland. Retrieved 10/12/08 from www.icisf.org

Mitchell, J. T. (nd). Jeff Mitchell Biography. Retrieved on 11/15/08 from www.nccm.org/biojeffmitchell.htm. 
Mitchell, J. T., \& Bray, G. (1990). Emergency services stress: Guidelines for preserving the health and careers of emergency services personnel. Englewood Cliffs, NJ: Brady.

Moore, A. S. (1998). Natural disasters increase the risk of suicide. RN Montvale, 61(5), 20.

Moynihan, P. J., Levine, J. L., \& Rodriguez, O. (2005). The experiences of Project Liberty in the Bronx. Community Mental Health Journal, 41(6), 665-673.

Moustakes, C. (1994). Phenomenology research methods. Thousand Oaks, CA: Sage Publications, Inc.

Myers, D., \& Wee, D. (2005). Disaster mental health services: A primer for practitioners. New York: Brunner-Routledge.

Nader, K., \& Pynoos, R. (1993). School disaster-planning and initial interventions. Journal of Social Behavior and Personality, 8, 299-320.

National Child Traumatic Stress Network and National Center for PTSD (2005). Psychological First Aid: Field Operations Guide (2nd Edition). Retrieved on 09/01/08 from http://www.ncptsd.va.gov/pfa/PFA.html

National Geographic (2007). Greensburg, Kansas tornado. Retrieved 5/29/09 from http://environment.nationalgeographic.com/environment/photos/kansas-tornado.html

National Institute of Mental Health (2002). Mental health and mass violence: Evidence-based early psychological intervention for victims/survivors of mass violence: A workshop to reach consensus on best practices (NIH Pub. No 02-5138). Washington, DC: US Government Printing Office. Retrieved 08/18/08 from http://www.nimh.nih.gov/health/publications/massviolence.pdf

National Institute of Mental Health (2008). Post-traumatic stress disorder (PTSD). Retrieved $10 / 19 / 08$ from http://www.nimh.nih.gov/health/publications/post-traumatic-stress-disorder-easy-toread/index.shtml

Neria, Y., Olfson, M., Gameroff, M. J., Wickramaratne, P., Gross, R., Pilowsky, D. J., et al. (2008). The mental health consequences of disaster-related loss: Findings from primary care one year after 9/11 terrorist attacks. Psychiatry, 71(4), 339-348.

Newman, E., \& Kaloupek, D. (2004). The risks and benefits of participating in trauma-focused research studies. Journal of Traumatic Stress, 17(5), 383-394.

Newman, E., Walker, E. A., \& Gefland, A. (1999). Assessing the ethical costs of benefits of trauma focused research. General Hospital Psychiatry, 21, 187-196.

Norris, F. H. (2002). Disasters in an urban context. Journal of Urban Health, 79, 308-314. 
Norris, F., Baker, C. K., Murphy, A. D., \& Kaniasty, K. (2008). Social support mobilization and deterioration after Mexico's 1999 flood: Effects of context, gender and time. American Journal of Community Psychology, 36 (1-2), 15-28.

Norris, F. H., \& Elrod, C. L. (2006). Psychosocial consequences of disaster: A review of past research. In F. H. Norris, S. Galea, M. J. Friedman, \& P. J. Watson (Eds.), Methods for Disaster Mental Health Research (pp. 20-42). New York: Guilford.

Norris, F. H., Galea, S., Friedman, M. J., \& Watson, P. J. (2006a). Methods for disaster mental health research. New York: Guilford Press.

Norris, F. H., Hamblen, J. L., Watson, P. J., Ruzek, J., Gibson, L., Pfefferbaum, B., et al. (2006b). Understanding and creating systems of post disaster care: A case study of New York's mental health systems response to the World Trade Center disaster. In C. R. Elspeth, P. J. Watson, \& M. J. Friedman, (Eds), Mental intervention following disasters or mass violence (pp. 343-364). New York: Guilford Press.

Norris, F. H., \& Kaniasty, K. (1996). Received and perceived social support in time of stress: A test of the social support deterioration deterrence model. Journal of Personality \& Social Psychology, 71, 498-511.

North, C. S., \& Hong, B. A. (2000). Field action report. American Journal of Public Health, 90(7), 1057-1058.

North, C. S., Nixon, S. J., Shariat, S., Mallonee, S., McMillen, J. C., Spitz, E. L., \& Smith, E. M. (1999). Psychiatric disorders among survivors of Oklahoma City bombing. Journal of the American Medical Association, 28(8), 755-762.

Oliver, D. T. (2000). Lessons from the Chicago fire. The Freeman: Ideas on Liberty. Retrieved September 13, 2008. Message posted to http://www.rr-bb.com/showthread.php?t-219561.

Phifer, J., \& Norris, F. (1989). Psychological symptoms in older adults following disaster: Nature, timing, duration, and course. Journal of Gerontology, 44, 207-217.

Pina, A. A., Villalta, I. K., Ortiz, C. D., Gottsschall, A. C., Costa, N. M. \& Weems, C. F. (2008). Social support, discrimination, and coping as predictors of posttraumatic stress reactions in youth survivors of Hurricane Katrina. Journal of Clinical Child and Adolescent Psychology, 37(3), 564-574.

Polkinghorne, D. E. (2005). Language and meaning: Data collection in qualitative research. Journal of Counseling Psychology, 52(2), 137-145.

Ponterotto, J. G., \& Grieger, I. (2007). Effectively communicating qualitative research. The Counseling Psychologist, 35(3), 404-430. 
Protection of Human Subjects (2005). Title 45: Public Welfare, Department of Health And Human Services. Part 46, Code of Federal Regulation. 45 CFR, 46.111.

Pryor, R. G., Amundson, N. E., \& Bright, J. E. (1995). Probabilities and possibilities: The strategic counseling implications of the chaos theory of careers. The Career Development Quarterly, 6(56), 309-318.

Pulido, M. L. (2007). In their words: Secondary traumatic stress in social workers responding to the 9/11 terrorist attacks in New York City. Social Work, 52(3), 279-281.

Regehr, C. (2002). Crisis debriefing groups for emergency responders: Reviewing the evidence. Brief Treatment and Crisis Intervention, 9, 87-100.

Rodriguez, H., Wachtendorf, T., Kendra, J., \& Trainor, J. (2006). A snapshot of the 2004 Indian Ocean tsunami. Disaster Prevention and Management, 15(1), 163-177.

Rosenstein, D. L. (2004). Decision-making capacity and disaster research. Journal of Traumatic Stress, 17(5), 373-381.

Rubel, B. (2008). Addressing community needs in disaster. New Jersey Board of Health, 15(2), 2-4.

Ruzek, J. I., Brymer, M. J., Jacobs, A. K., Layne, C. M., Vernberg, E. M., \& Watson, P. J. (2007). Psychological first aid. Journal of Mental Health Counseling, 29(1), 33-49.

SAMHSA's National Mental Health Information Center (2003). State Emergency Response 30 Capacity Grant SM 03-001. Retrieved 5/10/09 from

www.mentalhealth.samhsa.gov/grants/content/2003/2003funding.htm

SAMHSA's National Mental Health Information Center (nd). Crisis counseling programs for the rural community. Retrieved 10/18/08 from www.mentalhealth.samhsa.gov/publications/allpubs/sma993378/crisiscounseling_ch1.asp.

Saleh, M. A. (1996). Disaster and crises: Challenges to mental health counseling in the twentyfirst century. Education, 166 (4), 519-528.

Scheeringa, M. S., \& Zeanah, C. H. (2008). Reconsideration of harm's way: Onset and comorbidity patterns of disorders in preschool children and their caregivers following Hurricane Katrina. Journal of Clinical Child and Adolescent Psychology, 37(3), 508-518.

Schiraldi, G. R. (1999). The post-traumatic stress disorder sourcebook. Lincolnwood, IL: Lowell House. 
Schlenger, W. E., Caddell, J. M., Ebert, L., Jordan, B. K., Rourke, K. M., Wilson, D., et al. (2002). Psychological reactions to terrorist attacks: Findings from the National Study of American's Reactions to September 11. Journal of the American Medical Association, 288(5), 581-588.

Shapiro, F. (1989). Eye movement desensitization: A new treatment for post-traumatic stress disorder. Journal of Behavioral Therapy and Experimental Psychiatry, 20, 211-217.

Shear, K. M., Jackson, C. T., Essock, S. M., Donahue, S. A., \& Felton, C. J. (2006). Screening for complicated grief among Project Liberty service recipients 18 months after September 11, 2001. Psychiatric Services, 57(9), 1291-1296.

Skinner, E. A. (1996). A guide to constructs of control. Journal of Personality and Social Psychology, 71(3), 549-570.

Smith, D. W. (2007). Husserl. London-New York: Routledge.

Smoyak, S. A. (2006). Defining and working with the "new normal." Journal of Psychosocial Nursing, 44 (10), 6-7.

Solomon, Z. (2003). Coping with war-induced stress: The Gulf War and the Israeli response. New York: Plenum.

Solomon, Z., \& Green, B. L. (1992). Mental health effects of natural and human made disasters. PTSD Research Quarterly, 3, 1-7.

Solomon, Z., Mikulincer, M., \& Hobfoll, S. E. (1986). The effects of social support and battle intensity on loneliness and breakdown during combat. Journal of Personality and Social Psychology, 51, 1269-1276.

Solomon, Z., Shklar, R., \& Mikulincer, M. (2005). Front line treatment of combat stress reaction: A 20-year longitudinal evaluation study. American Journal of Psychiatry, 162, 23092314.

Strauss, A., \& Corbin, J. (1990). Basics of qualitative research: Grounded theory procedures and techniques. Newbury Park, CA: Sage.

Suite, D. H., Rollin, S. A., Bowman, J. C., \& La Bril, R. D. (2007). From fear to faith: Efficacy of trauma assessment training for New York-based Southern Baptist Church groups. Research on Social Work, 17(2), 258-263.

Van Emmerick, A. A. P., Kamphuis, J. H., Hulsborch, A.M., \& Emmelkamp, P. M. G. (2002). Single session debriefing after psychological trauma: A meta analysis. Lancet, 360, 766771. 
Vernberg, E. M., Steinberg, A. M., Jacobs, A. K., Brymer, M. J., Watson, P. J., Osofsky, J. D., et al. (2008). Innovations in disaster mental health: Psychological first aid. Professional Psychology: Research and Practice, 39(4), 381-388.

Vlahov, D., Galea, S., Ahern, J., Resnick, H., Boscarino, J. A., Gold, J., et al. (2004). Consumption of cigarettes, alcohol, and marijuana among New York City residents six months after the September 11 terrorist attacks. Journal of Drug and Alcohol Abuse, 30(2), 385-407.

Voelker, R. (2006). Post-Katrina mental health needs prompt group to compile disaster medical guide. Journal of the America Medical Association, 295, 259-260.

Walter Reed Army Medical Center (nd). American Red Cross: A history of helping others. Retrieved November 19, 2008 from http://www.wramc.amedd.army.mil/wramc/redcross/historyARC.htm.

Wang, P. S., Gruber, M. J., Powers, R. E., Schoenbaum, M., Speier, A. H., Wells, K. B., et al. (2008). Disruption of existing mental health treatments and failure to initiate new treatments after Hurricane Katrina. American Journal of Psychiatry, 165, 34-41.

Warheit, G. J. (1988). Disasters and their mental health consequences: Issues, findings, and future trends. In M. Lustad (Ed.), Mental health response to mass emergencies: Theory and practice. (pp. 3-21). New York: Brunner/Mazel.

Weaver, J. D., Dingman, R. L., Morgan, J., Hong, B. A., \& North, C. S. (2000). The American Red Cross disaster mental health services: Development of a cooperative, single function, multidisciplinary service model. The Journal of Behavioral Health Services \& Research, 27(3), 314-320.

WebMD (nd). Post-traumatic stress disorder (PDQr)- Diagnostic criteria and characteristics. Retrieved 10/11/08 from www.webmd.com/cancer/tc/ncicdr0000062793-diagnosticcriteria-and-characteristics

Whalley, M. G., \& Brewin, C. R. (2007). Mental health following terrorist attacks. The British Journal of Psychiatry, 190, 94-96.

Wikipedia (2008). June 2008 Midwest floods. Retrieved May 29, 2009 from www.wikipedia.org/wiki/June_2008_Midwest_floods\#Indiana

Wikipedia (2009a). Retrieved on June 30, 2009 from http://en.wikipedia.org/wiki/Phenomenology.

Wikipedia (2009). Greensburg KS. Retrieved May 30, 2009 from http://en.wikipedia.org/wiki/Greensburg,_KS. 
Zunin, L. M., \& Myers, D. (2000). Training manual for human service workers in major disasters ( $2^{\text {nd }}$ ed., DHHS Publication No. ADM 90-538). Washington, DC: U.S.

Department of Health and Human Services Administration, Center for Mental Health Services. 